\title{
Five Murders in a Fictional City
}

\author{
by \\ Alasdair Sinclair \\ A thesis submitted to Victoria University of Wellington in \\ fulfilment of the degree of Master of Arts in English Literature \\ Victoria University of Wellington \\ 2013
}





\begin{abstract}
Dashiell Hammett is best remembered for a series of attributes that are at best chimerical and at worst outright misleading. This thesis will briefly look at each of these red herrings and how they originated before offering an alternate theory for interpreting his work.

The superseded reading strategies are: that he invented the hard-boiled detective - as exemplified by Humphrey Bogart in The Maltese Falcon; that he translated his real-life experience as a detective for the Pinkerton Detective Agency into his fiction, thereby giving it a realistic, quasi-factual quality; and his unique combination of the excess and hedonism of the "roaring 20s" with a brand of nascent communism are deeply coded in his fiction. The foundation for all of these misconceptions is the dialogue between Howard Haycraft's description of him in Murder for Pleasure and Raymond Chandler's response, in the famous essay, "The Simple Art of Murder". The one truth that they agree on, and which survives in the critical discourse is that Hammett was an innovative and effective prose stylist.

This thesis looks past these conceptions of Hammett, and offers an alternate quality for which Hammett should be remembered: his reconfiguration of the detective formula not as a means in and of itself, but as a building block for stories that have a traditional novelistic value. This thesis uses five of the murders amongst the numerous killings in Red Harvest to illustrate this reading strategy in detail. Hammett's reconfiguration of this central genre feature lives on in numerous modern works of fiction and film that are broadly in the action or adventure genres.
\end{abstract}




\section{Contents}

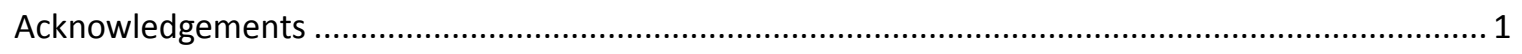

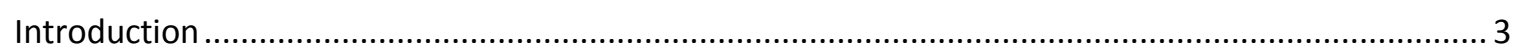

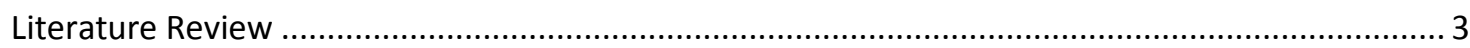

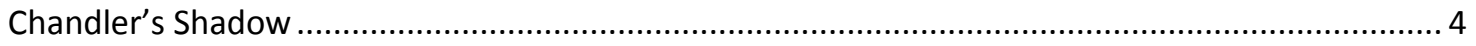

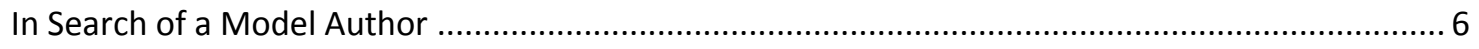

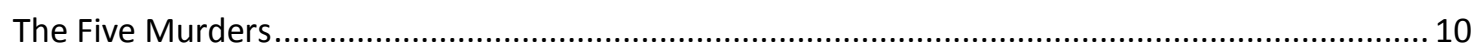

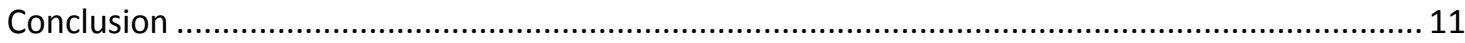

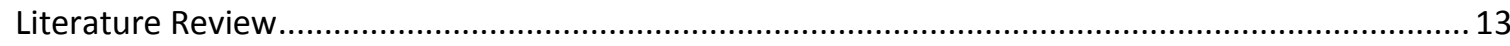

Hammett the Communist ..................................................................................... 14

Dean of the Hard-boiled school...................................................................................... 17

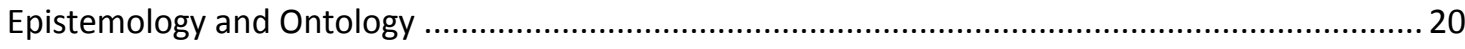

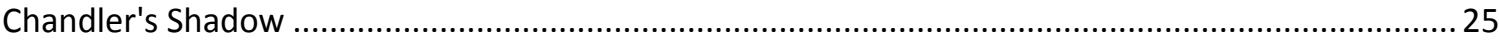

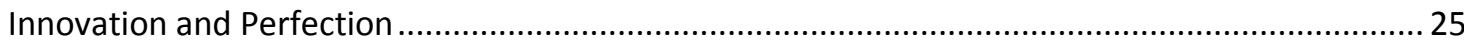

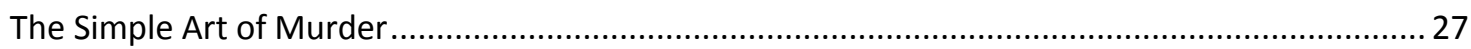

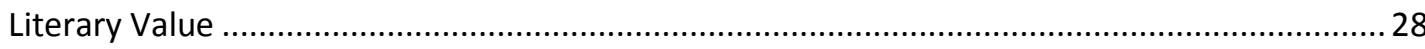

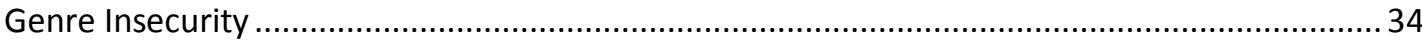

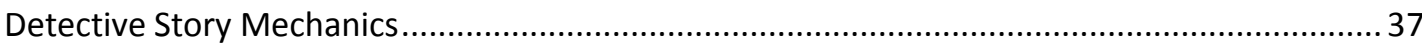

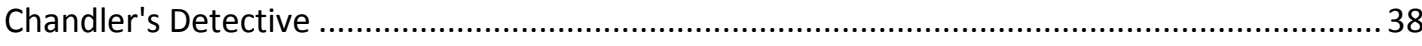

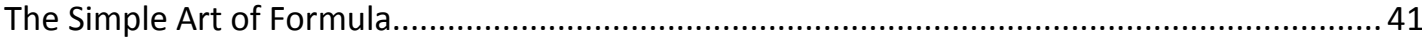

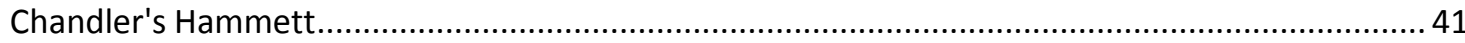

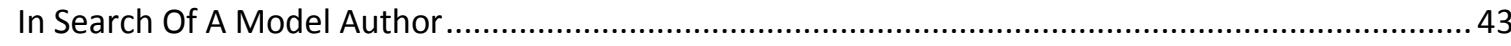

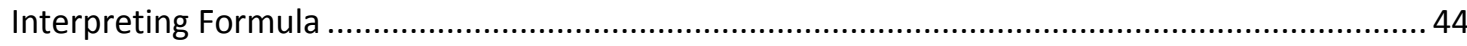

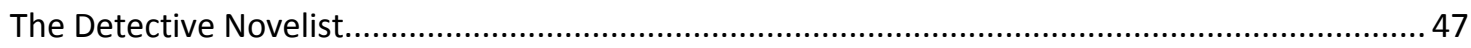

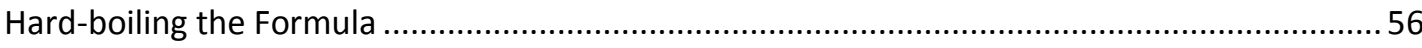

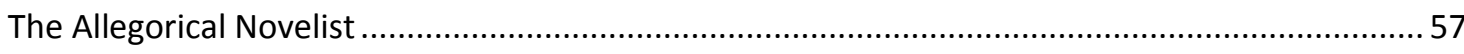

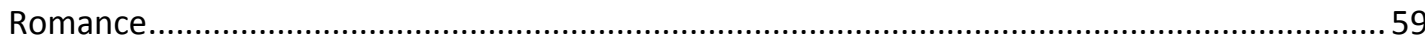

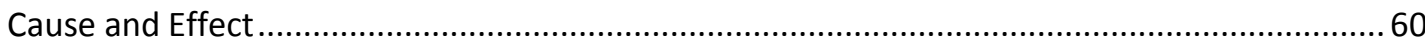

The Content of Romance and Inverted Romance ......................................................... 64

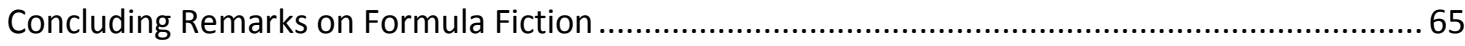

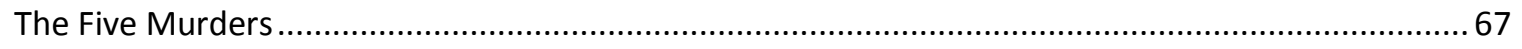

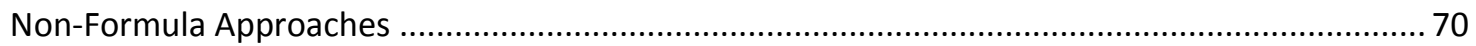


The Five Murders.

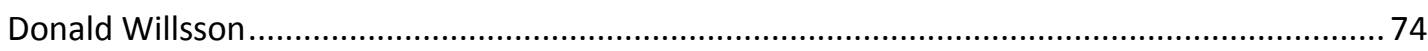

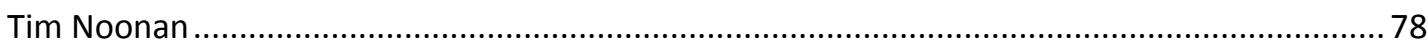

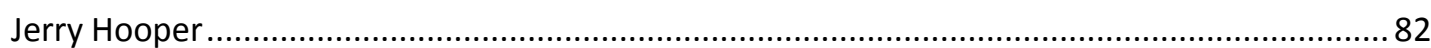

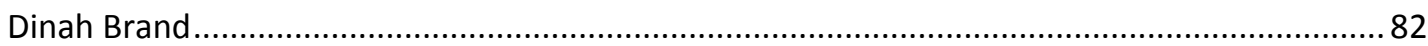

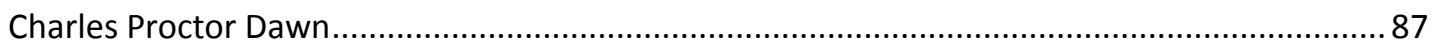

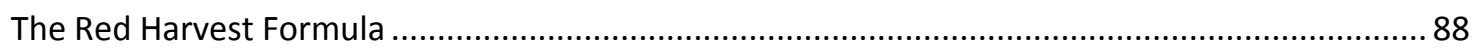

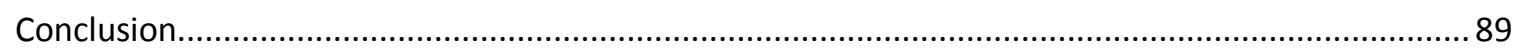

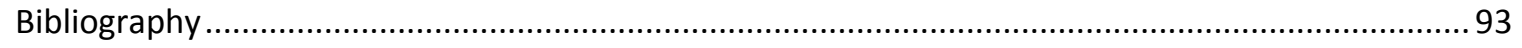





\section{Acknowledgements}

Every investigation draws on a number of human resources. I like to think of my two supervisors as Chief of Detectives Harry Ricketts, who wandered all over the crime scene with me examining interesting clues while making sure my paperwork was in always in order, and District Attorney Dougal McNeill, who ensured that I was always building a case against Chandler for murdering Hammett. I also owe a debt of thanks to the Patrolmen who reviewed the evidence and offered accounts, Nicky Sinclair and Clare Bycroft.

And special mention must be made of the Lawyer that couldn't be bought, Susan Harper, for keeping the case air-tight. 



\section{Introduction}

Dashiell Hammett wrote five novels, Red Harvest (1929), The Dain Curse (1929), The Maltese Falcon (1930), The Glass Key (1931), The Thin Man (1934), and around 40 short stories that were mostly published in the pulp magazine Black Mask, from "The Road Home" in December 1922 (Hagemann 63) to "Death and Company" in November 1930 (Hagemann 118). He is best remembered today for his third novel, partially due to the success of the 1941 film adaptation of the novel by John Huston. Hammett is widely acknowledged as the founder of a new school of detective fiction: the hard-boiled school, generally regarded as the major alternative to the kind of detective story perfected by Arthur Conan Doyle.

This thesis deviates from the usual approaches to Hammett by eschewing discussion of literary style, allegorical interpretations, and political inferences. Instead it focuses on him as an author of detective stories through a close examination not of his prose style but of his story mechanics. It surveys the critical discourse on detective fiction and Hammett's place in the detective canon, before examining how his most famous follower, Raymond Chandler, has influenced this place. The thesis then examines the formal structures of the detective genre before exploring in detail how Hammett's first novel uses these structures.

\section{Literature Review}

Howard Haycraft succinctly laid out the main features of Dashiell Hammett's work in Murder for Pleasure: The Life and Times of the Detective Story (1941). Haycraft establishes Hammett as "founder of the realistic or 'hard boiled' division of detective writing", a change so radical that "certain short-sighted formalists refuse to admit they are detective stories" (169). Haycraft credits "Hammett's own career" as a Pinkerton agent for much of his success, laying the groundwork for the claim of realism that characterizes early studies of Hammett's work (169). In trying to summarize the relative merits of Hammett's five novels, Haycraft makes the crucial statement that "because of their startling originality, the Hammett novels defy exegesis even to-day" (171). He makes the general claim that as "detective stories they can hold their own ... are also character studies of close to top rank [and] penetrating if shocking novels of manners as well" (171). Haycraft completes his sketch by mentioning the "indubitable sincerity of [Hammett's] interests in ... political movements of a Left-wing nature" (173). Subsequent criticism has followed Haycraft's lead by treating Hammett as a serious novelist, not just another manufacturer of detective formulations. This is what one might term "burying the lead", because the divergences which Haycraft elides are as or more significant as the "character studies" and "novels of manners".

While Hammett is routinely credited as the first important author of the hard-boiled school of detective fiction, he was not entirely consistent with its main features. Broad 
summaries of the genre often include a catalogue of hard-boiled qualities; for example, these from Philip Durham's “The Black Mask School” (1968):

$[\mathrm{H}] \mathrm{e}$ was always, essentially, the same hard-boiled hero ... indestructible, fearless, courageous; he was violent, often brutal, a dead-shot, killing when he thought it necessary; he was a celibate admired by women and feared by men; he had his own sense of right and wrong by which he lived, meting out his individual concept of justice ... The private eye was always on the side of right, but it was his own personal interpretation and definition of "right". (56)

While each of Hammett's heroes exhibits some of these qualities, none exhibits all. As with his deviations from the so-called "fair play" method that demanded rigorous focus on murder as a puzzle, these deviations are often downplayed or occasionally straightforwardly

misrepresented. One clear example of this comes from an early poster for the 1941 version of The Maltese Falcon, whose tagline is: "a story as explosive as his

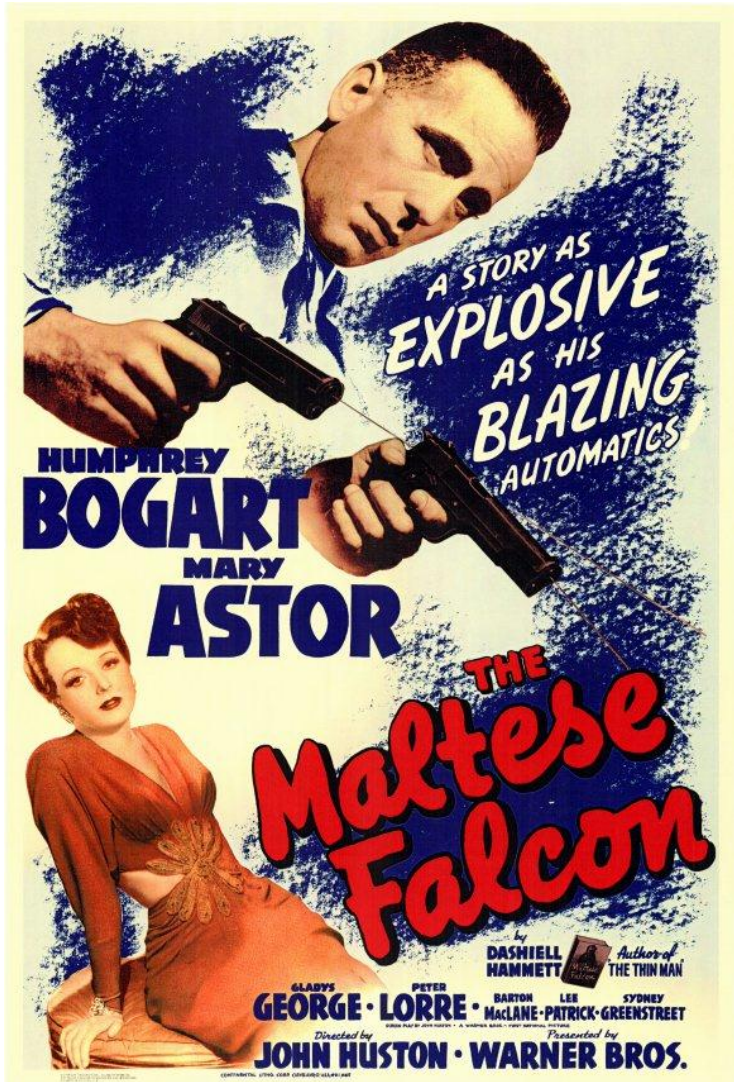
blazing automatics" (quoted by Layman,

Discovering the Maltese Falcon 271). This endorsement is clearly generic and not applicable to the film, in which not a single shot is fired on screen.

This tagline is exemplary of a general approach to Hammett that originates not with close examination of his work, but with a priori assumptions about it based on a broad pair of cultural phenomena, the hard-boiled story and the detective story. Of course Hammett has a role to play in both of these genres because there really are mysteries in his mystery stories, and there really is a hard-boiled aspect to them, but instead of becoming two useful descriptors for interpreting his work, these terms have become filters that remove much of what is interesting about Hammett's writing, especially its diversity.

\section{Chandler's Shadow}

In Chapter 3, I discuss “The Simple Art of Murder" (1944). Raymond Chandler wrote what is perhaps the single most important essay on Hammett as a broadside against 
Haycraft's single and limited perspective on detective fiction as a ratiocinative exercise. Chandler excoriated the so-called "Golden Age" of detective fiction by pointing out stylistic and logical flaws in several of its well-regarded works. The main alternative he offered was Dashiell Hammett. Chandler's argument is that the crime-puzzles at the heart of "fair play" tales had rendered the whole genre artistically stale, because they had nothing much in common with real life. He holds Hammett up as the exemplar of a new way of writing about crime, a "realistic" way. Chandler is light on details, but paints an evocative picture that endures as a touchstone for Hammett and Chandler criticism.

While Chandler identifies a writing aesthetic, he does not provide a holistic overview of Hammett's works, discussing only The Maltese Falcon specifically. "The Simple Art of Murder" has become one of the most-quoted essays that touches on Hammett, cited by virtually every piece of critical writing or biography relating to Hammett written after it. ${ }^{1}$ Key phrases from the essay have been sublimated into the discourse on the genre, such as "mean streets" and almost nobody can resist recycling certain evocative images, such as the "Venetian vase" from which Hammett rescued detective fiction. Chandler has successfully and almost invisibly framed most discussion on Hammett as a "hard-boiled realist" with a detective story interest.

Criticism of detective fiction is often concerned with the nature of the genre itself, its rules and its archetypes. Yet, at the same time, little criticism concerns itself with the deeper structures of detective stories. Even book-length studies of specific authors do not discuss story mechanics: how was the crime committed and how was it investigated, step-by-step; what features of the detective formula constrained the events and content of the fiction? Although it is generally agreed that the mystery must be difficult to solve, the consequences of creating difficulty are not explicitly treated. For example, the practical necessity of making the mystery difficult will mean that the murderer is on the face of it an improbable one, but the critical analysis does not usually extend this far. So while experienced readers of detective novels are aware that it will be the "least-likely" suspect, there is no critical apparatus or guidance explicitly treating that problem in the critical discourse. Instead, critiques such as Hammett made in his reviews of detective novels ${ }^{2}$ and Raymond Chandler's "The Simple Art of Murder" focus on the specific details of the murder. This blind spot means that only symptoms are treated, as can be seen from the Detective Club Oath, which forbids

\footnotetext{
${ }^{1}$ A sampler of citations follows; not all of these are detailed discussions of the essay and indeed, not all of them even cite the essay explicitly, merely borrowing phrases from it in support of some other point further evidence of how pervasive it is. (Dooley 139) (Gregory 1) (Marling, Dashiell Hammett 128) (Mellen 105) (William F Nolan, Hammett Casebook 2) (Panek 106) (Symons, Dashiell Hammett 2) (Wolfe 57) Diane Johnson is almost singularly restrained in not mentioning or quoting the essay in her biography, Dashiell Hammett: A Life (1985).

${ }^{2}$ See his column from New York Evening Post, 7 June 1930, p54, quoted in Bruccoli and Layman and elsewhere.
} 
"Conspiracies, Death-Rays, Ghosts, Hypnotism, Trap-Doors, Chinamen, Super-Criminals and Lunatics; and utterly and for ever to forswear Mysterious Poisons unknown to Science" (quoted in Haycraft, Art of the Mystery Story 198). These are all tactics previously adopted to cope with demands of genre for a difficult mystery. They are inadequate because the framers did not directly examine the detective formula, only examples of its misapplication. From this misunderstanding of the problem that they aimed to solve they forbid specific coping mechanisms that are not to their taste, but do not address why detective authors would need these story elements.

Instead of quibbling over story details, critics like W.H. Auden in "The Guilty Vicarage: Notes on the Detective Story, by an Addict" (1948) focus on the large-scale ideological structures of the detective story. Auden makes no reference to the details of any specific detective novel or its story mechanics: he is a little disdainful of these indispensable features of the genre he is advocating. These readings tend to have an allegorical structure: for example, The Maltese Falcon is read by John T Irwin through the prism of the story of Job in Unless the Threat of Death is Behind Them: Hard-Boiled Fiction and Film Noir (2006) while William Marling sees the story of the Prodigal Son as providing the ideological framework for the same novel in The American Roman Noir: Hammett, Cain, and Chandler (1995). As ingenious as these reading strategies are, they can be overly specific. Marling adopts the same allegory for all of his treatments, but Irwin does not re-use Job in his study though he does consistently foreground a work-life balance always favouring work in the novels he treats. In practical terms, these strategies explain the way action unfolds in a detective story, but none makes a detailed argument that their explanation should supplant a formula-based reading strategy, especially in terms of detailed story mechanics relating to the investigation.

\section{In Search of a Model Author}

Hammett is known primarily as a "detective" novelist, which means that his works use well-defined genre traits as part of their syntactical framework. There is a detective, there is a crime, there is a concomitant investigation and at the end of the tale there is some sense of resolution. Hammett, however, defies a number of the common structural features of this genre syntax, taking a new approach to the material. Part of the syntax of crime writing is laid out in a series of well-known essays from around the period when Hammett was writing. These essays define a series of rules relating both to content and presentation. Hammett's writing does not comply closely with these rules. For example, the description of the inhabitants of the Temple of the Holy Grail in The Dain Curse has the syntax and thus apparently the equivalent function of a description of the inhabitants of an isolated English Country Manor. The difference is that this scene does not signify the beginning of a mystery, but its continuation, and in the end both victim and ultimate perpetrator of the murder in 
the Temple are missing from the catalogue of inhabitants. Indeed, those inhabitants, whose every personality quirk would be the focus of the investigation in an Agatha Christie novel, remain merely names in The Dain Curse. A genre syntax is apparently used here, but its purpose is reconfigured.

Disentangling this arrangement of form, content and syntax is made difficult by the lack of generally agreed usage. Different scholars working on detective fiction have used numerous different terms for similar concepts and entities, or the same term for different concepts and entities. Perhaps the most overworked term is "plot".

"Plot" in the general critical discourse segues uncomfortably between the general case and the specific case, often while avoiding the non-genre implications of the word (Abbott 240). We might read about a murder plot, meaning that there is a murder, investigation and revelation, and we might read about a murder plot, meaning that Colonel Mustard killed Professor Plum in the Library, using the Complete Works of Shakespeare as his murder weapon. This creates a difficulty when discussing the absence or weakness of a "plot" in a detective novel, since on the whole there is a "complete and ordered structure of actions, directed toward the intended effect" (Abrams 235). A "weak plot" in the context of detective fiction means the author does not invest effort in the design of the mystery.

We have an underlying story formula for the detective story; a crime is committed and investigated. Simply, this is a meta-textual concept that imposes certain story elements on the text: it is a murder mystery, therefore there must be a body, and a guilty criminal must be revealed. A plot in this conception is a specific application of one or other story formula. There is scope for considerable variation in the application of the mystery formula, and it may not be the exclusive determinant of events inside the narrative.

But Hammett's experimental deviations from well-established conventions of the "fair play" method and associated story mechanics do not always work. Many of Hammett's short stories do not perfectly execute their rule-breaking agenda. So all the positive features above can also be flaws. This desire to use, but not be limited by, a strong structural convention leads to the biggest difficulty in approaching him as an author: when one looks in detail at his oeuvre, there is no single theory which explains how his fictions are structured or presented. If we borrow Umberto Eco's useful term, the "model author", from Six Walks in the Fictional Woods (1995), we can argue that all of those working in the "fair play" method are individual instances of a single "model author". With Hammett, not only is he outside of this convention, but since each of his own novels differs from the others, there is no single "model author" to be known as "Dashiell Hammett".

There are common strategies and motifs employed across Hammett's works but there is sufficient variability that general conclusions must be drawn carefully. To an extent this is the problem that all broad studies of him must address in order to find the common ground 
between a work of directed mayhem like Red Harvest and a fairly conventional whodunit like The Thin Man. The tendency is to assume a general stance based on a favourite Hammett novel and then try to fit the other novels into this template - the short stories are not consistently included. For example, W. Russel Gray in "Jimmying the Back Door of Literature" (2008) sees Red Harvest as Sisyphean and so struggles to convincingly read each of the other novels through the same prism.

George J Thompson, in the first such study, Hammett's Moral Vision", states that "we find a clear and definitive progression of man's potential to deal morally and ethically with decadent worlds" (26), and goes step-by-step through an analysis to conclude that "The Thin Man is Hammett's bleakest novel" (189), which means it is "Hammett's rendition of the end game" (190). However true that might be, this perception of continuity must overcome the more obvious summary of The Thin Man as being lighter in tone, bordering on the comic, and more or less using the standard conventions of the detective novel in a more or less conventional way. If The Thin Man is "nihilistic", then we must consider assigning that label to a large majority of detective fictions because they share a similar story structure and gallery of vaguely unlikeable characters.

For an author writing in the "fair play" mode there is no real moral dimension to the crimes: the corpse which prompts the investigation is merely a symbol in a logical system. For Chandler, crime is systemic, and so any given crime is merely one crime out of a larger number of related crimes and circumstances which prompt crimes. For Auden, the purpose of investigating and solving crimes is an inherent moral process through which guilt is purged from society. Chandler, the advocates of the "fair play" method, and Auden are discussing different things, so cannot reach agreement, even though there is nothing contradictory about a "fair play" investigation in the context of a range of systemic causes for crime, whose resolution restores part of society to correct moral functioning.

Hammett's writing makes use of all three of these conceptions of detective fiction, but none is sufficient by itself to explain all the features of any but his simplest writing. By looking closely at genre features, we can meet Haycraft's "short-sighted formalists" on their own terms by first offering a general theory of detective formula, then looking at how Hammett was able to use versions of these formulae to create effects and story structures beyond the simple resolution favoured by his peers (169). In other words, Hammett used detectives as a means to another end, not an end in themselves. His detectives do not detect

\footnotetext{
${ }^{3}$ Note, all references from Thompson are from the 2007 version of his work rather than either the 1972 dissertation or its serial publication in The Armchair Detective, as I have been unable to obtain these. From the context of citations by others of the earlier versions, I infer there to be few substantial changes in Thompson's argument from 1972 to 2007, but citations in the 2007 version imply that the text has been updated and altered significantly to incorporate later authors into his original argument.
} 
only to find the murderer, but to explore issues that are the traditional realm of the nongenre novel.

When Hammett, encouraged by his editor, came to write novels, he bridged into them by writing story sequences. His last experiment was the story pair, "The Big Knockover" and “\$106,000 Blood Money”, a pair of stories about a massive heist and the subsequent fallout. These two stories have some continuity, but can be read entirely separately. The combined length of the two stories is not quite long enough to count as a novel by even the most generous standards, but is too long to be described as a short story. His first novel, Red Harvest, was written and published initially in serial form, in four parts, with the intention of forming a single story (Layman, Shadow Man 90) (Panek 121) (G. J. Thompson 38). He sent this concatenated short story set to a publisher who helped him unify it into a single narrative. Close reading shows the seams in the sudden change of focus and pace after Donald Willsson's murder is solved and the inversion of action after Dinah Brand's murder. Hammett's second novel, The Dain Curse, is even more clearly modular, although it has other merits. His last three novels, The Maltese Falcon, The Glass Key and The Thin Man, were all conceived as single stories, a novel's worth of material in a novel-length text.

In each work, and this is true of his short stories as much as his novels, Hammett expanded on what he'd done before. He recycled story concepts, rather than specific plot configurations. For example, in "The House on Turk Street" (Apr 1924), the Continental Op is trapped by a group of desperadoes, but their alliance fractures with his assistance and in the end he's the only one still standing. Red Harvest uses this same story concept, but replaces the characters with factions and the house with a city. Having successfully executed the basic story formula in short form, he tries a long-form version of the same trick, combining it with a setting reminiscent of "Nightmare Town" (Dec 1924). Red Harvest has structural difficulties - for example, some critics see a superfluity of factions in the conflict but Hammett clearly understood what had worked about "The House on Turk Street" and extended its range (Panek 147).

The claim has been made that the detective story is a genre best suited to the short story: that was how Poe and Conan Doyle invented it (Symons, Bloody Murder 74ff) (Moretti, Signs Taken for Wonders 148). Agatha Christie proved how wrong that assertion was by being able to imagine larger and more complex plots with more and more moving parts, each perfectly balanced with the rest. Hammett proved how wrong that assertion was by refocusing away from an individual mystery and onto a wider criminal milieu and the effects of crime on the detective. 


\section{The Five Murders}

In "Criticism and Theory" (2010), Heta Pyrhönen lists some properties of detective fiction that could make it useful to literary theorists:

It demonstrates such features as the series of narrative levels and embedded texts of which narratives are comprised and the indispensability of generic structures that both conform to reader expectations and disappoint these same expectations ... Furthermore, detectives are portrayed as textually embedded model readers whose activities mirror those of their audience. Their investigation of various data resembles the general principles of reading that require one continually to try out different frames of reference and to modify and reinterpret one's inferences.

Each of Hammett's novels expresses most of these qualities, and varies them. For example, Sam Spade in The Maltese Falcon is both a model reader in Pyrhönen's sense (a detective who must determine who killed Miles Archer and what to do about it) and an author inside the fiction because quite aside from the various fabrications, evasions, and lies that are the basis of his interactions with the other characters, he tells a story, the Flitcraft parable. To that extent, any of the novels is suitable for a close genre-based analysis.

My final chapter focuses on Red Harvest because it is the novel that deviates the most from the baseline structure of the detective story, though the detective elements remain integral to it. To this extent, it is Hammett's most experimental work. Red Harvest is a difficult novel to summarize properly because of its apparently fragmentary and episodic action. Most summaries expand upon the novel's original title, "The Cleansing of Poisonville" (Nov 1927), but this under-plays the importance of the other organizing story, the murder of Dinah Brand. The novel opens by introducing these two elements, of Personville's corruption and the influence of Dinah Brand, and ends with their near-simultaneous resolution.

The Dain Curse uses a similar structure and approach to formula fiction as Red Harvest. It is a string of mysteries that are nested within the larger mystery that gives the novel its title, the curse of or on the Dain family. The Dain Curse uses much of the infrastructure and imagery of a gothic tale, especially in its second act, set in the Temple of the Holy Grail. In that respect, it represents a consolidation of techniques from Red Harvest, rather than continuing innovation.

The Maltese Falcon and The Glass Key both use their detective stories as framing narratives. The contained narratives in Red Harvest are also detective fictions or structured around detective conventions, but The Maltese Falcon and The Glass Key use their overarching mysteries as a backdrop and scaffold for non-detective activities. 
In some respects, that makes The Glass Key the end-point of Hammett's attempts to render the genre literary, because The Thin Man is clearly a conventional detective narrative discourse and story. It is somewhat ironic that it was the film adaptation of The Thin Man and its spin-offs were Hammett's greatest commercial successes.

\section{Conclusion}

Sean McCann summarizes Hammett in Gumshoe America: Hard-boiled Crime Fiction and the Rise and Fall of New Deal Liberalism (2000) as having "the notion that bringing the detective story artistic legitimacy would involve not just an effort to polish and improve it, but a struggle to transform its basic features" (92). The critical discourse since Hammett's lifetime, beginning with Haycraft, seems generally to agree that he accomplished a reformation of the genre. The element that has been lacking from this discourse is an inquiry into this specific aspect of his writing: how Hammett used, bent, and reformed the basic features of detection. Instead of recognising these innovations of genre, critics have followed Chandler's lead in discussing everything else that is meritorious. 



\section{Literature Review}

A 1930 review of The Maltese Falcon by the reviewer for The Outlook establishes the challenge that Hammett's novels have faced:

This is not only probably the best detective story we have ever read, it is an exceedingly well written novel. (W.R. Brooks, quoted in Layman, Discovering the Maltese Falcon 330)

Richard Layman, in his introduction to the 2005 special issue of Clue devoted to Dashiell Hammett, pinpoints the nature of this endorsement as "a masterpiece with a qualification" (6). Hammett is, for better or worse, part of the fraternity of detective authors, who have "always had an uneasy relation to what scholars and critics consider 'literature" (Black 76). The tone of advocates for detective fiction has always been defensive at best, as exemplified in 1902 by G.K. Chesterton's “A Defence of Detective Stories” or W.H. Auden's “The Guilty Vicarage". As will be discussed in greater length in Chapter 3, Raymond Chandler's famous polemic "The Simple Art of Murder" attacks the literary value of the genre. The explicit derision of critics like Edmund Wilson, in "Why do people read detective stories?" (1944) and "Who Cares Who Killed Roger Ackroyd?" (1945), is not needed for the detective fraternity to be quite aware of its sub-literary ambience.

Hammett had higher aspirations, to "take the detective story seriously ... to make 'literature' of it” (Selected Letters 47), and he received an odd kind of help from Raymond Chandler, who praised Hammett's literary style by comparing him to Hemingway and for using a vernacular "not supposed to be capable of such refinements" ("SAOM" 15). Chandler set the template for praise of Hammett in authentically literary terms of imagery, diction and characterization: of style. As Jon Thompson, in "Dashiell Hammett's Hard-Boiled Modernism" (1994), recognises these efforts were not successful: "[Hammett]'s work has generally been relegated to a second-tier status thought to be appropriate to 'genre' fiction" (118).

E.M. Beekman's study, "Raymond Chandler and An American Genre” (1973) shows that Chandler established the terms of reference for others' evaluations of Hammett: "[w]ith the debut of Hammett the "pure' tale of detection [is] dead" and instead we have "the creation of atmosphere and character", culminating in "something mandatory which only talent can provide: style" (151). Beekman then shows the real source of his critical apparatus by saying "there is nothing ingenious about a corpse lying on a sidewalk: death is then and there a dirty fact of life and no longer an Arcadian anachronism" (152), a virtual re-phrasing of Chandler's pithy summary that Hammett "took murder out of the Venetian case and dropped 


\section{Five Murders in a Fictional City}

it into the alley" ("SAOM" 14). Beekman's entire argument is in fact lifted from Chandler's and is positive reinforcement for a pre-selected stance on Hammett that does not make close reference to Hammett's novels. Despite implicitly conflating Hammett and Chandler in his early passages, Beekman's views Hammett as merely the precursor to the real talent, Chandler:

Blinded by Hemingway's terseness, commentators have praised Dashiell Hammett's spare staccato style ... [but Red Harvest] is little more than a literate comic strip ... Hammett's second novel, The Dain Curse, is an embarrassment, even as a tale of detection, while its use of occultism is a gothic gone flat. The acclaim for the characterization in The Maltese Falcon is ... clouded by the superlative film ... The Glass Key, considered Hammett's masterpiece, [does not] favorably compare with ... the far more subtle and complex The Long Goodbye. Only The Thin Man ... can withstand repeated scrutiny. Let us grant Hammett the honor of having been the founder of the hardboiled school of writing, but that does not automatically confer excellence. (168)

Edmund Wilson did not put it better, but was briefer, when he said that "Hammett lacked the ability to bring the story to imaginative life" ("Why Do People Read Detective Stories?").

Alongside these detractors, there are those who offer positive views on Hammett, such as Haycraft, who thought that "because of their startling originality, the Hammett novels defy exegesis even to-day" and that as "detective stories they can hold their own ... are also character studies of close to top rank [and] penetrating if shocking novels of manners as well" (Murder for Pleasure 171). The problem is that by-and-large these close readings are almost entirely focused on the method of presentation and representation and so neglect the core functional elements of the novels - the detective formula.

This approach is summarized succinctly by William W. Stowe in his inquiry "Convention and Ideology in Detective Fiction" (1989). He suggest that "it is also possible to read more conventional versions of the detective formula in a critical way ... to make demands on popular fiction that are similar to the demands we make on 'high' fiction ... a symbolic rather than a symptomatic reading" (571). Thus the innovations on the level of story and plot construction are completely overlooked in favour of what are essentially matters of taste. These literary perspectives neglect the single defining and unifying trait of Hammett's novels: detection.

\section{Hammett the Communist}

Haycraft completes his sketch by mentioning the "indubitable sincerity of [Hammett's] interests in ... political movements of a Left-wing nature" (173). This biographical fact has become a popular analytical prism, where critics sift through the novels, especially Red 
Harvest, looking for politics and emergent Marxism. In Shadow Man: The Life of Dashiell Hammett (1981), Layman is clear that "Hammett never used his fictions as a forum for his political beliefs" (Shadow Man 96). J.A. Zumoff concurs in "The Politics of Dashiell Hammett's Red Harvest" (2007) where he concludes that "Red Harvest, while obviously political, does not have any obvious politics", but this is nevertheless a significant strand of Hammett criticism.

Some articles have a startlingly "imaginative approach" to a political reading (Layman, Shadow Man 96), such as Paul P. Abrahams' "On re-reading the Maltese Falcon" (1995), positing that the construction of the novel is primarily a "synergy between the crusading Knights, World War I, and the tawdry contemporary diplomacy surrounding the KelloggBriand Pact" (7). Abrahams' perspective does not help much to explain why it is such a highly regarded character study, instead drawing conclusions such as "[i]n Hammett's scheme of imperialist relationships, Wilmer represents American finance capitalism, headquartered in New York" (4). This is difficult to reconcile with a less outlandish inference that "Wilmer might as well be an innocent sacrifice" in a Romantic reading (9). Even if we can link these two arguments, of Wilmer - both as stand-in for the capitalist system Abraham argues Hammett hates, and as an innocent sacrificial victim in a knightly quest this seems to fragment any meaning we could take from the text.

Zumoff explains that "by removing the emphasis from solving the crime ... Hammett creates the possibility for crime fiction to be a social commentary" ("Politics of Red Harvest"). This suggests that we can substantially divorce the story content from its structure. Whereas allegorical readings substitute one formula for another, this kind of reading can potentially disregard the story structure altogether.

Zumoff expands his comments on Red Harvest in "Tijuana the American Town: Images of the Corrupt City in Hammett's 'The Golden Horseshoe" (2008) to argue that "hard-boiled fiction often assumes political overtones, [but] as a genre has no inherent politics" (37). Andrew Pepper construes inconclusiveness in "The 'Hard-Boiled' Genre" (2010) as a deliberate strategy, so that the "hard-boiled" genre "is better understood as an ambivalent political outlook" (142) than an ideology per se. Both Zumoff and Pepper are ultimately responding to the texts themselves in drawing these non-conclusions. Abrahams is using a combination of allegorical assumption to re-filter the content of the story. He eschews wellsupported formulaic readings that can explain unclear aspects of the texts in favour of drawing dubious parallels with historical events that can only be interpreted through the novels after substantial research independent of the novels. Abrahams does not use these parallels to resolve any of the classic difficulties of The Maltese Falcon.

Pepper is ambivalent about the role of formula, saying the "hard-boiled" novel "focuses primarily on the investigation rather than perpetration of crime" but with the substantial 


\section{Five Murders in a Fictional City}

caveat that "this distinction is often blurred to the point where it is difficult to tell law enforcer and law breaker apart (and indeed what constitutes a crime in the first place)" (142). This ambivalence actually only exists at the peripheries of the "hard-boiled" canon, of Hammett, Chandler, Macdonald, and Spillane, with the possible exception of Red Harvest. The substitution of a state-controlled legal system for a personal ethical standard by a detective has been expanded out of all proportion here. The underlying formulaic structure of the "hard-boiled" novel encourages us to regard the detective as serving a higher or greater good than the law would or could. As the Continental Op explains at his breaking point, "I could have gone to him [Elihu] ... [he would] have given me the support I needed to swing the play legally ... but it's easier to have them killed off, easier and surer" (Red Harvest 137). There is no suggestion that the Op's goals are dispensable so the only ambivalence is in his method. Despite moral qualms we have about these methods, there is no real confusion about who is the law-man and who the law-breaker. The kind of ambivalence that Pepper perceives is a more recent development in the "hard-boiled" detective genre and plays a small part in the canonical works, even for Mickey Spillane.

Sean McCann makes a more considered argument for a socio-political-economic reading of Hammett by contrasting a general reading of the society Hammett constructed in his fiction with a general vision of society as reconstructed by McCann: "[p]oint by point, Hammett's [The Glass Key] dims the picture of civic triumph that ran through the rhetoric of his contemporaries and undercuts the very ground for optimism that they found" (Gumshoe America 131). McCann first attempts to understand the text and only then to search for parallels in Hammett's world. However, while his analysis appears to be on firmer ground, it too fails to explain the story mechanics or some of the odd features of the novels he treats.

Hammett experienced the excesses of the capitalist system, but in the latter part of his life was a member of the communist party. Drawing on his biography can thus support both communist and capitalist readings, depending on the inferred timing of the origin of his communist leanings. David T Bazelon draws on this tension in "Dashiell Hammett's Private Eye: No Loyalty Beyond the Job" (1949) to theorize that Hammett stopped writing "as soon as he got a 'better' job" (168), which he interprets as a "postponement, and after a few years he came upon Stalinism ... and crossed the t's of his lost art" (174). In other words, the latent drive toward communism was not fuel for his art, but the thing which smothered that art. It is unclear how this insight, even if true, can be used to help understand any of his novels, and that is typical of political readings of Hammett's work.

Carl Freedman and Christopher Kendrick, in their study "Forms of Labor in Dashiell Hammett's Red Harvest" (1991), frame Red Harvest as structurally critical of capitalism, because the city is riven "between 'legitimate' and 'illegitimate' capitalism" (210). They conclude that "the problem of exploitation remains, and the Continental Op's dissatisfaction 
at the end suggests an awareness that his own labor [sic] has inevitably been reified into an instrument wielded for the benefit of the despicable capitalist boss Elihu" (220). This reading, while persuasive, simply ignores the formulaic basis of the narrative in favour of an economic analysis, which creates problems in interpreting things like Elihu's reluctance to accept the Op's help. Their argument, intended to be particular to Hammett, is similar to Franco Moretti's argument, in Signs Taken for Wonders: Essays in the Sociology of Literary Forms (1983), that the basis of economics in detective fictions is that "unequal exchange between labour-power and wages ... is the true source of social wealth" (139).

In the pithily titled "'Going Blood-Simple Like the Natives': Contagious Urban Spaces and Modern Power in Dashiell Hammett's Red Harvest" (2005), Thomas Heise argues that the novel is an exemplar of a narrative of attack on the working class by those with greater economic power, because "poor and working-class urban spaces were seen as the point of origin [of crime]" (487). He does not use this as a springboard to discuss Hammett's political beliefs explicitly.

Perhaps the most successful approach to interpreting the political dimensions of Hammett's work comes from Erin Smith in Hard-Boiled: Working Class Readers and Pulp Magazines (2000) and a similar approach from Christopher Metress in "Dashiell Hammett and the Challenge of New Individualism: Rereading Red Harvest and The Maltese Falcon" (2005). Both position both the Continental Op and Sam Spade as operating in an antiquated mode of production where an individual's time was not commoditized in the way that is represented by industrial processes. This uses the formulaic arrangement of an individual detective's resistance to commodification as a building block for understanding the detective's resistance to the temptations of money and sex. This conception of the detective as an artisanal, rather than production line, worker rationalizes a feature of the detective formula that is otherwise explained by critics like Hall as an insubstantial reference to questing knights and/or the heroes of the old west, an association I will return to in Chapter 4. Smith and Metress explain the political dimension of the novels without distorting them into arguments for Hammett as a political writer.

\section{Dean of the Hard-boiled School}

Hammett's pre-eminence is echoed in most discussions of his writing, or that of his socalled successors, Raymond Chandler, Ross Macdonald, Mickey Spillane and later authors. His obituary in the New York Times describes him as the "dean of the so-called 'hard-boiled' school of detective fiction" (quoted in Bruccoli and Layman 225). Bill Pronzini and Jack Adrian later describe Hammett as the "patriarch of the hard-boiled crime story" ("Introduction" 8) in their anthology Hard-Boiled (1995). In a similar vein, John G. Cawelti, in his influential study of genre fiction, Adventure, Mystery, and Romance: Formula Stories 


\section{Five Murders in a Fictional City}

as Art and Popular Culture (1976), gives precedence to Hammett, who "invented the hardboiled detective" (163).

A typical view of the "hard-boiled" school parsed through Hammett is summarized by George J. Thompson - "[i]t is virtually commonplace to assume that the Hammett world is a demonic world of violence" (27), and that "society is itself corrupting" (29), though Thomspon resists the temptation to link this with a critique of capitalism. Tellingly, Thompson too adopts Chandler's enduring phrase that the detective "must walk down mean streets" (29 my emphasis). In the hard-boiled aesthetic that Thompson reads, "none of the novels leaves one with the sense that the heroic task has been heroically completed (a theme so familiar in the traditional genre) or that the world is appreciably better for the actions of the protagonist" (29). Thompson is creating a distinction between "fair play" novelists and "hard-boiled" novelists. He draws three distinctions: the aesthetic of the world inhabited by the detective, the moral implications of crimes' origins, and the detectives' handling of the cases. These bases are more in the nature of style and content than story structure, though Thompson makes explicit the invisible assumption in others' criticism of Hammett, that "it would be a mistake to try and divorce Hammett's work from the genre of crime fiction and the detective story ... in each there is something to be discovered" (29). He does not, however, explore these discoveries in detail or their moral implications as such. His treatment of the first central mystery of Red Harvest is a single paragraph which simply says that the Op's methods and Albury's motives are "typical" (40) and the only conclusion he draws about Donald Willsson's murder by Albury is that "Hammett has drawn a unified picture of a diseased world" (41). I show that there is more to this situation in Chapter 5.

Thus any reading of Hammett can easily find itself unconsciously influenced by studies of those who came after him, as Layman explains: "it is difficult to discuss The Maltese Falcon without first chipping away the cultural barnacles" ("Theme Issue" 5). We might add that the increasing gap of time between Hammett and the present is also significant because the 1920s and ' 30 s readers of Dashiell Hammett in the cheap pulp magazine Black Mask are not the same readers, demographically, who buy his novels in expensive Vintage Crime Classics paperbacks today. Reading these texts as classics is not at all the same as reading them as trash. The different reading protocols these labels invite in effect rewrite the text. (Smith 6)

Other de facto rewriting is outlined by Metress, in The Critical Response to Dashiell Hammett (1994), as the erosion of Hammett's critical esteem during the 1950s, which can be "be attributed, in part at least, to ... Hammett's association with the Communist party" (xxi). The implication is that it is periodically necessary to return to close readings of the novels 
rather than assuming that critical views of the past either have a solid foundation, or are still applicable to a modern interpretation.

George Grella's influential essay, "Murder and the Mean Streets: the Hard-Boiled Detective Novel", (1974) unabashedly imagines a prototype of a worldview "implied in Hammett's works, and fully articulated in Chandler and Macdonald" (418). Metress tries to reverse this association by optimistically claiming that in the past "the distinction between Hammett and Spillane [was] ... erased ... by eliding the difference between Spillane and Chandler, and then the difference between Chandler and Hammett", but that since then the situation has improved (by 1994), such that "most critics no longer lump together Hammett and [Spillane's] Hammer" ("Introduction” xxiii). Yet, Lewis Moore is still comfortable (in 2006) with discussing the "hard-boiled" school without much internal distinction in his study Cracking the Hard-boiled Detective. For all that Metress can perceive differences, Hammett's paternal relationship with other "hard-boiled" detective novelists remains intact.

The connection between Hammett and the so-called "hard-boiled" school has come to be almost an article of faith in Hammett criticism. None of the authors above conducts a detailed study showing either the structural or aesthetic links between Hammett and any other author. For example, none undertakes a close comparison of the character of any of Hammett's detectives and their assumed successors, Philip Marlowe, Lew Archer and Mike Hammer. Tom Nolan comes close to this in "Hammett and Macdonald" (2005), but the comparison occurs at a high level of abstraction where the different connecting statements are open to dispute or are not clearly derived from close reading of their respective works. When close readings are done with an eye to making comparisons within the "hard-boiled" school, the result is conclusions such as the discussion of the Continental Op in "Stirring Things Up: Dashiell Hammett's Continental Op” (1980) by John S. Whitley. He shows the problems with associating Hammett with Chandler et al by pointing out that the situations in Red Harvest "belong not to those writers normally designated as Hammett's obvious successors, such as Raymond Chandler [and] Ross Macdonald” (445).

Mark McGurl's article, "Making 'Literature' of it: Hammett and High Culture” (1997), argues that "Hammett's ambiguous place in early-twentieth-century cultural hierarchies, which he hoped to overcome by taking his genre seriously, paradoxically reveals itself in his habitual lack of seriousness with respect to the ontological status of his own representations" (706). Yet, it is just such ambiguity that drives criticism of the novels, especially in comparison with contemporaneous authors whose works were ontologically complete. It is no accident that the mysteriously dead Owen Taylor is the totem spirit of Chandler criticism, and the ambiguous Flitcraft story is "regarded by many readers as the key to the meaning of the [Maltese Falcon]" (Layman, "Theme Issue" 8). 


\section{Epistemology and Ontology}

Stowe summarizes the general case for detective fiction as "[p]olitically, morally, and epistemologically ... affirm[ing] rather than question[ing]" so that "truth in these novels may be elusive, but it is ultimately knowable" (570), in other words the detective "will have to reinstate the univocal links between signifiers and signifieds" (Moretti, Signs Taken for Wonders 146). As early as 1944, André Gide was aware that Hammett's equivocation was more intense than the general case with "dialogues, in which every character is trying to deceive all the others in which the truth slowly becomes visible through the fog of deception" (quoted in G. J. Thompson 28). Thompson attempts to dispel this fog by arguing for Hammett's Moral Vision, a darkening perspective on life unifying the artistic objectives of his novels, while Dean DeFino in "Lead Beams and Falling Birds" (2004) outlines "how the text constructs its own meaning", which he does through selective close analysis and inference, not by examining the use of formula or story mechanics (80, emphasis in original).

Steven Marcus leads other further into the equivocation by eloquently advocating uncertainty as a guiding principle in his 1974 introduction to The Continental Op story anthology. Marcus argues that Hammett is "not only morally ambiguous [but] morally complex and enigmatic" (12) leading to "ethical irrationality of existence" (14). Sinda Gregory continues this line in Private Investigations: The Novels of Dashiell Hammett (1985) where she argues "what we see, we believe, and what we think is what we have created ourselves" (62). For Marcus, this means "what happens in Hammett is that what is revealed as 'reality' is still a further fiction-making activity" (17). The Op himself explains this at the end of The Dain Curse: "[i]f you want to believe that it did, all right, I don't. I'd rather believe I saw things that weren't there" (284). Whitley concurs, claiming that "we are left unclear about a number of aspects of [the Dain Curse], including the identity of Edgar Leggett's murderer" (453). Likewise, Zumoff redirects his inquiry into Red Harvest's possible political messages via the idea that "such a perspective [as a political reading] can be read as an attack on the idea of reality itself" ("Politics of Red Harvest").

This is something quite different from "fair play" narratives, even ones which use the narrative discourse itself to mislead the reader. As explained by Emanuela Gutowski in her "An Investigation In Pragmatics: Agatha Christie's The Murder of Roger Ackroyd" (2011), "Christie's narrator never lies in his role as narrator, while he does in his role as character" in order to create a lie by omission that is the central puzzle of the novel. The narrator in this case has obscured reality, but there is still an underlying reality, affirmed by the narrator at the level of the narrative discourse and at the level of story by Poirot (58). Marcus et al suggest that the contrary is true in Hammett, that there is no definite reality, only nested narrative discourses, none of which can be definitively said to be the truth. 
Whitley also transposes this uncertainty from the fictional world itself onto the characters, arguing that "the problem with most of the women the Op meets is neither that they present a sexual threat nor that they offer the possibility of social compromise, so much as that they are shape-changers, indices of a world in flux" (451). This equally applies to many of Hammett's men, such as the villain Papadopoulos in Blood Money, the Quarres in "The House on Turk Street", or Joseph Haldorn and Owen Fitzstephan in The Dain Curse. Whitley concludes that Hammett's detectives' "strength resides not in a stable personality but in the ability to change like a chameleon to meet the needs of a fluctuating world" (454). He might well have summarized the Op's strength as "defined less as physical toughness ... than as the ability to construct an authoritative rhetorical ethos" (Freedman and Kendrick 211 ) - in other words to shape reality through rhetoric.

This doubled or tripled layering, where "reality becomes a kind of onion" (Dooley 27) of uncertainty can seem to destabilize any approach to reading or interpreting Hammett, but Peter J. Rabinowitz proposes an approach that evades these epistemological and ontological problems by returning to a formula-based understanding of Hammett. The title of his argument, "The Turn of the Glass Key: Popular Fiction as Reading Strategy" (1985), is close to a summary of its utility. The problem that Rabinowitz is trying to solve, however, is the opposite of that posed by Marcus et al, because he is concerned with problems deriving from the "so-called objective method", which focuses entirely on exteriority (418). The problem being too little rather than too much or contradictory information. He proposes that "one way ... of defining genres is to consider them as bundles of operations which readers perform in order to recover the meaning of texts rather than as sets of features found in the text themselves ... genres can be viewed as strategies that readers use to process texts" (419). In this reading approach, the problems of epistemology and ontology disappear because the reader brings the necessary missing information to make definite statements.

The problem with reader-created meaning in the context of detective fiction is outlined in "Novels and Noir in New York" (1995) by Lucille Kerr, who explains that "[t]o read criminal fiction correctly ... is to agree to read incorrectly, to occupy a position of ignorance for the duration of the reading" (733). She is arguing that the formulaic nature of detective fiction means that readers can get ahead of the revealed facts by recognising the formulaic role of any given character too early, and hence knowing their significance to the formula before the narrative discourse makes it clear. Readers must deliberately under-read detective fiction in order for the narrative to work as designed. This is the basis of the approach outlined in "Notes on the Semiotic Analysis of Detective Novels: With Examples from the Novels of Agatha Christie" (1978) by I.I. Revzin, who even presents a chart of character types and plot intersections. 


\section{Five Murders in a Fictional City}

If we cannot read Hammett straightforwardly because of the problems raised by Marcus et al, and to read within the genre is to "read incorrectly", we are, according to John Walker in "City Jungles and Expressionist Reifications from Brecht to Hammett" (1998), at an impasse such that "the emptiness of signification in Hammett's work negates the possibility of satisfactory closure to the mystery" (14).

Bruce Gatenby summarises the challenge to Marcus's argument and its derivatives directly in his essay "'A Long and Laughable Story: Hammett's The Dain Curse and the Postmodern Condition" (1994) by asking the rhetorical question: "If it is not possible for a detective, as a prior subject, to interpret 'truth', then does this mean we should abandon the concept of truth, that truth is something incapable of being discovered" (58)? An exploration of the detailed story mechanics and applications of formula might help to resolve some of these questions. He goes on essentially to agree that meaning in Hammett is elusive.

The instability of reality itself in these interpretive stances may be the most powerful critique of Chandler's claims of realism, and create ambiguity in a genre noted for the lack of ambiguity in its narratives. This is the direction suggested by Christopher T Raczkowski in his 2007 review of Christopher Breu's Hard-Boiled Masculinities, Charles J Rzepka's Detective Fiction and Horsley's Twentieth Century Crime Fiction, where he concludes that "the reader's pleasure is greatest when the material clues can simultaneously sustain multiple narrative arrangements" (880). Raczkowski is thinking too small here, in terms only of possible allocations of roles in a structure like Revzin's, rather than thinking in terms of the puzzle complex itself being used to create ambiguities in Hammett.

Yet, few of these authors discuss how this ambiguity interacts with the Hammett's stories as formula fictions, as the product of structures with a prescribed sequence of events and inherently complete sets of information. There is no examination of the complex clues used by his detectives to draw their conclusions, or how these clues fit within the detective formula. Such an approach is begun, but not completed, by Carl D. Malmgren in "The Crime of the Sign: Dashiell Hammett's Detective Fiction" (1999), which reasserts the validity of signs within the limitation of our ability to use realistic interpretations, "it is true enough to [Hammett]'s vision to call a spade a spade and show just what that means to the ground(s) that we tend to take for granted" (383). This has not persuaded some critics, like Christopher Breu, who argues for the unreliability of the Continental Op as narrator in Hard-boiled Masculinities (2005), but faced with the blizzard of uncertainty we may find ourselves echoing the Op when he argued "if you let it get away from you, then you've got to dive back into that foggy muddle to wangle yourself out another [theory] to take its place" (342), and accept that we've got to work from some assumed solid basis.

That basis cannot be a simple emphasis on stylish writing, nor can it be inferences based on assumed political motivations or messages. These aspects do need to be considered, but 
not at the expense of neglecting the most solid basis for interpreting Hammett's writing: the detective formula. This is the defining, unifying, and structurally central element in each of his novels. 



\section{Chandler's Shadow}

Raymond Chandler has had a profound effect on the critical perception of Hammett, and this effect in turn has affected how Chandler is perceived. In order to appreciate Hammett on his own terms, it is necessary to recognize this effect and ameliorate the distortions that it introduces. These distortions are a kind of doubling, where good (and bad) aspects of each are haphazardly transposed onto the other so that neither can be properly appreciated for their own merits. The link was partially an accident of history, as both authors began their careers writing short stories for Black Mask. However, the main force of the connection comes from deliberate efforts by Chandler in publications and correspondence, the most important of which is his 1944 essay "The Simple Art of Murder". The structure, arguments, and effects of this essay will be the main focus of this chapter. By the close of the chapter, we will have stripped away the layers of Chandler's influence so that we can appreciate Hammett's work on its own terms.

\section{Innovation and Perfection}

In Detective Fiction's (2005), Charles Rzepka introduces Chandler as Hammett's "protégé" (179), an almost ironic term in light of Chandler's influence on how Hammett is read. He, like other recent critics, is familiar with at least Diane Johnson's biography, Dashiell Hammett: A Life (1984), which reports that the pair only met once, at a Black Mask reunion party (Chandler quoted by Johnson 129). Rzepka's comment is not intended to imply a factual or personal relationship, so much as a sense of spiritual succession more directly expressed by John Shaw's descendent Milton Shaw: "as Hammett moved off the scene, his place was taken by Raymond Chandler" (89). Chandler picked up Hammett's mantle and carried on with the Black Mask style of detective fiction. Shaw and later Rzepka along with most others echo the common wisdom of the "hard-boiled" critical fraternity, positioning Hammett as the founder of a school of which Chandler became the master. Just as Virgil follows Homer and Pope follows Dryden, so Chandler follows Hammett. The first creates the field, the second perfects it.

Representing their relationship in this way distorts important aspects of both writers, distortions which are, in part, a deliberate device of the "protégé". Harold Bloom's book on the subject of artistic legacy, The Anxiety of Influence (1973), describes this process as "misreading ... so as to clear imaginative space" (5). Implicit in his argument is that the stronger a creative force, the more it distorts the works that came before it.

Misrepresentation and adaptation of existing works becomes a part of the creative process itself for all "protégés", where Chandler "played a pivotal role in establishing and shaping 


\section{Five Murders in a Fictional City}

the tradition of detective fiction we now think of as 'hard-boiled"' (Hickman 288). Chandler summarized this process with a different emphasis, claiming that "everyone imitates in the beginning" and because "Hammett has not written for publication since 1932 ... I have been picked out by some people as the leading representative of the school" (Chandler Speaking 52). This statement makes it sound rather a happy accident in which Chandler had no part. Later, Ross Macdonald too redefined and reacted to both Hammett and Chandler. In a letter to his publisher he claimed to "owe a lot to Chandler, and to Hammett ... [but] I am interested in doing things which neither of them was able or willing to do" (quoted in Bruccoli and Layman 255) ${ }^{4}$.

Bloom's arguments are intended only to apply to so-called "strong" authors who are conscious of an originating and surrounding tradition to their work. He consciously excludes trail-blazers, those who write without consciousness of predecessors. This might appear to exclude Hammett from his argument, but Hammett too was writing in a tradition and he was relatively scathing of this tradition in his own critical writing (Crime Stories 914). Hammett's representation of the weaknesses, especially in terms of realism, in other crime writers' efforts leads in part to Chandler's misrepresentation of Hammett.

Critics have always struggled to categorize Hammett's crime writing because his approach was idiosyncratic and varied and so there is a temptation, given the close association of Chandler and Hammett in the critical mind, to use Chandler's more unified work to represent both authors (and their contemporaries and successors). Stephen Knight is fairly uncommon in recognizing this in his two studies, Form and Ideology in Crime Fiction (1980) and Crime Fiction Since 1800: Detection, Death, Diversity (2004), pointing out that "Hammett remains an interesting figure, not least because each novel is different from the others. His restless mind avoided formulae" (Form and Ideology 136). Having thus introduced and stressed Hammett's importance, he uses Chandler's novels to show the relationship between formulae and meaning in the "hard-boiled" style because "[h]e did write to a formula, did create a constant hero and so has a more uniform direction: he repeats in form and content the patterns that shape the meaning of his texts" (Form and Ideology 136). Knight's reason for using Chandler rather than Hammett seems quite reasonable, given his specific interest in story formula, but the net result here is the same as with studies which are silent on their reasons. While there is an acknowledgement of Hammett's role in creating the genre, the discussion is usually about Chandler instead.

\footnotetext{
${ }^{4}$ I mention this only because it supports the general pattern of the argument. For a detailed discussion of Macdonald's relationship to Chandler, refer to Michael Sharp's "Plotting Chandler's demise: Ross MacDonald and the Neo-Aristotelian detective novel" (2003).
} 


\section{The Simple Art of Murder}

While "The Simple Art of Murder" has intellectual content, it is at least partially intended as a polemic. It is not a disinterested disquisition. Chandler, as a practitioner of the field he is critiquing, naturally wants to advocate his own approach in preference to that of others.

"The Simple Art of Murder" is framed explicitly as a contradiction to Haycraft's conception of the genre. "The Simple Art of Murder" is not a tightly focused document; it constantly shifts its focus and its terminology to include commentary on a lot of different issues. The majority of the text excoriates the habits, goals and practices of the "Golden Age" detectives so beloved by Haycraft. Chandler especially attacks The Red House Mystery (1922) by A.A. Milne by looking closely at the details of the story's crime and subsequent investigation. He makes brief comments on other authors, but offers no other sustained critical interpretations. Chandler also uses the essay as a platform to explain a partial theory of literary value, which is somewhat defensive.

Haycraft's ambivalent inclusion of Hammett in his survey created a chink in an otherwise air-tight definition of detective fiction which Chandler exploited to foreground his own contrasting vision. Haycraft described a specific conception, widely agreed upon, of detective fiction and had difficulty summarizing Hammett in that conception. This difficulty becomes a rhetorical asset for Chandler's argument about the problems with detective fiction as Haycraft described it. In this interpretation, Hammett is effectively an argumentative tool, a weapon with which Haycraft can be fought at least partially in Haycraft's own terms, by defining Hammett in a way that was useful for Chandler's rhetorical objectives. Chandler relates Hammett both to a wider world of detective authors and implicitly to himself, and these relationships have largely been adopted by subsequent critics.

The final section of the text is effectively a creative manifesto for detective fiction, where Chandler goes on the offensive, to set out his own terms. His immediately prior use of Hammett as the sole positive example combined with this agenda would forever link the two authors together by retrospectively imposing that creative agenda and style on Hammett. This successfully elides the differences of style and content to the point where a critic like George Grella can casually claim that "Hammett, Chandler, and Macdonald constitute a continuum of achievement" ("Mean Streets" 414), knowing that this is the critical consensus. In eliding the differences between the two authors, Hammett himself is virtually murdered as an author, becoming merely the precursor of Chandler.

Chandler applied these theories to Hammett, and effectively found him "by hypothesis, not incapable of anything" even if in practice, he found shortcomings in Hammett's work. 


\section{Five Murders in a Fictional City}

\section{Literary Value}

The essay proffers, modifies, and eventually rejects, a number of different ways of thinking about literary value. Chandler begins with realism, linked to authenticity, but his summary of where detective fictions fall short is more revealing:

[T] hey ["Golden Age" detective novels] do not really come off intellectually as problems, and they do not come off artistically as fiction. They are too contrived and too little aware of what goes on in the world. They try to be honest, but honesty is an art. The poor writer is dishonest without knowing it, and the fairly good one can be dishonest because he doesn't know what to be honest about. ("SAOM" 10)

We have here possible virtues of intellectually robust puzzles, artistic merit, realistic action, awareness of the world and honesty (if honesty can be distinguished from realism). Chandler moves uneasily between his criteria arguing one case and then another, but realism is never far from his conception of literary value. It is not easy to reconcile Chandler's summary here with the murky and perhaps unresolvable world seen in Hammett's writing by the critics discussed in Chapter 2.

Miranda B Hickman undertakes a detailed study of Chandler's essay in "Introduction: The Complex History of a 'Simple Art"' (2003). She points out that Chandler "advanced a theoretical statement about the idiom of hard-boiled that crystallized it in the readers' minds" (290) but "the way Chandler uses 'realism' ... is unstable" (290) and that ultimately "Chandler's claims about what defined his kind of hard-boiled fiction were ultimately not exactly those he offered" (298). This means that, for Hickman, "the portrayal of the detective and his world is valued not because it is 'realistic', but rather because it is compelling" (298). Hickman objects to the uncritical quotation of "The Simple Art of Murder" in relation to Chandler's method of writing, and while that is admirable, the genie has been out of the bottle since 1944. The concepts that Chandler advanced have ingrained themselves in the critical discourse, and particularly when it comes to the concept of literary value, we need to engage directly and seriously with the essay as a critical polemic, not as an abandoned prototype for the real argument that Chandler wished to advance, which is Hickman's conclusion.

For Chandler, the value of a literary work begins with its aspiration toward realism because "[f]iction in any form has always intended to be realistic", but as soon as he raises this concept he admits that this will be an aspect that changes over time so that "[o]ldfashioned novels which now seem stilted and artificial to the point of burlesque did not appear that way to the people who first read them ... Austen's chronicles of highly inhibited people against a background of rural gentility seem real enough psychologically" ("SAOM" 1). This does not address any of the other qualities of Austen's writing which could be 
considered to have a literary value. What at first appears to be a straightforward statement of art as simply mimicry-of-life is therefore immediately complicated by the need for an awareness of a work's historical context.

Chandler goes on to disconnect detective fiction from this kind of historicizing reading by arguing that "one of the qualities of this kind of writing is that the thing that makes people read it never goes out of style ... the same old futzing around with timetables and bits of charred paper" ("SAOM" 3). In other words, detective fiction is timelessly unrealistic.

The aspect of murder adds another dimension to the situation, complicating the implication of his opening sentence: fiction is intended to be realistic, unless it is about murder, when "nobody but a psychopath would want to read it" ("SAOM" 2). What this implies is that a murder mystery can never aspire to realism, which is the first of Chandler's requirements. Logically, any literary value it has must instead be based on some other quality that Chandler has not specified with such clarity.

Chandler has imposed his own criteria for a work succeeding or failing, rather than attempting to engage with it on its own terms. As he summarizes his position on the "fair play" method: "[the] only kind of writer who could be happy ... was the one who did not know what reality was" ("SAOM" 12). Instead of asking why those particular works were structured or presented the way they were, he dismisses them for failing to be realistic. Unfortunately, the realistic detective novel could be equally rejected for "lack[ing] the element of uplift" ("SAOM" 2). Detective fiction is positioned as inherently without value.

Chandler's critique of The Red House Mystery raises a number of legitimate logical problems, but his conception of realism goes beyond requiring these problems to be corrected. Chandler is interested in their context and universality. For example, Chandler argues that "the realist in murder writes of a world in which gangsters can rule nations and almost rule cities" ("SAOM" 17). This argument does not address the causes of the logical problems he found in The Red House Mystery. The statement is not about logic, but about a context for the story, a conception for the world that does not apply in a realistic sense to a detective story set in England. His entire conception of crime as spelt out in the penultimate section of the essay seems to refer to an entirely different order and manner of crime than the novels he destroys. Assuming one lived in an English country village and wanted to write a realistic murder story, Chandler's prescriptions are all essentially useless. One could argue that in his view, a murder in such a setting, or even the setting itself, becomes unrealistic. While Chandler was prepared to accept Austen as a product of time and place, he implicitly refuses the same consideration to detective novelists who do not inhabit his kind of city. The implication is that the typical setting of a "fair play" narrative is a simulacrum - it is a convenient fabrication with no corresponding reality. This is not entirely unjust if one considers the number of murders in St Mary's Mead, but it is not specifically the number or 


\section{Five Murders in a Fictional City}

frequency of murders in such a location that he is objecting to, so much as the construction of the fictional place itself, the very basis for its existence.

Chandler misses the opportunity here to make a concrete argument for realism based on the details of crime and investigation. He does not make the argument that the key elements of means, motive, and opportunity, must be realistic. This is implicit, but undeveloped, in his endorsement of Hammett's killers who kill "for reasons ... and with the means at hand" ("SAOM" 14). This advocacy of straightforward methods of crime threatens the basis of the ratiocinative detective story, where it is the very improbability, un-reality, of the story mechanics that can most easily create difficulty in solving the crime. Chandler offers no remedy for the logistical problem of constructing a realistic detective novel. Hammett had a similar perspective on this kind of realism, suggesting that "it is certainly not unreasonable to ask any one who is going to write a book ... to learn something about his subject" (quoted in Bruccoli and Layman 125).

In some senses then, realism has a chimerical quality to it in "The Simple Art of Murder". Chandler uses it to find faults in some "fair play" stories, but their unrealism is not his main objection to them, and his prescription for a corrective is a substantial aesthetic realignment rather than a system for adjusting logical problems in "fair play" narratives. Perhaps that is why his choice of examples focuses on works written primarily as entertainment, rather than those written with a stronger puzzle focus. Chandler tries to deflect this concept by quickly saying that because of their unreality, "they do not really come off intellectually as problems, and they do not come off artistically as fiction" ("SAOM" 10). What he really means is that they do not come off because they do not work artistically.

Taking Chandler's prescriptions seriously, one would read something like Erle Stanley Gardner's "Honest Money" (1932) as a better effort than any of the English novels that Chandler has explicitly discussed. This pronouncement cannot bear any kind of scrutiny because this tale of a lone wolf lawyer-cum-detective standing up to the crime-ridden city is pure wish-fulfilment. It is just as formulaic as anything from England of the period; it is just a different formula. Where it does distinguish itself from a sedate Poirot mystery is in its "vitality", a concept to which we will return below.

In keeping with the importance of realism, Chandler claims Hammett is realistic, that "he made some of it up ... but it had a basis in fact; it was made up out of real things" ("SAOM" 14). Having made this statement, Chandler does not offer a detailed exploration of a Hammett story to support the claim. This implicitly raises the question of whether this argument is supportable by close readings of Hammett's fiction . If it is, why didn't Chandler go to the effort of proving it, as he had disproven the reality of The Red House Mystery? Perhaps he felt it was self-evident, that anyone reading Hammett would be convinced of its reality. More likely, Chandler recognised that whatever facts were recycled into Hammett's 
novels, they remain fictions. Consider the introduction to The Maltese Falcon where Hammett explicitly describes Sam Spade as "a dream man ... he is what most of the private detectives I worked with would like to have been" (quoted in Layman, Discovering the Maltese Falcon 105 my emphasis).

Hammett wrote a number of very realistic stories, and perhaps a larger number that are unrealistic, but that claim is not easy to make about three of the five novels. Red Harvest has so many bodies and so much luck on the part of the Continental Op, that it is not easy to think of it as a realistic story. Moving from the serial to the novel, Hammett was obliged to remove a number of murders because Knopf found the sheer number strained credibility (quoted in Johnson 70). The Dain Curse is perhaps even less realistic, principally because of its solution: the insane genius of Owen Fitzstephan must surely rank him with the Moriarties and Blofelds. And The Thin Man, for all that it is a charming novel in its way, is exactly the kind of conventional affair that Chandler obviously did not respect. Hammett's fictions work artistically, persuading the reader of their reality, they are not real.

Chandler's real emphasis is not on the testable reality of Hammett's fiction, but on questions of style and aesthetics.

The second front in Chandler's shorthand for literary value is "vitality": "[e]verything with vitality expresses that vitality; there are no dull subjects, only dull minds" ("SAOM" 12). This is suspiciously close to abandoning his original high-minded purposes and simply requiring a work to be entertaining, as he goes on to say, "all reading for pleasure is escape" ("SAOM" 12). His choice of the word "vitality" carefully excludes the "agreeable book, light, amusing in the Punch style, written with a deceptive smoothness," such as The Red House Mystery that might claim to be "escape", but which Chandler sees as without literary value (“SAOM" 5).

Realism is, to some extent, an objective quality that can be tested as Chandler does for The Red House Mystery. "Vitality" is a much more slippery and subjective term, which Chandler foregrounds but then does not develop in the same way as he hammers home his point about realism. He repeats the kind of argument that he made about realism by describing Dorothy Sayers' as a "kind of detective story [as] an arid formula" (Chandler, Simple Art 12). This refocuses his complaint away from realism per se, and into the arena of whether a work is interesting, and returning to his demolition of The Red House Mystery, it appears that his perception of its dullness fills all of the crevices and colours the problems with its realism. 


\section{Five Murders in a Fictional City}

Vitality means "active force or power; mental or physical vigour; activity, animation, liveliness". ${ }^{5}$ In some ways, "vitality" actually derives from Chandler's conception of realism, because the kinds of criminals and crimes he advocates in "The Simple Art of Murder" are not as calculating or premeditated respectively as those of the "fair play" tradition. When Chandler discusses Hammett's murders as committed with the "means at hand, not with hand-wrought duelling pistols, curare, and tropical fish" the implication is that not only are these things unrealistic, but because of their incongruity and the exceptional planning required for their use, they are inert ("SAOM" 14). The kind of killer who does not kill "just to provide a corpse" is motivated by passion and by the immediate need to kill - they are expressing vitality ("SAOM" 14).

This vitality exists mostly at the level of story, rather than narrative discourse, because Hammett, Chandler and their peers often create a sense of detachment from the action. They do this by using so-called objective descriptions of exteriority and focusing on small details as synecdoche for the complete situation. Consider the following examples, one each from Chandler and Hammett, and one from their contemporary, Frederick Nebel:

I dropped to the floor as the Tommy gun cut loose in a short burst. Galbraith crumpled beside the desk, fell on his back with legs twisted. Blood came out of his nose and mouth. (Chandler, "The Man Who Liked Dogs")

I stepped out of Elwood's feeble hands, and went to work with the flat of my gun on the negro. There was a roll of fat where his skull and neck fit together. The third time I hit it, he flopped, taking Pat with him. (Hammett, "The Scorched Face" 385)

Somewhere in the darkness there was a shout. A split-second later a gun boomed and a flash of fire stabbed into the darkness and a bullet slammed into the window frame. MacBride fired around the room and lunged across the floor. He heard a man scream. If he could find a door, then he could find a light-switch, he reasoned. (Nebel 181)

It seems odd to describe this as "lively argot that gives vitality to writers like Hammett and Chandler" (Grella, "The Gangster Novel" 191). In each of these moments of intense action, there is not much emotion, there is a focus on details. When the Continental Op intervenes in order to save the life of his policeman companion, he is simply "working". Marlowe and his progenitors are generally laconic and melancholic men who plod through their investigations - in describing this, Knight even goes so far as to describe Marlowe as

\footnotetext{
5 "vitality". Oxford Dictionaries Pro. April 2010. Oxford Dictionaries Pro. April 2010. Oxford University Press. 3 June 2013 <http://www.english.oxforddictionaries.com/definition/vitality>.
} 
"not catatonic" (Form and Ideology 160). The narrative discourse is at odds with what it represents. The story is full of activity, but the text's treatment is ironic.

Vitality in Hammett's stories comes from proactive protagonists. The Continental Op does not passively wait for the world to present him with a mystery, he is always looking for opportunities to detect. In "The Whosis Kid", it is the Op who initiates the situation by spotting the kid and following him, hoping to turn a profit for the agency rather than being engaged to find the kid. The Op seeks out clues and does the legwork that Marlowe seems to somehow evade. This pattern continues in Red Harvest where the Op is one of the major causes of the narrative. In The Maltese Falcon, Spade is very much an active participant in the machinations that unfold. The Glass Key has Ned Beaumont actively looking for a killer that his boss seems to want not found. Nick Charles, as always, is the exception in Hammett's writing.

Neither of Chandler's criteria for literary value is really sufficient. Realism is chimerical, and there is an ambivalence about vitality due to the representational strategies of Hammett et al. Chandler tries to paper over the cracks in his argument, because he is aware that at best the qualities he describes are symptoms of a work being a successful literary product, they are not the cause of its success.

There are hints of a larger conception of literary value, in the ways detective novels fail to do something other than realism: "the murder novel has also a depressing way of minding its own business, solving its own problems and answering its own questions" (Chandler, Simple Art 2). Books with literary value attempt to ask and answer "penetrating and important" questions about human nature founded in psychological realism such as he finds in Austen (Chandler, Simple Art 2). This creates a back door for a detective novel to attain literary value, not through the main mechanisms of its plot and characters, but in matters orthogonal to murder. A detective novel cannot tell one anything new about why someone would kill someone else, because that must be represented unrealistically, but it can, almost by accident, tell one about something else in life. This desire is in direct opposition to the strictures, of Haycraft's "Golden Age" authors, to focus on the crime alone. Their strictures will be discussed more fully in the next chapter.

Chandler himself is not quite satisfied with this circuitous route to literary value, continuing to discuss detection even where perceiving literary value of some king. He identifies this as the failure in Dorothy Sayers' detective novels: "the weakest element in them is the part that makes them detective stories" ("SAOM" 13). She can, he argues, write realistic characters, but only when they are not in service to her mysteries. The mystery element holds back the achievement of a general literary value in her work. He wants to reconcile the dichotomy that he himself has established: psychological realism combined with a detective mystery, which also addresses larger artistic questions than simply "whodunit" 


\section{Five Murders in a Fictional City}

It is in this area that Chandler offers his real praise of Hammett, who "demonstrated that the detective story can be important writing" ("SAOM" 15). But just what does he mean by that? In what way is this writing "important"? Chandler does not directly address these questions. Instead he repeats his concepts of realism and vitality, while the real concept of literary value lurks in the background: the "penetrating and important" things that "art" does. When Chandler argues that "[i]t is easy to fake", he is arguing that the quotable content of a work does not reflect its value ("SAOM" 16). There is another intangible force in play here, whose symptoms are reality and vitality.

Finally, in the last section, he stops skirting his central concern to provide his real thesis, that "[i]n everything that can be called art there is a quality of redemption" ("SAOM" 18). Realism and vitality are difficult terms, and redemption perhaps even more so. Chandler claims this quality is lacking in Hammett and his peers. Chandler does not offer further elaboration of the term specifically, instead beginning his oft quoted catalogue of qualities possessed by the ideal detective. Redemption has an inherently moral and religious meaning and connotations, referring most often to the return to virtue from sin. The juxtaposition of this word with "mean streets" implies an awareness of corruption, but with hope for a corrective.

This is the central idea which links Chandler's and Auden's accounts of the detective story. For Auden, the central feature of the detective story is "the phantasy of being restored to the Garden of Eden, to a state of innocence, where he may know love as love and not as the law" (409). This is redemption. In this light, Chandler and Auden disagree about the extent of guilt and their level of optimism about possible outcomes. Chandler hopes for redemption, Auden expects it.

Hammett is not interested in redemption, "offer[ing] little by way of consolatory resolution" (Horsley 78). His detectives are amidst their corrupt worlds, and so although Sam Spade may not be "as crooked as [he's] supposed to be", he is no less crooked at the end of The Maltese Falcon (583).

In framing his theory of literary value in terms of "redemption", Chandler explicitly excludes Hammett, and indeed all prior crime fiction, from transcending the confines of genre to become "art". Hammett's realism, and vitality, that make the The Maltese Falcon worthy of praise, are insufficient.

\section{Genre Insecurity}

Chandler's puts himself on the defensive by excluding of detective fiction from "art" by default. He is, after all, responding not to attacks on the genre, but Haycraft's favourable and loving survey. In this, he is in step with earlier commentators from within the genre. G.K. Chesterton's "A Defence of Detective Stories" opens with the claim that "[it] is not true, for 
example, that the populace prefer bad literature to good, and accept detective stories because they are bad literature" (3). This is a line of argument that could hardly be more defensive and insecure. If the default assumption is that detective fiction is bad, this kind of argument attempts to transform that into a double negative: it is not that detective writing is good, but it is not bad. Instead, one might wonder why advocacy for the genre does not begin with a positive statement: detective writing is good fiction.

R. Austin Freeman, contemporaneous with Hammett, tries to skirt around the issue of quality in "The Art of the Detective Story" (1924) by simply "assuming that good detective fiction must be good fiction in general terms", without addressing, as Chesterton and Chandler try to, just what quality of detective writing makes this an unlikely proposition (11). When viewed as a comment on fiction generally, Freeman's various strictures on the qualities of the novel tend to exclude the main points of interest in a non-genre outing, especially his final conclusion that "the quality in a detective story which takes precedence of [sic] all others is conclusiveness" (17). Eco holds the contrary view on literature generally, that "literary works encourage freedom of interpretation, because they offer us a discourse that has many layers of reading and place before us the ambiguities of language and of real life" (On Literature 4).

By putting himself on the defensive, Chandler almost invites dismissive responses to his genre, such as those of Edmund Wilson. Wilson claims of Sayers that "she does not write very well: it is simply that she is more consciously literary than most of the other detectivestory writers and that she thus attracts attention in a field which is mostly on a sub-literary level" ("Who Cares Who Killed Roger Ackroyd?" 392). Hickman argues that this attitude is exactly what Chandler wants to evade (287). Wilson's critique begins to look mild in comparison to Chandler's comment that "the strange thing is that this average, more than middling dull, pooped-out piece of utterly unreal and mechanical fiction is not terribly different from what are called the masterpieces of the art" ("SAOM" 13). This perspective positions even the best detective stories as below the level of achievement of a real novel, the very point that he is trying to counter, at least in aspirational terms. Chandler at least stops short of Moretti's pronouncement that "[d]etective fiction ... is literature that desires to exorcise literature" (Signs Taken for Wonders 146).

Perhaps Chandler's insecurity is understandable when even the positively framed praise offered of detective authors by some purported fans of the genre seems to modern sensibilities to be back-handed at best. Auden's famous essay is built around the concept that detective novels are guilty pleasures that "have nothing to do with works of art" (400) but which are ultimately acceptable because they are really allegories of the Fall from Grace run in reverse (409). 


\section{Five Murders in a Fictional City}

This profound insecurity extends to the audience for Chandler's own writing, of whom he is continually dismissive, and he projects insecurity onto other detective authors, who would not be so common if "the job took any talent" ("SAOM" 13). Hammett and his Black Mask audience are singled out by Chandler as a suitable projection of his own insecurity: "[Some] one individual is picked out to represent the whole movement ... I doubt that Hammett had any deliberate artistic aims whatever ... He had style, but his audience didn't know it" ("SAOM" 14). While the main point Chandler makes in the essay overall is in praise of Hammett as the "Ace Performer", the sting in the compliment is substantial: Hammett's accomplishments originated out of a wider movement, any member of whom could have been chosen as emblematic in his place, were quite probably accidental in origin, and in any case were not accomplishments in the eyes of his core audience but have been retrospectively recognised later by readers of more discerning calibre, such as Chandler himself.

This was not Chandler's final word on the matter, and he did value Hammett's contribution, as made clear in his correspondence, where he wrote that "I [Chandler] did not invent the hard boiled murder story and I have never made any secret of my opinion that Hammett deserves most or all of the credit" (Chandler Speaking 52). Rather, it seems from the general tone of "The Simple Art of Murder" that the thought of anyone taking the form seriously in a literary sense was beyond his imagination.

In 1930 Hammett prefigured at least some of Chandler's objections in his review column in the New York Evening Post:

As a fellow who takes detective stories seriously, I am annoyed by the stupid recurrence of these same blunders in book after book. It would be silly to insist that nobody who has not been a detective should write detective stories, but it is certainly not unreasonable to ask anyone who is going to write a book of any sort to make some effort at least to learn something about his subject. (quoted in Bruccoli and Layman 125)

This reinforces the idea that Hammett did have artistic and realistic objectives. However, the longest critical argument he made was about advertising. Hammett dismisses the idea that advertising copy is any kind of sub-literary field, because "little examination of the subject is required to show that advertising copy is literature - literature specifically applied - and that nothing but harm can come from the attempt to separate it from its parent stock" ("The Advertisement IS Literature" 101). This is altogether a different stance from Chandler's. Hammett goes on in the piece to link advertising copy, his own work, to that of towering literary figures from the past, "Goethe, Carlyle, Croce, Spingarn [and] Mencken" ("The Advertisement IS Literature" 101). Writing, Hammett argues, is literature, and so distinguishing quality is not a matter of types, but of execution. 


\section{Detective Story Mechanics}

Whereas Chandler drew out extensive and intimate details of The Red House Mystery to excoriate A.A. Milne, he does not offer a similar level of detailed argument in favour of Hammett. This omission goes without comment in almost all of the critical works that cite Chandler's famous line that "Hammett took murder out of the Venetian vase and dropped it into the alley" ("SAOM" 14).

When it comes to discussing Hammett, realism is a key consideration. Hammett's fiction was "made out of real things" and "gave murder back to the kind of people that commit it for reasons, not just to provide a corpse" ("SAOM" 14). That is to say, that the murderers in Hammett's fiction look as if they will likely have a psychopathic lack of uplift.

Perhaps the clearest counter-example to Chandler's argument in favour of Hammett is the body of Miles Archer in The Maltese Falcon, who is murdered in order to create a corpse that O'Shaughnessy can use to keep Floyd Thursby under control. This simple point of motive is not considered in much, if any, critical commentary on The Maltese Falcon, beginning with Chandler's.

O'Shaughnessy is a murderer who appears to be "really good at it" and the opacity of her motive for killing Archer is ignored by most critical commentaries, but in many ways the problem of her motivation helps to explain the way the story unfolds, especially if we conclude that Spade knows she is the murderer early on. The mystery that Spade investigates in this paradigm is nothing to do with the falcon - he is investigating O'Shaughnessy's motive, and his inability to articulate just why he is turning her over to the police mirrors his inability to attribute a sufficiently cogent motive to her initial crime. Spade's avenging of Archer's death has no more or less motive than his killing did.

Hammett's acknowledged masterpiece is not really more realistic than other detective fiction, and this topic is very rarely touched on in criticism, even when citing some part of "The Simple Art of Murder", as virtually everyone does. Most positive criticism has focused on the Flitcraft tale that Spade tells O'Shaughnessy, working and reworking this now iconic "parable" as a fulcrum from which all the different theories of Spade's motivation and the meaning of the novel as a whole can be leveraged. It is surprising that Chandler did not make an attempt, looking at it for some aspect of the redemptive qualities he sought. A treatment of Flitcraft is practically mandatory when discussing The Maltese Falcon, and no two explanations are the same. That is perhaps the real genius of the parable, the Flitcraft story's ambiguity attracts critics, bolstered by the notion that this seeming opacity is evidence of literary value.

Chandler seeks a union between character action and story so that the story seems like a result of naturalistic choices by the characters. He carries on to say that while Sayers wasn't able to achieve this union, Hammett was because of his "simpler mind". The way that 


\section{Five Murders in a Fictional City}

Hammett allows his characters to make naturalistic choices is simple - he allows them to be aware of and shape the story they occupy.

\section{Chandler's Detective}

Chandler's creative manifesto for detective writing begins with his admission, already obvious, that "all this (and Hammett too) is for me not quite enough" ("SAOM" 17). This would seem to follow on from his qualification of The Maltese Falcon as signalling that once a detective story could be as good as that, it could "by hypothesis" be even better. Chandler was clearly aspiring to go beyond this hypothetically established zenith. Hickman describes his attitude as "irascibility about the reputation of detective writing, rather than [a] direct statement" (287). The first part of "The Simple Art of Murder" covers the irascible part, and the last is close to a direct statement:

But down these mean streets a man must go who is not himself mean, who is neither tarnished nor afraid. The detective in this kind of story must be such a man. He is the hero, he is everything. He must be a complete man and a common man and yet an unusual man. He must be, to use a rather weathered phrase, a man of honor, by instinct, by inevitability, without thought of it, and certainly without saying it. He must be the best man in his world and a good enough man for any world. I do not care much about his private life; he is neither a eunuch nor a satyr; I think he might seduce a duchess and I am quite sure he would not spoil a virgin; if he is a man of honor in one thing, he is that in all things. He is a relatively poor man, or he would not be a detective at all. He is a common man or he could not go among common people. He has a sense of character, or he would not know his job. He will take no man's money dishonestly and no man's insolence without a due and dispassionate revenge. He is a lonely man and his pride is that you will treat him as a proud man or be very sorry you ever saw him. He talks as the man of his age talks, that is, with rude wit, a lively sense of the grotesque, a disgust for sham, and a contempt for pettiness. The story is his adventure in search of a hidden truth, and it would be no adventure if it did not happen to a man fit for adventure. He has a range of awareness that startles you, but it belongs to him by right, because it belongs to the world he lives in. (18)

The result of Chandler's manifesto is "the lone-wolf Marlovian detective, smart, toughtalking, wisecracking, aloof, moving through a corrupt cityscape with ideals intact" (Hickman 289). Whether Marlowe himself really measures up to this ideal is debatable. Knight's close reading of Marlowe's attitude toward other characters implies that he does not perceive himself as a common man, and it is not controversial to point out that Marlowe is in no great danger of either seducing a duchess or despoiling a virgin (Form and Ideology 138).

Humphrey Bogart's depiction, capitalizing on his real-life involvement with Lauren Bacall, 
probably comes closer to this ideal than the textual Marlowe. Bogart's Spade and Marlowe were "defining performances" that "did more than anything to establish the popular image of the private eye" (Horsley 77).

Many of the other pulp detectives approximately fit Chandler's prescription. The reason is that this check-list of characteristics are all highly idealized qualities, in line with the basic function of pulp literature as wish fulfilment. Part of what makes Hammett worthy of study is deviation from this paradigm of the noble character (Rzepka 185).

Hammett's detectives do not fit this mould particularly closely, at least no closer than, say, Sherlock Holmes. Some are closer than others. Sam Spade and Alexander Rush are perhaps not too far from this ideal, in their way. Robin Thin is too bookish, and too selfinvolved to really be consciously aware: he is a savant of detectives, very much in the classical ratiocinative mould. The Continental Op seems almost ironically close to meeting Chandler's requirements for honour, poverty and stoicism, but is notably not a "complete man”, since he is never shown in any other situation than detection. However, in all cases, the code of professional conduct which guides the Op is distinct from a set of absolute morals, such as Marlowe has. One cannot imagine Marlowe "arranging a killing or two ... when they were necessary" (Red Harvest 135). The Continental Op works alone, but always as the agent of a higher authority that is substantially integrated with the police. As Panek notes, this is one of the major changes which appear in Red Harvest; but even there, the Op acts as an agent of the central authority in the city (130). He does not work outside the system, he is the replacement for a system that has become corrupt.

One aspect of Chandler's prescription for "redemption" that passes without much comment is it has little to do with the rest of the essay. Chandler's interest has been focused on realistic crime by realistic criminals, investigated by real characters, all flavoured with the concept of some kind of higher literary aim, such as "redemption". His discussions of other characters have been slight - little more than general attacks on a class of people that he does not like: aristocrats. This prescription for going beyond Hammett tells us little about the kind of story that an author should aim to write, and everything about the character who will inhabit that story. Furthermore, there is not much detail about this character as a detective. Even given that it is an assumed feature of the character, there is here no argument for or against any detective's approach to his business. Honour, or pride, or financial honesty, are all qualities which could apply equally well to other professions and other characters. When thinking about the qualities which define Philip Marlowe, both Chandler and Hickman omit what must surely be the most salient feature of any character purporting to be a detective: they solve crimes. Indeed, the qualities that Chandler emphasises bring to mind two entirely different kinds of character: the chivalric knight and the western gunfighter. 


\section{Five Murders in a Fictional City}

This invokes the on-going question of the origin of the detective story. Chandler here offers an alternative to the notion that the "hard-boiled" detective originated in the Western hero (Porter). The two possible origins can be reconciled if one perceives the Western hero as an offshoot from the same literary tree as the Knight. Pronzini and Adrian do when they slalom uncomfortably from the "western frontier" through "Melville's Captain Ahab" to end with characters that "have elements of the hard-boiled knight in their makeup" (5). It is Chandler's explicitly chivalric tone that derails the commonly assumed origin of the "hardboiled" detective in the western gunfighter. Andrew E. Mathis expresses the view in The Kind Arthur Myth in Modern American Literature (2002), that "the extent to which Chandler relied on the Arthurian myth has been somewhat underestimated" (43). This reliance, frequent use of chivalric allusions, and the influential history of "The Simple Art of Murder" have led scholars to see Chandler's specific inspiration as general. This in turn leads authors such as William Marling in Dashiell Hammett to claim "[t]hat [in Red Harvest] the Op is a moral quester is clear ... signalling the knight-hero's difference from his peers" (53). This assertion is not supported by close comparisons of specific actions and specific plot events between Red Harvest and any chivalric fiction or criticism. Perhaps Marling is thinking about the Op's relationship with Gabrielle Leggette, which could possibly be characterised as "courtly devotion", carrying that notion backwards in time to Red Harvest and generalizing it.

A stronger argument can be made for the redemptive qualities of both Sam Spade and Ned Beaumont, who begin or become entangled with morally dubious activities and people, but who emerge with a moral restoration. Spade turns over the murderess, Beaumont never deserts his friend and eventually leaves behind his corrupt city. Beaumont is even a little courtly. In terms of real redemption, however, it will not be until James Ellroy that detectives will fully complete the cycle of corruption and redemption, such as David Klein in White Jazz (1992), who begins the novel as a mob bagman and assassin but eventually plays a key role in removing the main source of corruption in the city, Dudley Smith.

In effect, we must regard carefully Horsley's summary of "The Simple Art of Murder" as calling for a rejection not only of the style, but moral content of detective stories (67). Horsley argues that Chandler sees a unification of style and moral content in each of the two schools, but this argument is incomplete while the detective remains an icon of moral virtue. The morality of the detective represents a shared unity in the essential and central nature of each kind of detective narrative. It is the Continental Op that comes closest to fulfilling that interpretation as a whole, despite missing some of the small specifications along the way, but there can be no doubt that the Op is included in Chandler's dismissal of Hammett as insufficient. Horsley's summary, like the others touched upon, suffers from trying to find a 
single coherent artistic vision where instead we have primarily fragments finely crafted together, but still requiring individual treatment.

\section{The Simple Art of Formula}

Chandler's demolition of the "Golden Age" offers us key terms, but does not offer us a schema for using these terms even if we conclude that we understand them, which is not certain. We can use them as elimination criteria, so that unrealistic or unredemptive works are not "Art", but that is all Chandler explicitly lays out. The relative importance of Chandler's criteria are unclear: how much "vitality" do we need so that "redemption" is unnecessary for a work to be art? If we agree with Chandler, we must conclude that these non-realistic, non-redemptive works are not art, and this implies that they are not valuable. Whether a work is or is not art may be a good question if one is forming a literary canon, but it does not explain why events unfold as they do inside a narrative, why those events are represented as they are, or how readers interpret those events and representations.

"The Simple Art of Murder" does not explain anything about how detective fictions function. One cannot use it to make predictions about how a work will unfold, and one cannot use it to explain features of the text whose purpose is unclear. Chandler provides detailed criticism of "fair play" narratives and their lack of realism but one suspects that similarly close reading will not find fewer faults in the writing of Chandler himself. Chandler's criteria are more suggestive of representation than story structure; we could describe an automobile as "red" and express a preference for "red" automobiles, without shedding any light on how automobiles work. We need more fundamental terms that relate to the story mechanics in order really to discern the difference that Chandler perceives between the work Hammett was doing and the "fair play" method derived from Poe.

\section{Chandler's Hammett}

It is apparent, even to such an unfavourable critic as Edmund Wilson, who seemed to miss the point of detective writing in a comprehensive way (Symons, Bloody Murder 25), that the subtext of "The Simple Art of Murder" is that Chandler wanted to "claim Hammett as his father" ("Who Cares Who Killed Roger Ackroyd?" 395). This being the case, he seems to have followed the Freudian trajectory of trying to kill him. He constructs Hammett as the best detective writer before himself, but, in doing so, he downplays or misrepresents much of Hammett's approach to writing and much of what he wrote.

In effect, Chandler suborned Hammett's reputation to bolster his own, and this has had an almost invisible influence on subsequent studies of the genre as a whole. For example, in "Murder and the Mean Streets", George Grella silently elides the differences between the two authors. Grella's article is in some ways a checklist of qualities for "hard-boiled" fiction, including summaries like "the private detective always finds the police incompetent, brutal, 


\section{Five Murders in a Fictional City}

or corrupt, and therefore works alone" ("Mean Streets" 414). This may be true in Chandler, particularly in his novels, but, as Panek points out, this is far from a universally applicable feature of Hammett's writing (69 ff). 


\section{In Search Of A Model Author}

Having recognised the distortions created by Chandler's misreading, we must decide on how to approach Hammett with a fresh perspective. In each of Hammett's novels a new theory is needed to account for the overall construction of the action, but in each there is at least one application of the detective formula in service of the novel as a whole.

In The Role of the Reader: Explorations in the Semiotics of Texts (1979), Umberto Eco constructs the idea of the "model reader" and says he will "renounce the use of the term lauthor/ if not as a mere metaphor for <textual strategy>" (11, symbols in original) but by the time he wrote Six Walks in the Fictional Woods he had adopted a complementary entity , "model author". The earlier term is the more useful for discussing Hammett, because he uses different strategies at different times inside each of his fictions. Eco goes on to define "open" and "closed" stories and formula. He analyses the novels of Ian Fleming and concludes they are essentially "closed" because of their formulaic construction (The Role of the Reader 147ff), just as "detective fiction does not permit alternative readings" (Moretti, Signs Taken for Wonders 144). For "closed" stories of the kind practised by formula authors "probably the Model Reader such popular texts require is a 'smart' one" (The Role of the Reader 33), a reader who is cognisant of the formula.

Formula is a bridge between the author and the reader, because it represents a shared textual strategy. A lot of Eco's work analyses the effort readers need to make in order to read a text correctly. This effort is not necessary for formula fictions once the salient features of that formula are understood because for both the "fair play" model author and the "fair play" model reader, it is sufficient to execute the formula correctly. This is essentially what Wright and Freeman are advocating in their criticism as outlined below, while Chandler wants to go beyond that. Chandler writes of "realism", "vitality" and "redemption", but these difficult terms are all merely motions toward literary value.

Chandler's argument in "The Simple Art of Murder" works because he assumes a wellunderstood genre with well-formed conventions - his intent is not to look at individual works, but to question the genre in which they belong and so individual texts are only used as examples. Chandler is applying evaluative criteria that are part of the generic legacy of detective fiction, not necessarily embedded in a specific text. When he offers "realistic" readings, he uses the detective mystery as his baseline. If we look at the structure of Chandler's own writing, we can see that generic baseline still in operation (Merrill). ${ }^{6}$

\footnotetext{
${ }^{6}$ Instead of using functional story schema in more complex ways for his novels, Chandler took clusters of short stories and spliced them, amalgamating characters and plots. The short stories that were not
} 


\section{Five Murders in a Fictional City}

Chandler challenge both facets of Eco's scheme, because Chandler wishes for readers to read against the obvious textual strategies of "fair play" narratives and he wishes the "fair play" model author to abandon its "arid formula" in favour of what Eco would describe as "open" narratives.

This chapter discusses different ways of reading Hammett's fiction. It is clear that while each of these can offer illuminating commentary, Hammett's writing was constantly evolving and changing, so that no single approach to or use of detective fiction emerges. This requires a very 'smart' reader indeed.

\section{Interpreting Formula}

In non-genre criticism, a plot is simply "the main events of a play, novel, film, or similar work, devised and presented by the writer as an interrelated sequence ${ }^{7 “}$. However, in genre criticism, "plot" is a far more specialized term. "Plot" more often refers specifically to the details of the crime and its resolution rather than the general events in the text, so that critics can argue that Chandler was uninterested in plot despite there being an interrelated sequence of events in each of his novels.

"Plot" can also be used to refer to the set of plots that share a similar structure, such as the example Cawelti gives, the plot of "boy meets girl, boy and girl have misunderstanding, boy gets girl" (Cawelti 5). We could thus talk about the "plot" of The Glass Key meaning variously the sequence of events experienced by Ned Beaumont; or the specific murder of Taylor Henry including the subsequent investigation; or the novel's inclusion in the general category of stories where a murder occurs within a closed circle of suspects.

The unifying quality is the concept of cause-and-effect, forming a story that is partially independent of the exact story contents. We could think of this as a story structure. Cawelti uses the term "formula", and examples are easy to find. There are numerous different versions of Pride and Prejudice where it has been translated into different settings and cultures. The films Bride and Prejudice (2005) or Bridget Jones's Diary (2001) use completely different cultural paradigms, but are recognisably the story of Pride and Prejudice. This story is in turn a subset of a more general arrangement. I will use the term "formula" in the same way Cawelti does, to describe the chain of events at the highest level of abstraction possible.

\footnotetext{
structurally compatible became self-contained episodes inside the overall concatenation. His physical writing process of writing scenes on large-sized index cards, made it a simple matter to rearrange the order of the cards and then write bridges between them. Therefore, I would modify Merrill's conclusions by highlighting that many of the structural oddities in Chandler's novels which look like a disregard for plot actually derive from Chandler's method of constructoin. Nevertheless, this does not seriously affect Merrill's basic point which is that Chandler's novels have just as much "plot" as those of any other detective writer.

7 "plot". Oxford Dictionaries Pro. April 2010. Oxford Dictionaries Pro. April 2010. Oxford University Press. 9 June $2013<$ http://www.english.oxforddictionaries.com/definition/plot>.
} 
We need another term, other than "plot", in order to discuss the specific application of a formula. I will use the term "formulation". In The Glass Key, the formula of murderinvestigation-revelation expressed is in the formulation of Taylor Henry's murder.

The most tightly constructed formula fiction represents something like a closed system of references. The text presents apparent questions, primarily "whodunit?" and then proceeds to answer those questions satisfactorily. In their way, Chandler, Auden, Cawelti, and Knight each try to look at the formula rather than specific formulations to try and leverage additional meaning from these works than are necessarily implied by the "model author" of the work.

In their way, each of these authors is seeking a way of discriminating between different fictions that share the same or similar formulae in search of recovering some essential quality of the work. Implicit in this approach is the assumption that an individual work is not of interest unless it is a specific implementation of a unitary art work that does have interest: the formula itself. Cawelti eloquently frames the problem faced by formula criticism:

Since [Spillane's] closest sales competitors are hard-boiled writers like Brett Hailliday and Richard Prather, prolific hacks who more or less imitate the Spillane recipe without adding much in the way of literary interest, one can easily envision mindless millions of cretins slobbering idiotically as Mike Hammer pistolwhips another naked female. But such visions are too vague and moralistic to be of much help in understanding the Spillane phenomenon. (183)

Cawelti locates the difference between Chandler and Spillane in the content rather than form, arguing that

Chandler fleshes out this fable with fairly complex characters and a richly symbolic action, whereas Spillane operates by leaving the basic formulaic framework as simple and uncomplicated as possible. Instead of adding human complexity to the skeleton, he heightens the pattern of the formula through violence. (183)

What links these two statements is the insistence on the divergence from formula in the form of "literary interest" or "rich symbolism". If Eco is right, and literary value is located in ambiguity (On Literature 4), then Cawelti is moving toward an interpretive mode for the text which has a way out of the formula's closed system. He is looking for something to not fully understand.

Fredric Jameson describes the centrality of the mystery formula as "synoptic", explaining that

[A] new kind of stereoscopic reading emerges in which each scene retains its sharpness while designating at the same time a well-nigh Platonic (yet 


\section{Five Murders in a Fictional City}

social-typological) ultimate unit behind it that the reading eye does not so much see as intuit. (34)

Jameson rejects this conception of detective fiction vis-à-vis Chandler, yet it is a cogent perspective on the role and purpose of formula. A synoptic view of formula fiction implies that the formula is not the main point of interest, which is how it acts as a shared element between reader and author.

This in some ways appears to be the objective of the advocates of the "fair play" style of story construction and representation. "Fair play" authors conceive of a central constraint on the detective story: that the reader of the novel should have sufficient information available to reach the correct conclusion at the point where the detective names the guilty party. This is most perfectly summed up in one of the oaths of the 'Detection Club': "Do you solemnly swear never to conceal a vital clue from the reader" (quoted in Haycraft, Art of the Mystery Story 198)? The Detection Club seeks to eliminate anything that is not detection as they understand it. The oath calls for members to avoid "[g]angs" and "conspiracies" as well as "[g]hosts", despite the obvious criminal implications of the first two and the obvious irrelevance of the latter. These are equally forbidden mostly because they do not accord with the requirements for style.

The effect here is to try and control the details of a story and the manner in which that story is represented, they are not explicitly discussing a story structure. No mention is made in the oath that the resolution to the mystery should make sense, that it should accord with any conception of reality, even its own. What they require is that the reader is provided with the same information as the detective, sufficient to determine the correct solution to the puzzle, and that the puzzle does not contain anything they find distasteful. Later evolutions of the detective formula can often negate specific parts of the detection club oath while retaining the correct structure.

In terms of story formula, then, we cannot necessarily differentiate between Chandler, Wright, or Hamilton. They all make use of the mystery formula. The argument here is that while different events inside a fiction appear to have a cause-and-effect relationship in the manner of a non-genre plot, in reality events in the fiction unfold in accordance with the story formula, so that cause-and-effect inside the fiction becomes a matter of content, rather than story structure. For example, it does not matter whether a suspect breaks down and confesses because of remorse, or whether they are tortured into confession: both fulfil the structural needs of the formula. At the end of The ABC Murders (1936), Poirot tricks Franklin into confessing by claiming to have found an incriminating fingerprint. Christie allows Poirot to be aware of the usual dramatic ploy of a revelation, and despite this untruth, all parties follow through with the end-game of the formula. The reason Franklin is tricked is 
not because of the plausibility of the bluff, but the necessity for a confession at that point in the formula ${ }^{8}$.

Where Chandler and Christie are different is in their representational strategies, and the aesthetic of the story contents. A "hard-boiled" private detective has the same story function as a disinterested and eclectic genius. A novel which "plays fair" is different from one which elides key facts in the completeness of its representation, not necessarily in the operations of the story. We must therefore treat carefully claims like Cawelti's that the "hard-boiled" detective story was "so different from the classical genre that it constituted a different type" (Cawelti 139). Cawelti's "classical genre" includes not only the story formula but most of the non-formula trappings of location and character types.

Some of Hammett's writing uses the mystery formula in the conventional way, most notably his novel, The Thin Man. However, his other novels all use the mystery formula for other artistic objectives, rather than as an end in itself.

Consider the archetypal summing-up scene, where all the suspects are gathered together ready for the revelation of guilt as a prelude to the purgation of it: Auden's inverted fall. Instead of bringing the situation to a close, Hammett uses this device in Red Harvest to accelerate the internecine warfare. The Op gathers the various gangster bosses together ostensibly to discuss peace, but instead uses the meeting as a platform to reveal who murdered Tim Noonan, which spurs the gangsters into further action. This is a subversive use of the scene, typical of Hammett.

Hammett is making use of the mystery formula, he is not implementing it. This allows us to differentiate Hammett's novels from other detective novels on the basis of story structure as well as representational strategies and content.

\section{The Detective Novelist}

The term "formula" has distinctly scientific connotations that are perfectly summarized by Sherlock Holmes in The Sign of the Four:

Detection is, or ought to be, an exact science, and should be treated in the same cold and unemotional manner. You have attempted to tinge it with romanticism, which produces much the same effect as if you worked a lovestory or an elopement into the fifth proposition of Euclid.

This gestures toward an ideal situation, as explained in meta-fictional terms by Wright and Freeman, of a closed system of meaning and possibility, directed and controlled by the formula. When faced with a non-formula intrusion, the purist insists that the extraneous information be discarded, if not in the construction of the story, then in its interpretation.

\footnotetext{
${ }^{8}$ See also Marling, Dashiell Hammett p. 20 for a cogent summary of such conventions.
} 


\section{Five Murders in a Fictional City}

However, science is equally firmly specified by Sherlock Holmes in "A Scandal in Bohemia" when he says:

It is a capital mistake to theorize before one has data. Insensibly one begins to twist facts to suit theories, instead of theories to suit facts.

The reader of detective fiction is caught between these two poles, because the "tinge[s] of romanticism", implicitly to be discarded, are part of the reading experience. Despite the strictures of Wright and Freeman, discarding those non-formula elements is very much twisting facts to suit theories.

This tension, between formula and non-formula features, has caused difficulty for a number of Hammett's readers. Gray seems confused when he claims that Ned Beaumont "resorts to rent-a-sleuth measures", as if Beaumont's position as protagonist automatically grants him the skills and experience of a full-time professional detective like the Continental Op (768). Gray's confusion derives perhaps from Gregory's discussion of the novel. She claims the solution is "both contrived and unconvincing", as if the metric for evaluating The Glass Key were a whodunit from the "fair play" school (Gregory 119). If the facts here do not fit the detective ideal of Wright and Freeman, should we condemn the facts as failures, or construct a new theory?

The difference between the so-called "fair play" and "hard-boiled" schools could be coded as a shift from "closed" to "open" narrative discourses. However, after analysing Chandler's novels, Knight reaches the conclusion that Chandler "rejects the ... 'readerly' novel, one that opens itself to the reader's own interpretation and cooperation, and settles ... for a 'writerly' text, controlled by the author" (Form and Ideology 148). In contrast, the "epistemological" difficulties outlined in Chapter 2 of this thesis can be seen as virtually requiring a "readerly" or "open” approach to Hammett's novels.

Julian Symons undertook the same kind of exercise as Howard Haycraft did in Murder for Pleasure, in Bloody Murder: From the Detective Story to the Crime Novel (1985). Symons did not have Haycraft's limited aesthetic of a puzzle in mind, and he proposes that "the book that has no interest whatever except the solution of a puzzle, does not exist" (15). He points out that "to call The Glass Key a detective story and leave it at that, is to limit rather than announce its merits" (15). While Symons rejects Haycraft's very restrictive conception of the detective formula, the general argument is similar to Glover's, that detective novels are part of a wider movement of "sensational literature" (15). In his biography-cum-analysis, Dashiell Hammett (1985), Symons goes on to explain "the puzzle is undoubtedly part of the enjoyment ... [but] the story is partly about masculine friendship" (84). At a high level of summarization, Symons balances these two facets as co-existing, parallel, lines of action inside a presumably masculine novel of "sensation". We can extend this idea to see that the detective story is a way of applying stress to the central relationship that Symons identifies. 
It is not two separate parts, as he implies, but two stories existing symbiotically. This does not obviate the need for a model reader of detective stories, it augments it by also requiring a model reader of the "sensational" story.

Symons two studies begin a useful analytic process. The primary point is that The Glass Key uses two different major textual strategies, the mystery, and the complex relationships between Janet Henry, Paul Madvig and Ned Beaumont. This analysis highlights the problem facing a reader expecting to act as the model reader of detective formula but it must be continued by asking why and how these two strands are juxtaposed inside the narrative. On the central mystery of Taylor Henry's actions, Symons only echoes other critics that "the stick and the hat are as good as any such clues in Agatha Christie" (Dashiell Hammett 84). Putting aside the mystery to consider how the other strand of the narrative is constructed, we can summarize the situation as Beaumont wanting to help Madvig, who is deliberately oblivious to his own best interests. Madvig has two goals, the re-election of his cronies and possessing Janet Henry. To be dramatic and interesting, each of these goals must be somewhat difficult to achieve, and ideally when a dramatic character has two goals, those goals should be opposed in some way. The murder of Taylor Henry economically enables that opposition. Of course, there were other options than a murder, but other options would have potentially brought other difficulties. Using a murder mystery, a story formula that Hammett had already mastered, to create the pressures on the characters saved a certain amount of labour compared to devising a non-formula "A" plot.

Earlier in his career, Hammett had experimented with mysteries as background for other narrative aims. At around the time he wrote "From the Memoirs of a Private Detective" (Mar 1923), he wrote several detective stories that act as a platform for showing investigative technique (Crime Stories 909). The first substantial example is "Zigzags of Treachery" (Mar 1924). It is awkward to read "Zigzags of Treachery" solely as a model reader of detective stories because the necessary exposition for the "fair play" story part is concentrated in a few pages at the start of the story. The central part of the text carefully shows the Continental Op's investigative techniques, providing examples similar to those discussed in his memoirs and suggestions, but not particularly showing information needed for the "fair play" mystery. The story hurriedly wraps up the narrative with an almost unprompted confession from the killer. The model reader of detective stories is not needed for the large middle section of the text, but close reading shows that it is a story that does "play fair". In "Zigzags of Treachery", Hammett switches between different textual strategies wholesale, using the "fair play" formula as a framing narrative for a topic of more interest to him, the mechanics of detection. In The Glass Key, there is a more continuous balance required, though again, the model reader of detective stories has more to do at the beginning and end of the novel than in the middle. By varying his textual strategies to integrate both 


\section{Five Murders in a Fictional City}

formula and non-formula stories, Hammett prevents a "closed" reading of The Glass Key on a structural level.

Critics show little interest in the intimate details of the crimes or their investigation. Agatha Christie is the most prominent example of an author persistently and critically underrated by this holistic habit. "Notes on the Semiotic Analysis of Detective Novels" extracts a number of character types from a close reading of a handful of Christie's novels and notes the structural equivalence of different characters. The author's choice of murderer is "the problem of synonymy, to choose one from a series of signs with identical meaning" (Revzin 387). In the game Cluedo, Professor Plum is in all ways identical to Colonel Mustard insofar as the resolution of the story goes, but, in fictions, the functional equivalence must be read as a complement to the representational difference. For example, we cannot regard it as insignificant that all of Chandler's murderers are alluring women. Breu discusses the Black Mask school as structural misogyny, but he does not offer an explanation of Hammett's varied women as a contra to the universally dangerous women in Chandler. Instead, Breu casts Dinah Brand in Red Harvest as a femme fatale, a correlation I will explore in Chapter 5 .

Once critics like Revzin observe that formulae are in use, they consider that a sufficient observation of the detective novel and do not explain it. This approach to reading Christie is too abstract and so misses that the meaning, worth and pleasure of formula fiction derives from the control of the details. Formula fiction is a labour-saving device, which allows an author to populate a fictional world without needing to devise an entirely new story. Thus, the use of a story formula actually de-emphasizes plot, allowing author and reader to focus on the content.

In the extreme case, the rote utilization of formula as a skeleton for literary value can become self-defeating. Chandler is disdainful of the "arid formula", by which he meant having nothing other than the formula. However, despite the care he takes in using elaborate imagery, his work uses formula concepts, creating the possibility of "synoptic" readings of the kind dismissed by Jameson. Chandler's disdain for formula, to focus on content, has inadvertently fallen prey to the problems of modernist poetry outlined by Robert Graves and Laura Riding in A Survey of Modernist Poetry (1928). They argue that poetry in the late Victorian period became so formulaic that "anybody could write poetry ... if he obeyed the rules, without necessarily being a poet" (40). They claim that in seeking to break the bonds of formula, early modernist poetic movements failed: "all that happened was the same old stock-feelings and situations were served up again, only with a different sauce" (56) and that they "did not make new poems, only a new kind of stanza which seemed to them more real than traditional stanza-forms because it was new" (73). The objectives of the advocates of the "fair play" method seems to align with the Victorian poetical objectives and Chandler's 
advocacy of change appears to fall prey to the same illusion of progress as the early modernists. Hammett, by significantly changing both the content and the structure of his fiction compared to the "Golden Age", while still using the detective formula gets both the benefit of using a strong literary form and avoids the pitfall of having it lack originality.

Cawelti undertakes a content-focused analysis, looking at two similarly plotted Christie novels in order to determine which is the more successful work (111). Cawelti shows that when one really pulls Christie's novels apart and looks at the intricacy of the formula application and the close harmony of that formula with the content, one cannot help but admit that she was the best at what she did, perhaps the best possible. We can see Christie's own interest in the details rather than plot construction per se in mature works like Cards on the Table (1936), where Poirot resolves the crimes not through an exhaustive crossreferencing of facts, but by recognising the similarity of key details in the murders.

Form cannot be completely separated from content. Cawelti's focus on the details of the two Christie novels shows that in one the content supports the form, whereas in the other it strains credulity. There is a natural tension because the author must make the revelation of the criminal both surprising and inevitable in hindsight. The mysteries in which the criminal remains the least likely suspect after the detective's summation are the weakest. To this extent, all successful "fair play" detective stories have a "twist" ending, causing the reader to re-evaluate what they thought they knew at each previous stage in the narrative.

Chandler has often been interpreted in the opposite way to Christie. He could write memorable prose so the construction of his plots is often assumed to be weak. Knight discusses the numerous loose ends of Farewell, My Lovely in this light, pointing out small problems like "[t]he criminals who are alleged to have stolen the jewels, killed Marriott and beaten Marlowe make no appearance in the plot - they are completely imaginary" (Form and Ideology 155) and Jameson offers that the "speed of the plot's rotation ... can be counted on to distract us from everything that is unmotivated or gratuitous" (33) but despite "imaginary" criminals, Knight concludes that "Chandler's plots may be sketchy, even unconvincing, but they do not actually break down" (Form and Ideology 150).

This is perhaps one reason why critics tend to look for non-detective formulae to use as interpretive stances. In his defence of Chandler's plotting Merrill diverts us from the conception of a detective novel, arguing that "[i]f the first half of [The Big Sleep] captures Marlowe as a dedicated professional, the second half testifies to his now famous knighterrantry" (8). The detective formula is insufficient to explain all the features of the Big Sleep, but does explain some, which has been neglected in criticism of Chandler just as with Hammett.

Instead of formulations per se, close reading of literary texts can be done in combination with a cypher, such as the Bible, through which the text is parsed to determine a meaning. 


\section{Five Murders in a Fictional City}

In this conception of analysis, the Bible serves as a concordance of story forms and reusable content that provides a wider context for a work. This method of construction is sometimes foregrounded by the title of the text. For example, Dryden's Absolom and Achitophel explicitly utilizes the biblical story as the chassis for a satiric attack. Hammett produced one story in this vein, "Ber-Balu" (1925) a satire of the Samson story (Hammett, quoted in Bruccoli and Layman 98). The story form has been retained, but the content has been replaced. This allows a doubling of the text, so that it can be read on two levels: a selfcontained work and intertextually with the relevant concordance. Rabinowitz summarizes a genre-based approach to a concordance as having "different bundles of rules that readers apply in construing texts" (420).

This method of reading focuses on the fine details of a text, inasmuch as they are apparently intertextual. Where there is no concordance, a work must supply all of its own mythological framework; run this argument from the opposite direction and works that fail to provide their own mythological frameworks are all a form of parataxis, with understanding of genre providing the linkages. This is what Eco offers in his concept of the "model author", discussing ways a text shows the reader what is important.

Eco's example of the problems with fictional dates not aligning with real ones in The Three Musketeers implicitly calls for readers to disengage from unsuitable templates for understanding fictions. Yet, no work is truly an orphan, because whether a concordance exists or not, any specific text will share similar form and content with other works. This is the basis of the concept of genre, so where Rabinowitze reads fiction with respect to "the author's intended meaning" (421), Eco's concept of a "model author" rather than an "actual author", allows us to construe genre fiction as the product of the "genre author", drawing on features of the genre as a whole. Some genres, including the detective story, have specific limitations implicit in the generally understood idea of the genre. Once these become codified, these genre templates, or formula, can seem to explain all features of a text adequately.

One needs to balance a view of the details with an understanding of the system they form. That system may be purely "ratiocinative", but it may well contain substantial contamination from other, potentially even contradictory, formulae. A small example is the difference in the interpretation of physical spaces in Chandler's novels between Knight and Jameson. Knight emphasises the "domestic detail" (Form and Ideology 154) where Jameson sees only variations on the theme of the office, arguing that "dwellings all at once explicitly demand subsumption under the enlarged figurative category of the office" (42). Both interpretations yield insights into the texts, so should be read as parallel possible meanings, rather than giving either a privileged analytical value. 
Hammett, suffers critical under-appreciation from both ends of the spectrum. Most of the mysteries in Red Harvest and The Dain Curse are resolved either by a Holmesian piece of insight or by a bloodbath which sorts the guilty from the innocent, while the mysteries in The Glass Key and The Thin Man are not complex when measured against Christie's. His best prose is ironically understated, frugal and efficient, all virtues requiring skill but not easy to quote in isolation as so many of the great stylists are. The way I have framed this explanation would make it tempting to position him holding some kind of middle position: more stylish than Christie, less than Chandler; more plot-capable than Chandler, but less than Christie. Instead, we should see Chandler and Christie as each excelling in one of two aspects of writing, both of which were done well by Hammett.

Hammett integrated detective formulations into narratives that have non-formula interest and with considerable style. His style can be appreciated in a way that Christie's perhaps cannot, and his detective formulations can stand close scrutiny in a way that Chandler's cannot. Hammett represents an early template for an approach to detective writing with literary value that nevertheless takes detection seriously. While tracing his legacy is beyond the scope of this thesis, operating successfully in both artistic and formulaic terms has made him, rather than Christie or Chandler, a good template for the likes of James Ellroy, who have largely managed to escape the ghetto of genre association.

Hammett's novels are each radically different, as "each of his novels presents a different kind of problem and pattern of action" (Cawelti 162). The kind of formula, whether detective or romance, that are used to interpret Chandler are not of primary importance for understanding Hammett. If, as Merrill argus, Chandler linked two mysteries such that "to solve the first problem Marlowe must also solve the second", that still leaves us with two similarly structured forms with a shared fulcrum (Merrill 5). When Knight argues that Hammett's "restless mind avoided formulae", he is only partly correct (Form and Ideology 136). Hammett used formula to tell stories but in structural terms they are not the sole objective of the text.

Jameson constructs then dismisses the argument that in structural terms Chandler's writing implies analysis can "run the equivalent episodes side by side for our inspection" and hence derive meaning purely from the changes in content because "the 'original' episodes have themselves already been contaminated" (Jameson 34). Jameson here appears to be refuting the very notion of "formula fiction", while yet going on to use structural and spatial equivalences to reinterpret parts of Chandler's individual novels in light of these shared structures. Knight argues it is the similarity of Chandler's novels, and the unity of structure that makes an "ideological study, [of Chandler] ... more revealing" than a similar exercise for Hammett (Form and Ideology 136). A "synoptic" approach is possible with Hammett, but only within a far more limited scope. 


\section{Five Murders in a Fictional City}

Formula, and hence formulations, have a necessary syntax. Auden provides one summary of this syntax as moving from a "peaceful state before murder" through the crime, investigation, and arrest to a "peaceful state after arrest" (401). Auden's scheme is crude, but it points to a formal and necessary order of events inside the fiction and potentially of the representation of those events. Without these scenes and events, the formula cannot function: you cannot have a murder mystery without at least the appearance of murder.

The improper use of a story formula can lead to non-sequiturs, where something happens without cause within the fiction, but is required for conformance with the formula. This is a particular problem in early crime fiction, as described by the historical accounts of genre development by Knight and Moretti. They show that the basic pattern of crime-investigationrevelation emerged before the logical syntax needed to explain the relationship between the different elements of the pattern. Early detective authors "sensed that these curious little details [clues] were really popular, so they decided to use them - but they didn't really understand why clues were popular, so they used them in the wrong way" (Moretti, "Slaughterhouse" 214). Conversely, one of Eco's "smart" readers of detective fiction knows not only how clues work, but understands the meta-construction the clues form. "Smart" readers use knowledge of typical formulae to explain features of the text which appear to be nonsequiturs or which do not appear to contribute to the meaning of the text. For example, in The Glass Key, the model reader of detective stories will spot immediately that Taylor Henry's missing hat is significant, even though it appears irrelevant at the time. In one of Hammett's subversions of the formula, Beaumont uses this real clue to frame his bookie and hence get paid the money he is owed. Beaumont's ploy has a purpose inside the story, and on a meta-fictional level, Hammett is encouraging us to think that this apparent clue has already served its story function, making it a red herring.

Formula in The Dain Curse helps create the epistemological problems outlined in Chapter 2. After each phase of the story there is a summation by the Continental Op that appears to adequately explain the events witnessed within a formulaic paradigm. All of these apparently-adequate explanations are then overturned by the revelation of Owen Fitzstephan as the mastermind behind all the crimes. This creates a problem where the detective formula that governs each individual segment clashes with the Gothic formula of the overarching story. There is very little evidence to support the preference of the Gothic formula over the nested detective formulae. For example, the inadequacy of Leggette's letter as a suicide note is a matter of opinion on the part of the Op; there is actually very little evidence to support his claim of murder. That suicide is still more plausible than Owen Fitzstephan's confession of murder. The evidence inside the fiction cannot completely rule out Alice Dain being the killer. Ultimately, the decision about guilt comes from a decision 
about whether to rely on the detective formula, and hence agree with the Op, or whether to rely on the Gothic formula, and hence accept Fitzstephan's confession.

In general, the "fair play" story uses a kind of story efficiency, in the same spirit as Chekhov's famous injunction that if a gun appears in Act I, it should have been fired by Act III (Eco, On Literature 13). This is a syntactical statement about the language of narrative, just a summary of good story grammar. It works in reverse too: if Act III needs a gunshot, one needs to show the gun in Act I. The Glass Key distorts this by firing the same gun twice, and The Dain Curse distorts this by showing two guns for a single shot.

Chekhov's gun is not a story formula by itself because it is not clear merely from the presence of the gun without a story context how, when, or why it will be used. Alfred Hitchcock shows this technique in operation in his ability to foreground and then tantalize the artefact. The body in Rope is a clear example because the tension of that film is derived from the audience's expectation of its revelation. If one did not know about the body, the film would be less entertaining. Hitchcock succumbs to the obvious moral implications of the body and so reveals it, exposing the murderers.

Story efficiency is about information structure: why show something that is not relevant? There is, of course, much great fiction which is swathed in digressive material, unnecessary for the basic plot, but that material is then usually key to the thematic needs of the fiction. In detective fiction, efficiency is usually treated as paramount and runs both forward and in reverse.

The presence of the body signifies the past use of a gun (or other implement), and the future presence of a murderer, both of which will be revealed by the detective formulation denouement. In the extreme case formula fiction sublimates all possible aspects of the work into this kind of utility. The inexorability and inevitability of the solution can reduce dramatic tension unless the reader can suspends their knowledge of the formula. Thus " $[t] \mathrm{o}$ read criminal fiction correctly ... is to agree to read incorrectly, to occupy a position of ignorance for the duration of reading" (Kerr 733).

In a play, the gun may be fired to close Act I, to open Act II, or as the final act on stage before the curtain falls. In Rope, the body might be found at any time - there is no guarantee that Hitchcock will delay until the final minutes of the film. To inject some life, the writer of "fair play" stories will usually reap lives from their tales - murders, rather than murder, spread over the length of the novel. The body becomes again a dramatic entity: the signal, perhaps, of more bodies to come. In Christie's And There Were None (1939) the living function as a dramatic count-down to the end of the story, when they will all be dead: who will die next, and how? This is a far more dynamic question than merely motive, means, opportunity. Christie is here experimenting with major deviations from the mystery formula. 


\section{Five Murders in a Fictional City}

\section{Hard-boiling the Formula}

In the discussion so far I have shown that the "arid formula" of which Chandler was disdainful is not so very remote from his own work. Marlowe experiences the same sequence of events as Poirot, once the story is in an abstract form. Yet, as "The Simple Art of Murder" makes clear, Chandler had very different artistic objectives to those he inferred for Milne et al. These differences are expressed primarily in two ways: a replacement of the content, and a reduction in focus on the formula. These are primarily aesthetic rather than structural considerations. The suggestion that Marlowe is less than assiduous in his investigative strategy does not alter his conformity with the detective formula in its simplest form (Knight, Form and Ideology 150).

Perhaps, though, there is no better example of the distinction than Hammett's final novel, The Thin Man and the two story treatments he wrote for sequels to the film of the same name..$^{9}$ The Thin Man is a formulation that could have been prepared by any of Haycraft's "Golden Age" icons; although it occurs amongst speak-easies and with a supporting cast of professional criminals, violating the spirit if not the letter of van Dyne's rule 17 (192). The ending of The Thin Man was altered for the film version. In the novel, Charles confronts Macauley at what appears to be a chance gathering at Mimi Jorgensen's house, but in the film version the suspects are all invited to a dinner party and Charles eliminates them one by one, almost appearing to derive the solution as he goes along. This and other changes were made to remove the last vestigial traces of hard-boiling.

In Chandler, this change in content means that different explanations are needed inside the fiction for the same phenomena. For example, it is well known that the police in most "fair play" narratives are incapable of catching criminals, and the various reasons for this add up essentially to their lesser competence than the real detective. In Chandler, the reason that the police are inefficient as crime-solvers is because they are corrupt, and this conflict of interest means that Marlowe is in a better position to solve the crimes. By remaining detached from the world, Marlowe shares the objectivity of the "fair play" detective. Similarly, his detachment has a different origin despite its similar effect. Poirot is separate from the English society he redeems because of his age and his foreign origin. Marlowe's separation is self-imposed as he holds himself separate and considers himself morally superior in a way that Knight recognizes as bordering on the "solipsistic" (Form and Ideology 145).

Hammett negates this feature of the detective formula by allowing his detectives various levels of integration with the official police force. The Continental Op operates hand-in-hand with the police throughout the short stories. Beaumont has himself declared a special

\footnotetext{
${ }^{9}$ Hammett provided story treatments for After the Thin Man (W. S. Van Dyke, After the Thin Man) and Another Thin Man (W. S. Van Dyke, Another Thin Man) which were recently published for the first time.
} 
investigator in order to facilitate his inquiries. Charles's situation is a reversion to the usual "fair play" relationship. Only Spade stands defiantly separate from the police, but, as he explains, he can only operate that way because

I never forget that when the day of reckoning comes I want to be all set to march into headquarters pushing a victim in front of me, saying: 'Here, you chumps, is your criminal.' As long as I can do that I can put my thumb to my nose and wriggle my fingers at all the laws in the book. The first time I can't do it my name's Mud. (The Maltese Falcon 546)

For both Hammett and Chandler, the police are an active ingredient in the formula, rather than simply a foil to show the wit of the detective as in the "fair play" school. Yet, as noted, this does not change the fundamental story mechanics in operation. The detective, rather than the police, is still always the primary crime resolver; the difference is in the representation of this primacy.

\section{The Allegorical Novelist}

Auden's "The Guilty Vicarage" is a response to "The Simple Art of Murder" in which he challenges Chandler on grounds of "redemption", Chandler's final theory for literary value. Unlike Chandler, he is interested in discussing the murder mystery formula directly. Auden, perhaps unnecessarily, imports a moral message along with his structure, but he tries to understand how the narrative functions.

Auden's opening salvo is that he is a detective mystery addict, but rather than extol the virtues of the form, he dismisses them: "[s]uch reactions convince me that, in my case at least, detective stories have nothing to do with works of art" (400).

The society Auden imagines is the idyllic English countryside, or some equivalently functional alternative. He tackles Chandler's claim of a redemptive necessity directly by reading detective stories as a temporary fall from grace, requiring the intervention of a detective before "innocence is restored, and the law retires forever", he does not directly address Chandler's notion of society as fundamentally corrupt (403). In effect, he is examining the English tradition, rather than directly engaging with Chandler's development of an American tradition.

Auden's argument is based around a story formula, providing a tool for predicting how a detective narrative will unfold and for evaluating unclear parts of the narrative. He sees the detective story moving from a perceived state of innocence through a crime and investigation to a true state of innocence. While this schema is somewhat reductive, it makes an attempt to explain how the different elements of a detective story interact in a way that Chandler's essay does not. We could characterise this as an "allegorical" reading of detective fiction, because it has religious, specifically Christian, overtones, but in effect Auden offers a 


\section{Five Murders in a Fictional City}

complementary formula for interpreting the texts. Allegory in this context is different from formula because of the moral connotations Auden's allegory brings with it. We could consider the analyses of Cawelti and Knight as attempting to infuse the detective formula with other connotations, specifically with conservative political ideology, and render the detective formula as the detective allegory.

All such points of correspondence must be used very carefully. Auden takes great care to show how his moral framework explains and coincides with the events that routinely occur inside detective fictions. Other critics are not so careful, drawing on few events to support an allegorical alternative to the detective formula. One example is from Gray, who claims that "the personal implications of a case Spade narrates to the client who hired him [the Flitcraft story] ... makes the Sisyphus parallel a better fit" (771). In Greek myth Sisyphus was a king whose punishment for hubris was endlessly to try and roll a boulder to the top of a hill. Gray's sketchy association does not clarify in what way Spade's detective activities are a punishment for pride, and while Spade experiences some repetition and set-backs, he does ultimately resolve the dual mysteries of Miles Archer and the black bird by the end of the story. Gray asserts that at the end of the novel Spade is "physically and psychologically where the case began", but this is not correct, because there is no marriage impeding Iva Archer's advances, he has no business partner, and relations have soured with his assistant (771). Yoking this detective to this particular myth seems specious in this instance. Robin D. Laws' construction of an "iconic hero" in the introduction to the anthology The New Hero, as a character who uses an adherence to a personal code to restore the world around him to proper function, addresses Gray's lack of change in the personal circumstances of the detective as well as the actions he takes (6). Gray is on firmer ground when connecting the murder of Taylor Henry to a "Laius complex" but that does not replace the detective formula in understanding the details of the crime or its investigation, and it is not clear what additional meaning that correlation generates in a more general critical mode (771).

Auden's substitution allegory for formula means that while he wishes to oppose Chandler's views, each is discussing different a operational level of the text. Chandler describes the apparent contents: the characters, the places, the details of representation. Auden discusses the underlying structure of the stories. Chandler's problems with the authors he excoriates originate in the gap between his perception of reality and their depiction of it. He does not, and cannot, object to the underlying structure of the story.

Chandler deliberately moves the argument away from the formula per se and into its contents. Wright and Freeman were attempting to control the syntax, content and form of the detective story in ways that Chandler did not agree with. Chandler's argument is not that a detective story should omit any of the key structural parts, but that those parts should be seen in a larger context than simply the puzzle of "whodunit?" We could therefore consider 
Chandler to be neutral toward the rules of detection espoused by the others, the governing principle at the heart of the "fair play" method.

\section{Romance}

The dilution of the formula in so-called "hard-boiled" fictions creates a second avenue to search for literary meaning. By allowing contaminants, and by not tightly resolving all aspects of their plots, such as the famously inconsequential death of Owen Taylor, "hard boiled" authors allow other interpretive stances. ${ }^{10}$

It is common for critics to draw parallels between detective stories and Romance, usually this is relatively off-hand, a passing comment. A few critics use this equivalence as a central axiom, such as Susan Rowland's "The Wasteland and the Grail Knight: Myth and Cultural Criticism in Detective Fiction" (2010) and Jasmine Yong Hall's "Jameson, Genre, and Gumshoes: The Maltese Falcon as Inverted Romance" (1994). But these articles do not specify a syntax for a Romance as such; there does not appear to be a reliance on a central poetics in the way that Aristotle's Poetics influences the study of tragedy or Chandler's "The Simple Art of Murder" permeates criticism of "hard-boiled" detective fiction. The main "original" source for the connection between detectives and romance seems to be Northrop Frye's The Secular Scripture: A Study of the Structure of Romance (1976), which does not offer a point-by-point comparison of detective formulae with romance formulae.

Frye, like those who allude to his work, simply assumes that detective fictions fit within the Romance Genre. His discussion of detectives part of the idea of conventions as the framework for genre:

In the general area of romance we find highly stylized patterns like the detective story, which are so conventionalized as to resemble games. We expect each game of chess to be different, but we do not want the conventions of the game itself to alter, or to see a chess game in which the bishops move in straight lines and the rooks diagonally. Whether we consider detective stories worth reading or not depends on our willingness to accept the convention. Edmund Wilson, for example, refused to accept the convention, and remarked that readers of detective stories were obviously neurotics trying to attach an inflated importance to a pointless activity. Now if we do find wit, lively plotting, vivid characterization, or cogent social comment in detective stories - and it is not so difficult to find such things - we should appreciate the author's ingenuity in getting good writing into such ritualistic a form. The right next step for criticism, it

10 Knight notes the solution offered by the text itself, that Taylor commits suicide. The willingness of critics to believe the well-worn story about the late-night call to Chandler during filming of The Big Sleep (1946) implies more about the search for ambiguity than about the text itself. See "Killing Owen Taylor" for a bland statement about the ambiguity of Taylor's fate as the basis for a whole theory of narrative continuity in film. Yet, for all that, Owen Taylor's death is hardly remarked upon: it is incidental to anything that Marlowe cares about. 
seems to me, is not to assume that there is a difference in value between detective fiction and other types of fiction, but to realize that all fiction is conventionalized, and that it is equally a tour de force of ingenuity to get good characterization and social insight into a story as complicated as Tom Jones or Emma, both of which also contain mysteries impelling us to continue reading until we reach the "solution". (45)

On the basis of this paragraph many of his assertions about Romances are somewhat uncritically applied to detectives by subsequent scholarship like Rowland and Hall, who use this reading to draw conclusions which seem strange at best.

In other words, Frye does not prove the structural link. However, in providing something of a taxonomy and typology of Romance, Frye provides us with criteria that we can use to make an inquiry into the similarity of formulae, which I shall do below. One problem is that Frye's "structure" is sometimes so metaphorical and generalised that it seems like anything could be twisted into shape with sufficient ingenuity.

Frye frames his discussion of romance as a discussion of mythology, which he sees as occurring where works become intertextual such that they form a larger narrative framework. He contrasts that perspective with "folktales" which may share structural features with mythologies, but each can be read in isolation. If we are interested primarily in form and not content, then to an extent, this distinction does not matter for an examination of a specific story simply because the intertextuality occurs at the level of content rather than formulation.

Chandler argues that authors in the realist mode offer an explanation of the world. "It's not a very fragrant world, but it is the world you live in" ("SAOM" 18). Chandler sees "hardboiled" fiction as consciously creating a mythology in Frye's terms - a way of explaining the world. This may be an unintended consequence of the details of Hammett's Op stories. While the order of the stories might not matter much (they are heavily jumbled in anthologies), they all point to a particular conception of the world. The use of realist details builds a sense of a consistent world, and offers an explanation of that world, and so ironically contribute to a romance in the structural terms discussed by Frye.

\section{Cause and Effect}

In our conception of formula, there is no sense of how cause and effect operate in the structure of the detective fiction. It is sufficient that the necessary steps occur in approximately the necessary order. Moretti discusses this kind of problem, in "The Slaughterhouse of Literature", (2000) where he outlines the evolution of clues in detective fiction. All the fictions that he reads share a narrative pattern, but in some clues appear, and sometimes when clues appear they are necessary and sufficient for the resolution of the mystery. Clues are an intellectual way of resolving crimes, but physical toughness can also 
be used to resolve the criminal situation. Cawelti gives the example that Mike Hammer's "investigative technique consists of beating up the suspects to force confessions" (186).

These two operational modes find corresponding modes in Frye's theory of romance in the form of "force" versus "guile" (65). Frye combines consideration of this dichotomy of resolution with a larger-scale conception of the story framework, which he phrases as "hence" versus "and then" (47).

Frye illustrates "force" versus "guile", using the two key heroes of Homer (66). Achilles is a hero who relies on "force" to achieve his goals. He is undefeatable in battle, and knows it. His story is about direct conflict. Odysseus is capable of "force", but he primarily relies upon "guile" for his victories. He hides from Polyphemus and he disguises himself in Ithaca.

These two narratives can also illustrate the difference between "hence" and "and then".

The Iliad is a tightly controlled set of interlinked episodes whose action is all driven by the disagreement between Achilles and Agamemnon. Almost everything that happens derives from their conflict. It is a "hence" narrative, with the connectivity implied by that logical relation. The Odyssey, on the other hand, is a concatenation of discrete events that could be rearranged. The apparent cause of the whole adventure is that Odysseus angers Poseidon by blinding Polyphemus - it shares that apparent spark for action with The Iliad, but this merely provides the connective tissue between adventures. Does it really matter in what order Odysseus encounters Circe or Scylla and Charybdis?

We can use these criteria to group different kinds of detective fictions, to help discriminate between narratives that seem similar, but are operating in quite different ways. That is, two stories may share the same characters and broad setting, but may have different story mechanics in operation.

The differences between "fair play" and "hard-boiled" narratives in terms of their content are already well discussed above, but so far we have not clearly expressed whether there are structural differences. To an extent, "force" and "guile" operate on the level of content, while "hence" and "and then" represent differences between formulae.

The "fair play" group is homogeneous in this scheme because they share the necessity for a "hence" structure. Given a certain cast of characters, motivations, and means, a murder occurs and there is a consequential investigation. Everything that happens is a consequence of something else inside the narrative, so events cannot be reordered without sacrificing significant details of the story. They are also almost entirely "guile" stories, because of the detective's ratiocinative methods. Clues are examined, suspects interrogated, and conclusions drawn. When violence intrudes directly into the narrative, delays the cerebral resolution; it does not propel the action forward.

The "hard-boiled" school is not very homogeneous. Considering only the canonical authors, we find all four combinations occur. 


\section{Five Murders in a Fictional City}

Chandler and Macdonald largely remain within the "hence" structure in their novels. Both fold their stories back on themselves, creating doubled detective stories; in order to solve Crime A, it is also simultaneously necessary to solve Crime B. This leads to the cliché of two separate cases turning out to be a single case, as so perfectly satirised in Kiss Kiss, Bang Bang (2005).

"Force" occurs far more often in American novels than English. The "force" is often directed at, rather than by, the detective; Marlowe and Archer are beaten unconscious to deter them. However, while the detective is not usually a proactive participant, their storylines are often resolved by acts of "force", so that it is structurally important in a way it isn't for the "fair play" crowd. Consider the last meeting between Moose Malloy and Velma in Farewell, My Lovely; his death resolves the cycle of violence, bringing the narrative to a close (except for a coda on her eventual fate but by that point in the narrative all of the nominal mysteries can be accounted for without that final act of violence.) We could also interpret Dinah Brand in this way, as an agent of chaos whose removal from the narrative signals its end.

Mickey Spillane is far more interested in "force", both as a tool for Mike Hammer and as a narrative mechanic. Almost all discussions about Hammer focuses on this aspect of his adventures: to whom is violence done, and with what apparent justification and effect. Critics concentrate on Spillane's apparent misogyny in depicting women as sexual objects and then destroying those objects. ${ }^{11}$

That critical obsession helps demonstrate the primacy of "force", but it is interesting that the mechanics of this tool have not been explored in great detail. The inclusion of violence allows the "hard-boiled" detective to go into story areas where their "fair play" counterparts cannot venture. If Poirot had been setting out to clear Madvig's name in The Glass Key, the story would necessarily have ended at his capture by Shad O'Rory, since Poirot could not have survived the torture without compromising Madvig in a way orthogonal to the detective formulation. Miss Marple could not have successfully navigated the Temple of the Holy Grail, since she would not have had the fortitude to survive the gases, nor to kill Joseph in the final confrontation. The ability to use or even merely survive the use of "force" opens story possibilities.

Daly is clearly Spillane's master; Race Williams does everything Mike Hammer does, but with less sexualised violence (refer to William F Nolan, The Black Mask Boys 41 for fuller discussion). Which brings us to Hammett, and the difficulty of making any general statements about his five novels: they are each so different from the others that they might as well have been written by different people.

\footnotetext{
11 See Humann for an example
} 
Red Harvest appears shapeless, just an extended series of set pieces and interrogations. It clearly does not have the a single (or doubled) "hence"-based structure as we expect from the other examples discussed. Yet, most individual sequences depend on details from previous scenes such that make a large-scale reordering difficult. Red Harvest uses a structure based on "and then" until the murder of Dinah Brand. After that, everything that happens is a consequence of actions taken in the past.

"Force" appears to play a major part in the narrative, but, aside from the initial murder of Donald Willsson, every act of violence is predicated on a deception, and so is more characterized by the term "guile".

The Dain Curse, too, resists classification. As it unfolds, it appears to be a series of "and then" events, which bothers the detective, who intuits a "hence" connection. It is not until the final fifth that the unifying cause is revealed. Most surprising is that while "guile" is important in the way the story unfolds, it is actually resolved mostly by "force" at each step Alice Dain is killed in a struggle with Fitzstephan, the Op must shoot Joseph Haldorn, and Fitzstephan is finally stopped by an explosion.

The Maltese Falcon and The Thin Man are both in the "hence"/"guile" camp.

The Glass Key has an extreme focus on objective reporting without affect. That style of narration makes it difficult to draw conclusions about the motives or emotions of the characters. Parsing it through Frye's dichotomy can show how it is different from a conventional "fair play" narrative in functional terms. This allows us to go beyond the obvious differences apparent in the contents of the formula to see whether the story's operation is different from a "fair play" narrative.

Beaumont is a consumptive friend of Madvig, who is implicated in a murder at a politically sensitive time: during an election campaign. Madvig is a Capone-style gangster who almost rules a city ("SAOM" 17). Beaumont believes Madvig is innocent and sets out to prove it, almost against Madvig's wishes. The Glass Key has many of the hallmarks of a "fair play" narrative, with suspects, questioning, and clues. However, what gets this apparently weak character through the narrative is really his ability to survive the violence directed toward him.

The denouement has the shape of a typical "fair play" summing-up, but it is slight by "fair play" standards. Beaumont latches onto the vital clue at once, and that single investigative avenue eventually yields the murderer. The puzzle component of the novel is not a brilliant assemblage of clues: we reach the eventual resolution because of Beaumont survives. The Op's motto is to claim that if you're tough enough to survive, you'll come out on top. That is far truer of Beaumont than for the Op himself. Reconsidering "force" as the 


\section{Five Murders in a Fictional City}

principle of action removes strengthens the ending of the novel. It is the reliance and inclusion of "force" as a method for resolving individual scenes that really differentiates The Glass Key from a typical "fair play" outing.

The dichotomies that Frye proposes pose difficulties in application; they can be counterintuitive. Yet, at the same time, they can provide insight into how stories are structured, and explain features that are otherwise difficult. They help us understand in what ways these works are structurally different, rather than simply versions of the same formula.

\section{The Content of Romance and Inverted Romance}

There is a critical discourse based on the assumption that an investigation is fundamentally similar in structure to a romance quest. In the case of "hard-boiled" detective fiction this is usually discussed in terms of an inverse romance, implying that the romance is a useful mode for interpreting the work based on opposing outcomes and strategies.

While a "fair play" detective story is usually a continual accretion of clues in a deductive chain, Hammett's stories often have a burst of information at their start followed by a lengthy period of exploration and activity with no particular informational content but several challenges to the Continental Op's character. The conception of the story as a quest allows some of the apparently disjointed stories to be re-conceived as a single construction.

Both Chandler's The Big Sleep (1939) and Hammett's The Maltese Falcon have been described as "inverse romances". Interpreting the work in this way looks for the opposite of a romance or chivalric formulation or entity. The "hard-boiled" interpretation of the quest looks for betrayals of its values. Instead of finding the Grail, or rescuing the damsel, or resisting temptation, the grail is a lie, the damsel is a femme fatale and corruption is embraced. Structurally and functionally, the plot actions may be similar: traversing a dangerous landscape, encountering dangerous foes, and so on.

The quality of "inversion" can be a little difficult to define and interpret, so that where Hall sees an inversion in The Maltese Falcon based on the unreality of the falcon and the dangerousness of Brigid O'Shaughnessy, Marling believes that Sam Spade is "more perfectly than the Op a knight" (Dashiell Hammett 76), having characterised the Op stories as having "the external appearance of realism and the internal tensions of the quest or the allegory" (Dashiell Hammett 24).

In Chandler there are major structural inversions of this scheme. His hero, Marlowe, seems never to rescue a damsel, instead discovering that she is the origin of the trouble. Similarly, he observes a plethora of evil but never defeats them. For example, in The Big Sleep the gangster Eddie Mars escapes without so much as a caution. The Op may be less virtuous than Marlowe, but he is more successful. 
Whereas Chandler has completely inverted the allegory, the romance elements in Hammett are ambiguous. Hammett is interpreted in a romance mode because of the close connection created by Chandler, another layer of misinterpretation caused by that association.

This approach to reading detective stories, especially in the Hammett tradition, does not use the allegory to explain the details of the stories. In The Faerie Queen many strange things happen for no reason apparent from inside the fiction, but whose purpose becomes clear when considering the allegory being developed. Strange and arbitrary things do happen in "hard-boiled" fiction, but they are not better explained by allegorical structures imported from chivalry than by the detective formula.

\section{Concluding Remarks on Formula Fiction}

Texts, literary or otherwise, are systems of signs that need interpretation. Morretti summarizes the objective of an interpretive stance as "establishing the basic and most abstract system" (Signs Taken for Wonders 149), "provid[ing] the best possible explanation of the phenomena it discusses" (Signs Taken for Wonders 2). The default tool used for interpreting fictions is our understanding of the real world, but this is inevitably modified by caveats and structures inside the texts, which means that a better interpretation of Hammett is reached using the detective formulae. The more tightly and explicitly structured the text, the more departure can be created from the baseline, becoming "perfect[ly] selfreferential" (Moretti, Signs Taken for Wonders 149), so that a pure fiction could be described quite well by Baudrillard's definition of a simulacrum from Simulacra and Simulation (1994) as having "no relation to any reality whatsoever: it is its own perfect simulacrum" (6).

Formula fiction emerges from an aggregation and synthesis of a mass of similarly structured works, which allows the production on a mass scale of conventions that structure the reading experience. Once a formula is developed, it is possible to use it, as one uses reality, to help with the interpretation of texts. It is all too easy for this system to become inward looking, which is where Chandler perceives it to be directed in his polemic, "The Simple Art of Murder". It could even be argued that the formula became outward looking, used instead of reality. In "Murder Trials, Murder, and Twenties America" (1981), John R Brazil explains "[t]here appears to have been an effort to make the trials the same, to invest them with a stereotypical plot constructed of stock situations, stock characters, and formulaic descriptions" (166). Chandler is taking on a challenge beyond his imagination.

In order to interpret fully a formula fiction, it is necessary to move back and forth between a formulaic reading of the text and an interrogation of the detailed content of that formula. It is not sufficient simply to identify the component structures of the formula as 
Five Murders in a Fictional City

expressed in a specific work, but it is not possible fully to appreciate the details of the work without understanding their formulaic function. 


\section{The Five Murders}

Red Harvest is the third most famous, the second most critically appraised, of Hammett's oeuvre $^{12}$ and is the favourite of his daughter (Jo Hammett 61). The Maltese Falcon is by far the most famous and critically acclaimed, due in part to the success of John Huston's film version. The Thin Man's fame in its day was symbiotic with the success of W.S. van Dyke's screwball comedy-cum-mystery film. The Dain Curse and The Glass Key are largely forgotten now even though The Glass Key is consistently reported as Hammett's own favourite of his novels.

So my discussion of detective fiction has been quite general, drawing examples from Hammett and others as illustrations of specific concepts more-or-less in isolation. The succeeding discussion of Red Harvest shows how these concepts have been reconfigured by Hammett uses the detective formula and syntax to tell a story that is not a formulation. Hammett's varied structure poses problems when trying to develop a model author, because different reading strategies are needed at different times. The careful "fair play" reader will find the opening murder satisfactory, if slight, but the two dreams are not easy to interpret in formulaic terms and so non-formulaic analysis must be undertaken. Formulaic interpretations must be undertaken carefully, because Hammett will sometimes comply with only part of a formula. William F. Nolan's summary of Red Harvest in his 1969 study is typical:

The Op arrives on a call from the publisher of the local paper, Don Willsson ... Willsson is shot to death that same night, and the Op goes to his father, old Elihu Willsson ... having seen his son gunned down, fearful for his life, hires the Op to "clean up Poisonville".

The Op accepts the job, shrewdly and coldly deciding to play off one gangster against another. (Hammett Casebook 47)

Nolan says the Op "accepts the job", when the reverse is true: Elihu Willsson must be bullied into accepting that the Op is already working on it. In The Cambridge Introduction to

\footnotetext{
12 Many biographies and critical surveys treat most or all of the novels. Below is a general summary of the treatments of only one or two of Hammett's novels:

Red Harvest: (Cawelti 168) (Freedman and Kendrick) (Glover) (Heise) (Malmgren) (Marling, The American Roman Noir 106) (Walker) (Whitley) (Zumoff, "Politics of Red Harvest")

The Dain Curse: (Gatenby)

The Maltese Falcon: (Abrahams) (Cawelti 167) (DeFino) (Edenbaum) (Hall, "Maltese Falcon as Inverted Romance") (Haycraft, Murder for Pleasure 172) (Irwin 1) (Malin) (Marling, The American Roman Noir 126) (Rzepka 192) (Layman, Discovering the Maltese Falcon) (Layman, "Theme Issue") (Christopher Metress, "Reading the Rara Avis") (Mooney) (Peltier) (Rivett)

The Glass Key: (Horsley 78) (Rabinowitz)

The Thin Man: (Alvarez)
} 


\section{Five Murders in a Fictional City}

Narrative, $2^{\text {nd }}$ Edition (2008), Abbott raises the possibility "that when these masterplots [formula] are activated it is impossible to break out of the vision they create" (49). This is what Nolan does when he misrepresents both the story and the narrative discourse where they deviate from the formulaic norm, substituting genre-typical formulaic descriptions of the action for specific variations from the formula.

This interpretation of the Op's involvement is echoed across Hammett criticism because it appears sufficiently to explain an otherwise unclear aspect of the text. The detective formula requires that there be a detective and that he investigate, and so he does. If we cannot interpret the story using that typical formulaic construction, it is not easy to make a definitive statement about why the Op stays in Personville rather than returning to San Francisco. This kind of difficulty is precisely what prompts the detailed exploration that is the basis of scholarship of non-formula fiction and is precisely the kind of ambiguity that Eco advocates (On Literature 4). The problem with Nolan's summary of the involvement of the Op is not so much that it is incorrect, but that its logic is invisible: the problem of his motivation is simply not dealt with because the formulaic assumption is not clearly stated.

In a fundamental sense, Red Harvest is a formula fiction. Claiming that Red Harvest's "innovation was the abandonment of the intellectual-puzzle formula as the basis of narrative construction" (Freedman and Kendrick 209) or "[h]ard-boiled writers broke [the detection club oath]'s rules with adolescent abandon" (Smith 40) is correct, inasmuch as executing a formula is not the main objective of the narrative discourse, but on the level of story, much of the action relies explicitly on the resolution and revelation of murder mysteries. As my reading of Red Harvest shows, the rules are broken with care and attention. They are not abandoned, they are re-used for a more elaborate and ambitious aim.

The factual account of how the Op gets hired is that he uses the mystery around Donald Willsson's murder to get $\$ 10,000$ and ostensibly his client's aid. There were other options for this story event, but he chose to use an unsolved murder, and this unorthodox use of formula has been confused with its absence. As will be explained in detail when examining each of the formula applications, the formulaic aspects of the novel cannot be omitted from consideration without fundamentally misunderstanding how the story unfolds.

The detective formula is not the only formula used in Red Harvest, it also uses story concepts and syntax from the wider genre of the criminal underworld, and in effect it helped create the formula of the warring factions that would be important in films like Yojimbo (1961) and its two remakes. ${ }^{13}$ Yojimbo is a combination of elements from Red Harvest and

\footnotetext{
${ }^{13}$ A Fistful of Dollars (1967), which follows Yojimbo closely, and Last Man Standing (1996), which reverts the setting back to the 1920s. Millers Crossing (1990) also follows the basic formula of Red Harvest and is not considered a remake of Yojimbo. All of these films amalgamate the plots of Red Harvest and the characters from The Glass Key to some extent.
} 
The Glass Key. This formula is infinitely replicable in the corrupt environment of Personville: as one corrupt leader is removed, another rises to replace them, so that Chief Noonan is replaced by McGraw, who proves his corruption by swearing in bootleggers as deputies. The clearest example of this is Lew Yard. His scarce mention is a problem for LeRoy Lad Panek in Reading Early Hammett: A Critical Study of the Fiction Prior to The Maltese Falcon (2004), where he argues that Hammett “introduces too many characters, and doesn't know what to do with them ... Lew Yard and Pete the Finn stand witness to this" (147). Conjoining this argument is Peter Wolfe's assessment in Beams Falling: The Art of Dashiell Hammett (1980) that Reno Starkey "could be lifted from the novel without affecting plot or idea" (85). These two complaints miss the point where they meet - that Reno Starkey is simply Lew Yard as far as Personville is concerned, and Starkey taking Yard's chair at the so-called "Peace Conference" is primary evidence of the scope of problems faced by the city. As I will show when discussing the murder mysteries embedded in the text, Reno Starkey is far from a minor character.

Red Harvest is a composite of 4 short stories published in Black Mask magazine starting in 1927; these were "published as separate stories rather than [a] conventional serial" (Hagemann 118). The action in Red Harvest is complex, but is framed around two central strands - the conflict between the different criminal factions in the city, and the life and murder of Dinah Brand. Summaries of the novel tend to focus on the first of these two strands, and tend to position the Op as an agent provocateur, but in many ways the Op is more like a catalyst, enabling an unstable situation to disintegrate, than someone creating strife where none existed previously. As Marling summarizes, "aside from the bogus "peace conference' that he arranges, the Op only stirs a little" (Dashiell Hammett 55).

The story is narrated by the Continental Op, Dashiell Hammett's main character from his Black Mask short stories beginning with "Arson Plus" (Oct 1923). ${ }^{14}$ As Panek points out, the Op in Red Harvest has major differences from the Op in the short stories, as does the world he inhabits. The Op becomes "isolated and confrontational" (138) and focuses more on "the world of organized crime" (139). Perhaps the most striking difference, however, is the change in focus from the Op stories which have their "emphasis [on] the process of detecting itself", (Zumoff, "Tijuana" 38) to the novel in which the carefully described drudgery of investigation is largely absent, instead having an "emphasis on action" (Panek 139).

Red Harvest represents a significant departure from the style of the short stories, but it is nevertheless indebted to techniques and prototypes from them (Marling, Dashiell

\section{Hammett 52).}

\footnotetext{
${ }^{14}$ Previous detective stories published by Hammett featured other private investigators.
} 


\section{Five Murders in a Fictional City}

This introduces a number of important structural problems into the narrative, the most important of which is the bifurcation of the narrative hinging on the first murder. On first reading, it seems that the main "plot" is resolved by the quarter mark, as Marling observes, "[with] the murderer apprehended, the Op should leave; it requires a sudden eruption of vengeance on his part to create a bridge to the second section" (Dashiell Hammett 55). Marling has missed the details of the Op's initial approach to Elihu, which emphasises the political aspect "[that has] got to be looked into" (17). The Op can be read here as arriving on the scene with the intent of expanding the scope of his job from finding a murder and into something like Donald Willson's assumed mission of cleaning Personville. The Op is hired to cleanse the town first and foremost; Elihu's inquiry about the Op's progress in finding Donald's killer (40) comes after the Op has been hired to "clean this pig-sty of a Poisonville" (38). Nevertheless, Marling's misreading derives from unconsciously applying the simple version of the detective formula that is probably familiar to every reader of the novel at the time or since. It requires a disciplined reading to pick up on the cues as to the Op's real agenda and not accept at face value his explanation to Elihu that he's going to stick with the job because "[y]our fat chief of police tried to assassinate me last night ... I'm just mean enough to want to ruin him for it" (57). The Op here explicitly ties his own actions into a revenge formula, and so it is certainly understandable that a reader might find themselves forming this view, however incorrect.

The point remains, however, that whereas a typical detective novel would see a murder like Donald Willsson's as a complete story, Hammett instead uses it as a springboard for the remaining narrative.

The origin of Red Harvest is usually seen in terms of stories that share a similar kind of setting or mode of action. The setting is said to come from "Nightmare Town" and the main activity of the Op playing crooks against each other deriving from "The House on Turk Street", "The Whosis Kid", with other short stories are brought into the genealogy depending upon the preferences and prejudices of the critic. Panek's assessment of the importance of "Corkscrew" comes closest to understanding the overall design of the novel, because "Corkscrew" is "a compendium of popular story bits" in much the same way as Red Harvest is a compendium of popular formula (124).

\section{Non-Formula Approaches}

Red Harvest receives critical attention partially because critics try and reverse engineer it in light of Hammett's communist activities in his later life. The novel is set in the aftermath of union busting by means of criminal gangs, and so doesn't present a flattering portrait of corporate America. There are suggestive details spread throughout the text that money and power have had a corrupting influence, but Hammett does not explore how this 
interacts with a capitalist economic system in any detail. Even the defeat of the striking workers is not framed clearly as a reassertion of capitalist over socialist principle. It is not a re-integration into a capitalist system because it is about power rather than money. Critics that regard the defeat of the strikers as part of a "larger critique of capitalist exploitation" (Breu 64) do not usually explain whether this critique connects with the explicit parallel drawn by the text with "Italian history", (Red Harvest 10) which was Elihu's undoing. Elihu lost control to his gangsters; there is no mention he was financially disadvantaged. Linking "the Op's 'blood-simple' vigilantism to the town's ethic of capitalist exploitation" as a quasicommunist critique of the capitalist system, places more weight on impersonal economics than on the personal motives of most of the killers (Breu 66).

Dinah Brand provides most of the concrete references to the capitalist system in her use of Bill Quint to make money on the stock-market and her commodification of the privileged information she has acquired (32). Yet, Brand is a parasite feeding on this system, she is not integral to its function, and so we are left to draw parallels and inferences without much explicit support from the narrative. We do not have to look far to find a more compelling and complete critique of a capitalist society - Hammett provided one himself in The Glass Key, where the specific political and economic functions of the city are more explicitly linked to criminality.

Wolfe is an enthusiastic advocate for a communist agenda, possibly because he did not have access to any of the major biographies that were in production while he was writing his study, all of which locate any tangible connection with the Communist Party after Red Harvest was written. He summarizes the case that "this substitution of excess for creative energy stems from the Marxist impulse behind Red Harvest. The belief that capitalism destroys character and that the creed of rugged individualism destroys individuality" and adds the appellation "Marxist" to Hammett at frequent intervals in his discussion of the text (Wolfe 91).

The city itself is a point of significant critical interest that intersects with views of the Hammett of 1927 as a nascent communist. Different authors regard these things in opposite directions. The main contested claim is that specific scene locations and the characters exist largely within the confines of the working classes (See Heise). The argument is made that there is an implicit conflation of working class environments and criminality.

While working-class characters intrude into the spaces frequented by the narrative and the narrator, so do middle-class characters and their interests. The first quarter of the text is concerned with the murder of a man running a newspaper and the main aid in the investigation is a banker - hardly the working poor. The Op occupies primarily criminal spaces, which makes it clear that these transgressions intrude into all levels of society, from city-ruling gangsters down to the down-and-out grifters. The conflation of space 


\section{Five Murders in a Fictional City}

and criminality is an over-simplification rather than an explanation of why the narrative plays out the way it does. This inhabitation primarily of criminal spaces means that there are precious few "civilians" in the tale, everyone (with the possible exceptions of Donald Willsson and Dan Rolff) who dies is "in the game" - crooked cops, outright criminals, blackmailers. To a large extent, that means that while there are numerous corpses, there are few true victims, only those whose survival skills are lacking.

Whitley structures his analysis around the places where Hammett deviates even from his own literary tradition, "break[ing] sharply with previous conventions of the detective story" (443). This was picked up by David Glover in an article adequately summarized by its title, “The Frontiers of Genre: Further to John S. Whitley's 'Stirring Things Up: Dashiell Hammett's Continental Op"' (1981), which clarifies and codifies some of Whitley's key insights.

The most useful position Whitley takes is that "Hammett raised death to a level of almost Jacobean melodrama which rendered it at once common and absurd" (444). ${ }^{15}$ His argument is that, while murder features heavily in the work, it has a completely different significance in Hammett than in, say, Christie. Whitley implies that in Hammett, killing is not a transgression, but a normalcy to be navigated and controlled. This insight explains a large number of the features of the text which cannot be explained with reference to the "fair play" method. Perhaps the clearest example is the men killed at the Cedar Hill Inn (108) whose deaths require no reparations because "they get paid for taking chances" (129). Their deaths have no meaning to Pete the Finn in comparison to his destroyed liquor, the protection of which was their livelihood. Where Whitley falls a little short is in not recognising that different deaths do have different significances, with a crucial handful operating both as a formal mystery and as a negotiation tool amongst the various killers. When Jerry is killed, it is really a message from Starkey to Thaler, albeit one not understood by Thaler until the Op explains it to him (131).

Whitley goes on to point out the reversion in approach to murder that occurs in Chandler's novels, implicitly separating Hammett from his successors (Glover 447). Chandler, for all his aesthetic sensibilities, has a fundamentally similar perspective to Christie et al when it comes to a dead body. The short stories, more closely aspiring to Hammett's standard, do feature murder-as-medium to some degree. For example, in Chandler's "Spanish Blood" (1935), Joey and Max Chill are killed as a message to the detective, Delaguerra. He in turn construes a connection between them and Stella to the criminal bosses who ordered the Chill murders, incidentally framing her for murder.

\footnotetext{
15 Whitley carefully explains that he refers to deviations from within the "hard-boiled" school, as well as
} classic detection. 
Delaguerra does this in order to precipitate a gun fight that the detective expects to leave alive while all of the criminals will be killed. Almost all of the killing in "Spanish Blood" is based on misapprehensions of the situation, and Delaguerra uses that confusion to allow the murderess to go free, for essentially sentimental reasons. Delaguerra's approach to Imlay's murder is reminiscent of the Op's "stirring things up", but "Spanish Blood" was never cannibalized for any of Chandler's novels. Marlowe never finds himself in a similarly incendiary situation. The murders of Harry Jones in The Big Sleep or Lindsay Marriott in Farewell, My Lovely are more typical of the killings deriving from criminal activities. Those two deaths can be construed as messages, to Agnes and Amthor respectively, but while Marlowe is present at their deaths, he is not involved. Afterwards he seeks justice for them to the point where the death of Harry Jones motivates him to kill Lash Canino, almost Marlowe's only violence. Other killings in Chandler's novels are usually shown to have a motive relating to the victim specifically; they are not usually arbitrary.

"The Simple Art of Murder" provides a way of reading Red Harvest. Indeed, Red Harvest seems almost perfectly aligned with his prescription for the setting of a "hard-boiled" detective story in a "world in which gangsters can rule nations and almost rule cities" (17). But the very point, the origin of the action, in Red Harvest is that gangsters cannot do these things because without the rule of law their money-making systems break down too, a point made more explicitly in "Nightmare Town". The city becomes unstable, with competing factions going to war. There is a shortage of civilian casualties in Red Harvest, but nevertheless, the instability of the situation is highlighted at every opportunity. The novel closes with the action so out of control, with the city so corrupt, that Federal authorities are called in to clean out the city under martial law. ${ }^{16}$ It is, in that sense, an argument for authoritarian governance.

The city in Red Harvest is literally a "Poison"-ville, but it is the very instability and insupportability of the arrangement which begs for the correction carried out over the course of the novel. As Chief Noonan's early moves against Thaler make clear, the Op does not cause this underlying tension, he accelerates and enables it. He is a catalyst rather than a reagent, a strategy that Breu summarizes by saying that "the text resist[s] making him its cause [of violence]" (66). Yojimbo is typical in its adaptation of this concept by making the protagonist far more involved in the action - the nameless Samurai shifts the balance of power in a way that the Op does not. It is not, as Chandler implies, a realistic state, and the cleansing of Poisonville is far from redemptive: quite the opposite. This lack of redemption means that, for Chandler, Hammett was not quite enough.

\footnotetext{
${ }^{16}$ Critics are split on whether the Op is successful or not. In favour of success are (Breu 62) (Freedman and
} Kendrick 209) and implicitly (Pepper 144), against are (Heise), (Layman, Shadow Man), 


\section{Five Murders in a Fictional City}

Red Harvest is possibly a critical favourite because it is not a novel that provides many answers for its questions. It is a first-person narration where we are continually aware that our story guide is misrepresenting himself to others, withholding information from us, acting on conclusions and information that he knows to be false but which seem expedient. The Continental Op is far from being a reliable narrator, and he is operating in an environment where nobody else is either. Yet, we sense that the truth must be somewhere near what we are being told - after all, everything does eventually get resolved. Far more compelling than simply "whodunit", we are asked to figure out "whatdunit" and "whydunit", and the answers seem tantalizingly close.

\section{The Five Murders}

Several readers, beginning with Mrs. Alfred Knopf, have noted that "the violence seems piled on too heavily; so many killings on a page ... make the reader doubt the story" (quoted in Johnson 70) and typically quoting "twenty-five murders" (Wolfe 91). Even the narrative discourse contributes by titling Chapter XXI "The Seventeenth Murder" in case the reader has lost count (141). The problem with these broad-brush summaries is that they treat all of the killings as essentially similar although each death occurs for a different reason and has a different story function. Despite the proliferation of corpses, there are actually only five murders in the novel that would be recognized as such and described as such by Wright's or Freeman's rules of detection: Donald Willsson, Tim Noonan, Jerry Hooper, Charles Proctor Dawn and Dinah Brand. Each of these people is killed in a way that requires classical ratiocination from the $\mathrm{Op}$ to solve, but these solutions are not the resolution of a story in the way envisaged by strictly formula authors, rather they are prompts for action.

\section{Donald Willsson}

The Op arrives in Personville in order to begin working for Donald Willsson, who is murdered by persons unknown while the Op waits for him at his house. As Op waits, Willsson's wife goes out and comes back with blood on her shoes. The Op later connects her exit with Willsson's death, but he is not immediately suspicious of her, despite the imputations of guilt from her father-in-law, Elihu Willsson. His response to Elihu's summary of her character is that "none of that means anything. It's kind of childish" (16). Instead, the Op is interested in the possibility that he was killed for political reasons. He insists to Elihu that "the other angle has got to be looked into too - the political end" (17).

While he does not share his detailed reasoning with us, we can see at work the classic trio of detective questions: means, motive and opportunity. We can assume that Mrs. Willsson could have had access to a gun, and Hammett has clearly established her opportunity, but so far there is no motive apparent. This is the information that he seeks first from Elihu Willsson and then from Donald Willsson's secretary. 
The rules of detection as understood by Freeman and Wright would exclude from consideration a cynical political killing. The kind of impersonal political move that the Op suggests to Elihu is ruled out by Wright's $12^{\text {th }}$, $17^{\text {th }}$ and especially $19^{\text {th }}$ rules: "The motives for all crimes in detective stories should be personal" (192). The reader who is familiar with detective conventions, Eco's "smart" reader, aware of the rules of the game, should not have much difficulty in using their experience of other detective stories to guess that Mrs. Willsson is innocent, as she is too obvious, and that the murder will turn out to be nonpolitical. We could think about this as meta-gaming, because it does not rely strictly on information provided by this point in the narrative, but on a holistic understanding of formula applications. This reading strategy is not without some risk, however, as the earlier discussions of formula misapplication show.

The murderer turns out to be Robert Albury, a character essentially unknown to Donald Willsson, but acting for personal reasons (54). It is not clear at what point the Op realizes who the murderer is, but it seems at least possible that he has reached the correct conclusion before he is actually hired by Elihu Willsson in Chapter V, because in his summation of the crime he uses no information gathered after that meeting with Elihu. Even then, the Op is hired because Elihu "want[s] Personville emptied of its crooks and grafters" rather than to find out which of them murdered his son (38).

The Op's summation is unusual because while it is apparently the correct answer, he has little by way of concrete evidence: it appears almost to be a hunch that leads him to confront Albury. Albury provides the details of the crime himself, including motive and staging. This is typical of Hammett, and a major inversion of the way in which other detective novelists stage the resolution, a seldom-discussed tension in the detective fraternity. In The Murders in the Rue Morgue" (1841), Poe allows the hapless orang-utan-owner to outline the bulk of the events; Dupin assures the seaman that he knows "perfectly well that you are innocent of the atrocities in the Rue Morgue" before urging him to "confess all you know" and so the seaman provides the detailed summary of events leading up to the deaths in the Rue Morgue, as paraphrased by Dupin's nameless companion (218). Doyle and Christie more typically use their detectives to explain the murders, even in cases such as The Murder of Roger Ackroyd where the narrator is also the murderer and so more than capable of providing a detailed explanation of events. This is not quite as severe as Wright's stricture that "the detective who does not reach his conclusions through an analysis of those clues ... has no more solved the problem than the schoolboy who gets his answer out of the back of the arithmetic" (Wright, Rule 6), but it is analogous to a schoolboy who answers correctly without showing any working.

The usual rhetorical function of having the summation by the detective is to create what Sean McCann describes as the "detective-genius" (Gumshoe America 89). The Op is not a 


\section{Five Murders in a Fictional City}

detective-genius. What Panek perceives as a shift of "emphasis on process to an emphasis on the detective's brilliance" could also be perceived as an increase in confidence on the part of the Op (139). When he goes up against Albury, Albury is a conventionally-obvious suspect: someone with means, motive and opportunity. The Op relies upon Albury cracking because he has no proof. The Op claims he will find proof later, if Albury does not confess, and uses the threat of Thaler being framed as leverage. The earlier Op tried similar tactics successfully, such as in "The Zigzags of Treachery" where in the final confrontation with the killer, Ledwich, he reveals to the reader that, while he "morally sure", he is bluffing about his ability to follow through on that certainty because "a private detective on the witness stand unless he is absolutely sure of every detail - has an unpleasant and ineffectual time of it" ("Zigzags of Treachery" 111). ${ }^{17}$ The difference here is partially that a lengthy investigative process has not been minutely described, because it was unnecessary, but it is also partially that for once the Op is interrogating a bank teller rather than a hardened or experienced criminal, and so can be surer that intimidation and emotional manipulation will be effective.

Albury's motive for murder appears to be a conventional one: removing a romantic rival. His broken confession seems inadequate to some critics ${ }^{18}$ because it does not seem to advance Albury's interests in any way. Critics for whom the motivation is a problem find support from Albury himself who "can't now - quite understand - fully - why I did what I did" (55). Killing Donald Willsson does not remove Thaler from Dinah Brand's life and it does not return Albury to her affections. At best, it removes Donald Willsson from her affections. However, he is merely the latest conquest of a woman who "took her pick of Poisonville's men", getting "[e]veryone she wanted" (27). Albury claims that "all I could think about was that I had lost her because I had no money, and he was taking her five thousand dollars" (54). This is suspiciously sentimental for Hammett's murderers and there are few such poorly conceived murders in his fiction with so a slender rationale, although there are other crimes deriving from passion. Jon Thompson offers another way of thinking about this inadequately motivated crime: "a crime in hard-boiled fiction always signifies the presence of a wider social or political malaise of which the corpse is merely the signifier" (129). If we are not satisfied with Albury's stated motive, Thompson's interpretation of Hammett's other work suggests that we should dig deeper. Why does Albury kill Donald Willsson?

It is always dangerous to ponder alternatives to story events within an existing narrative, but in this case we need to consider the function of the entire mystery inside the greater narrative discourse, and the role that this murder plays in the overall structure of the novel, and one convenient way is by disengaging from the details of the story to look at

\footnotetext{
17 Nick Charles will have a different view (“The Thin Man" 941)

18 Find citation
} 
the formulaic requirements. As discussed in the first part of this chapter, the two main threads which extent the entire length of the novel are the theme of corruption and the life and death of Dinah Brand, and these are complementary through most of the novel.

The basic mode of action in the novel is typically summarized as "[t]he Op decid[ing] to set crook against crook" (Marling, Dashiell Hammett 50). Albury has no place in this scheme because he is not a crook per se, but merely afflicted with the general situation that Lee Horsley, in Twentieth Century Crime Fiction (2005), describes as a "world ... characterized not by remediable political-economic ills but by deep-seated moral disorder" (167). In order for this main line of action to proceed, the murder must be resolved. There are really only two other suspects, Mrs. Willsson and Max "Whisper" Thaler, and neither are as suitable for propelling the story forward.

The unsuitability of Mrs. Willsson was discussed above. The objection that she is too obvious is not strong, as it would not interfere with the way the rest of the story plays out. Helen Albury could become Mrs. Willsson's sister instead. Motive is easily supplied, since it can be the same motive as prompts Albury - a misunderstanding about the nature of the $\$ 5000$ cheque. The formula of the implosion of a criminal conspiracy cannot explain Albury's guilt.

In order to understand why Mrs. Willsson cannot be the guilty party, we must look to the second unifying strand of the novel, Dinah Brand. As will be elaborated when discussing her murder, Dinah Brand's presence touches all parts of the narrative, but Mrs Willsson has no direct connection to her. This may seem a trivial point, but without the centrality of Dinah Brand, the novel as a whole loses much of its coherence as a single narrative.

Max "Whisper" Thaler is even less suitable as the murderer. While Marling et al ascribe the factional infighting to the Op's influence, it is Chief Noonan that begins that trajectory. When questioning Mrs Willsson, Noonan leads her to conclude that the voice she heard over the telephone was Thaler's (25). Thaler's guilt at this stage in the narrative would abruptly end the game of claim and counter-claim that fuels the rest of the narrative. Despite having means, motive, and opportunity, his guilt would abort one of the two main organizing strands of the novel's structure: the internecine warfare of Personville's ruling caste.

The murder of Donald Willsson specifically by Albury is a structural lynch-pin in the narrative, subsuming Albury into the structure of the narrative, rather than considering him to have some kind of independence from the demands of the formula that could divert the story into another direction. This follows the approach of Vladimir Propp, as explained by David Bordwell in "ApProppriations and ImPropprieties: Problems in the Morphology of Film Narrative", (1988) that "[i]nstead of treating a character as a person with the capacity for action, Propp treats her or him as an emergent entity, an effect of structure" (Bordwell 10). 


\section{Five Murders in a Fictional City}

This also means that it is the demands of formula that determine Albury's guilt, so that Frye's concept of "hence" does not apply at the level of the reality inside the fiction.

This murder, and hence Albury, cannot be arranged in another way without significantly restructuring the relationships and events in the rest of the narrative. The murder prompts Elihu Willsson's associates to begin the collapse of their conspiracy, including sending someone to kill Elihu himself which is the move which formally enlists the Op in the action. Donald Willsson's murder uses the familiar formula for a detective story, obeying the rules for such things as understood at the time, but rather than the murder being the objective of the fiction, Hammett uses this formula to support a larger-scale story that is not a detective formulation. In detail it is not correct then to suggest that Hammett's innovation is the abandonment of formula, instead we should see him as having adapted its architecture to a new purpose.

\section{Tim Noonan}

The murder of Tim Noonan has the same basic pattern as the murder of Donald Willsson. It is an event which happens outside of the Op's direct narration; it is reported to him by a third party, in this case Dinah Brand. The obvious suspect for the murder is again Thaler, and this time it is the Op rather than the Chief who produces the evidence against him - testimony from the dying Myrtle Jennison. The evidence is a little stronger this time, but in formulaic terms it has the same function of setting Chief Noonan against Max Thaler. The similarity of these two murders allows a synoptic view, where we can infer meaning not only from the formulaic structure as outlined above for Donald Willsson's murder, but from a close comparison of the two murders. This synoptic tendency is what prompts even such a shrewd critic as Erin Smith to describe Donald Willsson as Dinah's ex-lover, for which there is scant evidence in the text (160).

Albury's motive is essentially to prevent another suitor from becoming involved in Dinah Brand's life. Bob MacSwain kills Tim Noonan essentially as revenge-by-proxy for Tim Noonan's abandonment of MacSwain's wife after she had left MacSwain to be with him. This suggests a similar perspective on romantic relationships to the earlier murder. Dinah Brand is "strictly pay-as-you-enter" and her expectation is that once the money runs out, the relationship ends, but her suitors do not seem to agree with that relationship structure at all (27). The same expectation exists in the marriage of Bob MacSwain. Both killers have difficulty relinquishing their claim: MacSwain continues to believe he has some responsibility toward his wife.

This is the same kind of connection that will cause Reno Starkey to visit Dinah Brand whilst hunting for Thaler. Reno believes Brand and Thaler are still connected, and perhaps we can infer from Thaler's killing of one of his own associates over hitting Dinah that Reno is 
at least partially right. Indeed, Rolff will kill Thaler as revenge for his assumed role as murderer. Rolff's and Thaler's mutual slaying closes the last loose ends of Dinah Brand's life, allowing the narrative to finish.

Thaler is implicated in Donald Willsson's murder by his presence, and Chief Noonan leads Mrs. Willsson to positively identify his voice on a telephone call luring her to the scene of the crime. Chief Noonan does not display great investigative skills during the novel, and so we cannot conclusively state that this is deliberate - it could perhaps be a genuine mistake. Thaler does have means, motive, and opportunity, after all. The Op similarly acts on hearsay when he approaches Myrtle Jennison and asks that she sign the statement that he has written implicating Max Thaler as Tim Noonan's murderer (81). Chief Noonan leads Mrs. Willsson to make her statement, almost talking her around to his perspective. The Op's approach is far more explicit about getting the answer he wants. He does not ask for her to repeat her account, merely to agree to his version of it, which is now third-hand. In his interactions with Jennison he lies outright about his own intentions and about the relationship between Thaler and Brand.

This replaces Chief Noonan with the Op as the perpetrator of a perversion of justice. We are more inclined to forgive the $\mathrm{Op}$ for this transgression than we are sympathetic to Chief Noonan's irregular justice because of their apparent motives. The most likely reason that Chief Noonan would want Thaler removed from the picture is as a grab for power. The Op's ostensible goal is the removal of the criminal element at large from Personville, which is a goal the reader can approve of. Nevertheless, this transgression equates the Op with Chief Noonan in terms of methods of operation, and so implicitly asks whether the means justify the ends.

Cawelti argues that Hammett exonerates the Op when "the violence and corruption are finally attributed to the city itself" (172). In our synoptic view of Willsson's and Noonan's murders, that would exonerate the Chief too. Of the big five, said by Bill Quint to control Poisonville, Chief Noonan is the least clearly defined as a villain. As Chief Noonan explains, "I got to play with them that play with me" (88) which in Poisonville means criminals. An honest cop would certainly not have survived as long as Noonan. Noonan is also the only character to express remorse over his part in all the killing: everyone else, including the Op and Dinah Brand, evade taking moral responsibility for their contributions to the mayhem. Noonan says he's "sick of the butchering" to the point where he'll forgive the murder of his brother (126). The Op will lament that "this burg 's getting me" (135) before going on to place the blame instead on Dinah, claiming "even I haven't escaped your influence" (139). We must recognize that it was the $\mathrm{Op}$ who picked his assignment and we can conclude that despite his protestations, his stirring of the situation does not necessarily run contrary to his nature, he has simply lacked opportunity in the past. Yet there is an ambivalence here because were the 


\section{Five Murders in a Fictional City}

Op unaffected by his choices, he would not require laudanum to forget his part in the deaths. To recognise that this toll has some sustained effect on him we can contrast the apparent attitude the Op takes with all comers before Brand's murder with his timidity in the face of Charles Proctor Dawn after it. While Breu claims that "in being tough enough to like murder, enjoyment becomes the logical conclusion of his ethic of hardness, rather than its antithesis" (69) we can contrast the Op at even his bloodiest with Mike Hammer relishing in violence to recognise there is a difference in the level and type of "enjoyment". Whatever moral conclusions we reach, this repetition and refocusing of the same formula within Red Harvest makes it clear that the Op has become one of the poisoned.

The Op's deviation from legality and morality places him in a quite different position to one that Sam Spade or Ned Beaumont will find themselves in, and altogether removed from the major "hard-boiled" detectives who will follow in his footsteps. Philip Marlowe and Lew Archer are far too sensible, refined and self-possessed to ever succumb to blood sickness. While the Op remains tough, this position inside the complex of guilt is summarized by Robert I. Edenbaum in "The Poetics of the Private Eye: The Novels of Dashiell Hammett" as an immunity from ordinary morality: "He is capable of any action, without regard to conventional morality, and thus is apparently as amoral - or immoral - as his antagonists" (179). As this formula-based discussion makes clear, however, it is not the Op's morality that is at stake so much as Hammett's ability to recognise and use the detective formula in nonconventional ways.

Hammett does not make explicit exactly when the Op realizes who killed Tim Noonan, but in his summary of why it was MacSwain, he uses no facts acquired after the signed statement from Jennison. We must choose between considering the Op unlucky in the timing of his realization, or as deliberately framing Max Thaler for his political ends. As he confesses to Dinah Brand, he has "arranged a murder or two, when they were necessary" but this is hardly conclusive (135). This ambiguity can only be resolved by weighing a number of different small pieces of evidence to form an understanding of the Op and his methods. This is the narrative tactic that will become the basis of The Maltese Falcon, where there is critical dissension about the timing of Spade's realization that O'Shaughnessy is the murderess. Edenbaum argues for Spade's early resolution of the murder (180), while William Marling claims that conclusion is only possible in a highly allegorical reading, isolating some examples of behaviour inconsistent with his knowledge of her guilt (The American Roman Noir 145). Of course, neither looks closely at the chain of clues that point to her guilt and eliminate alternative suspects to determine when it is that Spade has the information he needs to be sure, or even if he ever has sufficient information or is simply guided by intuition, merely treating the text as a literary work that happened to have a detective and crime in it. 
In The Maltese Falcon, that judgement of timing will inform how the rest of the novel is interpreted. If one concludes, as Jasmin Yong Hall does in her summary of his work "Dashiell Hammett (1894 - 1961)" (2010), that "Spade knows from the moment that he sees Archer's corpse that Brigid is the killer", then the centre of action must be relocated away from the formal problem of the murder (456). There are two main options for interpreting The Maltese Falcon. The first is to use a mystery formula to make Spade's inquiries about the falcon itself the point of the novel; he must determine why his partner has been killed, how the falcon and those who hunt it fit into Miles Archer's death. The second main option is to regard the story as Spade's struggle to decide what to do about the murder. He must decide whether the attraction he feels for O'Shaughnessy and the possible circumstances surrounding the death require action, or whether he can forsake his partner in death to try for a life with O'Shaughnessy. Many scenes can be read both ways; for example, when Spade explains that "if necessary I'll go ahead blind-folded, but I can't do it without more confidence in you than I've got now", we can choose to emphasise the personal nature of his doubt: it is about her, not about the mess she is in (439). We could alternatively choose to place our emphasis on the following sentence, that "you've got to convince me that ... you're not simply fiddling around by guess and by God, hoping it'll come out right somehow in the end" (439), which appears to relate more to the circumstances surrounding her actions and choices. Depending on the weight we place on different evidence, this one exchange can be read as relating to the mystery of the falcon, or as a more personal inquest into who O'Shaughnessy is.

Either way, it appears to be a significant under-reading to conclude, as Hall does, that as "Spade's story is itself not justified by the need to uncover Archer's murderer, then the novel is revealed to be like its namesake, an entertaining diversion hiding nothing beyond its patina of black ink except meaninglessness" ("Dashiell Hammett" 457). If we adopt either of the stances I suggest above, then Spade's actions are a search exactly for meaning in an act which at first appears to be arbitrary indeed. Virtually every critic has their own theory on the meaning of the Flitcraft parable that Spade tells O'Shaughnessy (442). It is the story of a man who narrowly escapes death from an arbitrary falling beam, who gives up his life in one city as a consequence, only to form a new life of similar structure in a new location. My interpretation of this story derives from this search for meaning: the question is never raised why the beam fell. Flitcraft may have concluded that men only lived while blind chance spared them, but somewhere high above the ground a bad decision was made by a steelworker, deriving from pressures completely external to Flitcraft. In seeking the motive for Archer's murder, Spade is symbolically searching for meaning in the highest order. If Hammett does not eventually provide a full explanation of the action, that should not 


\section{Five Murders in a Fictional City}

necessarily lead to quite such a nihilistic interpretation as Hall reaches. After all, whether the falcon itself is real, it has and retains "the value in life you people put on it" (483).

In Red Harvest, the creation of ambiguity over motive is used for a much smaller end; it is just a test case of the technique Hammett will use later.

\section{Jerry Hooper}

Jerry is introduced as one of Thaler's gang when he comes to negotiate with Dinah Brand and the Op over Myrtle Jennison's confession (91). When he dies, it is as Thaler's "right bower" in the words of the Op at the Peace Conference (131). ${ }^{19}$

Jerry's murder is a cold-reveal, not set-up by Hammett or the Op. When the Op points out that it was Reno who had him killed, that is the first time the reader is aware that the case is anything other than someone getting themselves killed during a robbery. The explanation of means, motive, opportunity and the trail of clues are thin for the murders discussed previously, so this is Hammett not "playing fair" in the terms of the detection club. There is little to indicate that Jerry's death is not incidental, let alone who did it.

To an extent, this may be an example of what Panek characterises as Hammett's "inexperience as a novelist" (147). In "The House on Turk Street" and "The Whosis Kid", which had a similar story structure, there was some level of betrayal between each possible combination of the factions. Hammett needed to achieve the same thing in Red Harvest and had only really cemented a feud between Noonan and Thaler. Pete the Finn's generalpurpose declaration of willingness to go to war using his "army of young fellows that know what to do on any end of a gun" is not as compelling as personal and specific quarrels (131). The formula of warring factions requires a further wedge, other than between Chief Noonan and Whisper. Jerry's murder, and the circumstances that surround it, provide the impetus for warfare between Starkey and Thaler. The replacement of Noonan and the entry of Pete the Finn on general grounds expand the conflicts in the necessary way but Jerry's death is far less intricately developed than the previous plots.

Jerry's murder is more interesting when taken out of its formula context. He is killed both in order to frame Thaler for the bank robbery and to weaken Thaler's ability to fight Reno Starkey. His corpse is also almost a message from Reno to Thaler, that Thaler will suffer casualties in the fighting. A murder as a coded message between criminals is not the kind of motive that is contemplated by Wright or Freeman.

\section{Dinah Brand}

Dinah Brand is one of the central characters in the narrative. Donald Willsson is meeting her instead of the Op at the novel's opening, and the novel ends expeditiously after

\footnotetext{
${ }^{19}$ A reference to a particularly useful card in the card-game 500.
} 
Reno Starkey confesses to her murder. Yong describes her as "the Op's female counterpart" ("Dashiell Hammett" 453) and Smith says that "though not an employee ... [Brand] functions in this novel as the hard-boiled helpmate" (160). Brand exists in descriptive and functional terms as a central character, and so cannot be completely described in formulaic terms the way I constructed Robert Albury. Another way of summarizing her varied position is that at different times she is motive for murder, witness to murder, and victim of murder - three different formula roles, at least. Therefore we must discuss her in a more general way before viewing her through the lens of formula.

As outlined earlier, Red Harvest has an unusual structure, because while it begins with a classic whodunit, it quickly moves into other story modes. The disjunctions between these different parts of the text reduce markedly if we consider the novel to be about Brand, rather than about any of the crimes or political conflicts that are the focus of most analyses. Red Harvest opens with her involvement in the affairs of Donald Willsson and finishes once her murder is resolved. Much of the action in between hinges on her involvement.

Before she appears on the page, we have several descriptions of her which all agree, but which conflict in tone. Contrast Chief Noonan's description: "A soiled dove ... a de luxe hustler, a big-league gold-digger" (22) with the banker Robert Albury's:

You'll be disappointed at first. Then, without being able to say how when it happened, you'll find you've forgotten your disappointment ... She's moneymad, all right, but somehow you don't mind it. She's so thoroughly mercenary, so frankly greedy, that there's nothing disagreeable about it.

Chief Noonan's introduction focuses on her procedural power, as a significant force within Personville society, while Albury focuses on her method of achieving this significance. As the Op wryly remarks, "She seems to have had everyone on her string at one time or another" (27). Men are mere objects to her, to be picked up if interesting, used while flush with cash, and then discarded. Her connections place her at the centre of the criminal conspiracy that de facto rules Personville. Her decision to ally with the Op enables almost all of his machinations, and so it is no surprise that after her murder the Op moves from hunter to hunted.

When we are introduced to her, we can't help but feel the promised sense of disappointment:

She was ... about five feet eight. She had a broad-shouldered, full-breasted, round hipped body and big muscular legs ... her face was the face of a girl of twenty-five already showing signs of wear. Little lines crossed the corners of her big ripe mouth. Fainter lines were beginning to make nets around her thick-lashed eyes. They were large eyes, and a bit blood shot. 


\section{Five Murders in a Fictional City}

Her coarse hair - brown - needed trimming and was parted crookedly. One side of her upper lip had been rouged higher than the other. Her dress was a particularly unbecoming wine colour, and it gaped here and there down one side, where she had neglected to snap the fasteners or they had popped open. There was a run down the front of her left stocking.

This was the Dinah Brand who took her pick of Poisonville's men, according to what I had been told. (29)

This is amongst the longest character descriptions in all of Hammett's writing, as further developed by Marling (The American Roman Noir 117). Contrast the description given of Chief Noonan, one of the major crime figures and the person the Op spends the next most time with after Dinah:

Noonan, the chief, was a fat man with a twinkling greenish eyes set in a round jovial face. (21)

Noonan is an indisputably important figure for the structure of the novel - his clumsy assassination attempt lends impetus and justification to the Op's decision to "clean" Poisonville, he is the Op's primary cats-paw in fomenting violence in the first half of the novel, and the Op's betrayal of Noonan at the sit-down of the bosses causes the Op to recognise the meaning of his actions. He gets one line of description, and few characters manage better. Hammett is lavishing descriptive effort on Dinah, and that effort is not primarily geared around making her a sexually desirable object, in the way that one would expect from her apparent position in society, and as might have been written by contemporaneous pulp writers. This passage is geared around evoking a sense of personality that makes Dinah Brand instantly memorable, if possibly disappointing.

By the time we get this description from the Op, Brand has been mentioned four times by different people. Nobody else is mentioned as much, not even the Op's client. So the common argument that "[n]obody except the Op stays alive long enough to touch our hearts" we should interpret this as hyperbole to emphasize the number of killings, rather than as a cold assessment of the emotional movement inside the novel (Wolfe 91).

Brand is thus the second most important character in the novel, indispensible for the various machinations inside the story, providing a central connective tissue for the disjointed episodes, and occupying both substantial amounts of the text itself and the sympathy of the reader.

Breu's highly gendered reading of the text positions Brand as "the text's femme fatale" (62) but he does not explore the term beyond generalizing that "she allegorizes all the forms of connection - economic, national, sexual, or racial - that the hard-boiled male disavows" (69). This does not address the story functions she fulfils, instead filtering Brand through 
allegory at the level of textual "meaning". To assist, he re-interprets Marling's discussion (The American Roman Noir 119) of Brand's specific sexual appearance and story functions as "allegorically equated ... with both capitalist and erotic speculation" (Breu 69). Breu's focus is too tightly on questions of masculinity to directly treat a question of female identification or its details, and so he simply ignores the details in favour of generalities. He argues that the $\mathrm{Op}$ and Brand cannot form a relationship because she is a femme fatale, a description for her that he has supplied and which does not specifically address her as a character or her functions in the story (Breu 69). Breu goes on, via Freud's concept of the "melancholic cultural fantasy that underpins Red Harvest" (71), to discuss "[t]he aggression that the hardboiled male demonstrates towards the 'fallen' femme fatale" (72), which only has a tangential connection to the Op's relationship with Brand. Once again, we have the replacement of allegorical concepts for formula concepts, which destabilizes meaning in the text rather than helping to interpret it.

Can we describe Brand as a femme fatale as Breu does? She fulfils a role in the story that is broadly in line with the archetype. She is a woman who uses her sexual power to ensare men, eventually betraying them, possibly leading to their death. Dinah Brand has moved in the rarefied circles of Poisonville's criminal elite, all of whom are marked for death and most deaths are via her assistance. Conversely, while she provides the Op with certain information that is useful to him she is almost naive in the way she does so. Later femme fatales, like Hammett's own Brigid O'Shaughnessy, will have conscious control of the damage they do, but Brand assumes that the information she provides will form part of a criminal investigation - the Op has no such intention. He also has no real intention of protecting her from the fall-out of her actions:

“Stop it, sister. If he's that dangerous he's just as likely to get you here as anywhere. So what difference does it make?"

"You don't give a damn what happens to me. You're using me as you use the others - that dynamite you wanted. I trusted you".

"You're dynamite, all right". (116)

The Op is speaking as a man of action, whose philosophy is that he "can count on being one of the survivors of whatever blow-up there is" (“The Whosis Kid" 339). Brand, it's fairly clear, is going to have to look out for herself - something she seems at least modestly well equipped to do. As it happens, when it comes to the physical rough-and-tumble that the Op routinely survives, Brand is not as well equipped. She is killed in exactly the kind of quick and dirty fight in which the Op has been shown triumphant many times.

One way of looking at the Op's attitude is that he is simply using her as another tool to be discarded once useless. If we come to this conclusion, then painting Brand as the 


\section{Five Murders in a Fictional City}

dangerous female seems a little unfair. She is providing information acquired more-or-less legitimately over the course of her affairs, gotten from men who pay well for the privilege and without any illusions as to what is going on since Brand is, on the whole, a woman of negotiable affections. It is sometimes commented that the Op alone does not pay for her services, albeit different services to the others - this is not quite true, because he provides her with inside gambling information on an unfixed boxing match, and other incidentals (Wolfe 85). She regarded Bill Quint's similar payment as adequate (Red Harvest 32). Brand is, in this model, just another character crookedly trying to make their way through Poisonville's dangerous atmosphere - she's hitched her star to the story's hero, and if she were a man, we would not for one second consider labelling him as a homme fatal, no matter how alluring he was to the women in the novel.

Another way of looking at the Op's attitude is that he has formed a genuine attachment to her. Hammett focuses almost exclusively on characters' exteriors, so one must make an inference from character actions. Red Harvest is a first-person narration that nevertheless shields the narrator's inner thoughts from the reader's inspection. Since character actions are often highly constrained by generic or formulaic considerations (e.g. Robert Albury) that can be difficult. Spade is the apotheosis of this technique: there is endless debate about whether he loved O'Shaughnessy and at what point he realized she killed Archer. The Op is a less complex character, but he visits Brand several times where there is no real procedural purpose. She is also the only person to whom he expresses any emotion at all, in the oftquoted speech about how Personville has gotten under his skin and is driving him "bloodsimple" (138).

In that view, his refusal to protect Brand is a sign of respect - he marks her as more-orless his equal, and up to the challenge of protecting herself. As noted, this is not a very good evaluation in terms of physical rough-and-tumble, but in all other respects Brand does appear to be more than capable of looking out for her own interests. We could summarize this perspective by saying that the Op has come to the conclusion that she is a femme fatale, not a damsel in distress. Brand has seduced men, bled them dry, then sold their secrets to their enemies - hardly a safe woman. Hardly a woman needing his protection.

Both of these positions are well supported by different parts of the text, and can resolve ambiguities in how events play out and in their significance. This ambiguity is the kind of objective for literariness that I discussed in the introduction.

Brand's death is the turning point in the action because she was the Op's principle ally. The Op becomes the main suspect in her death, since he wakes up with his hand on the murder weapon. Hammett encourages the reader to consider the possibility he is guilty by having Dick Foley believe it, and consequently leave the city (164). While we consider the Op possible, the detective conventions mean that a reader is unlikely to conclude he is guilty 
without specific evidence. Breu argues that "the offhand confession the Op extracts from a dying man becomes at the very least less than conclusive", but the structure of the novel reinforces the essential nature of the detective, eliminating him as a suspect (Breu 80). Starkey is a late-comer to the top echelon of Poisonville's criminal underworld, he has little personal or specific connection with Brand or the Op. They know Starkey from rescuing him from the Silver Arrow, but they have not betrayed him or hurt his interests. This means that he can provide the Op with an alibi and has no reason not to. The remaining characters with apparent motives are Rolff and Thaler, but their motive for killing Brand is redirected into their mutual annihilation. Having either as the murderer would be to double-up on their story function. Having Brand's murderer be the last remaining criminal member of the Peace Conference wraps up both of the organizing strands at the same time. Thaler is an unsuitable "winner" because he has been the Op's main adversary. Thus structurally, Starkey must be guilty. He commits the most important murder, Brand's, and is the Pyrrhic victor in the struggle for dominance of Personville's criminal underworld. To agree with Breu means reading surface detail in the narrative discourse in opposition to its structural design.

\section{Charles Proctor Dawn}

Unlike the other four murders discussed, the purpose of Charles Proctor Dawn's life and death are not related to the unfolding of the main story of internecine warfare of the criminal class. Dawn contacts the Op somewhat mysteriously, claiming it will be in the Op's best interest to meet with him, a meeting which duly occurs. When the Op arrives for a second meeting, he finds Dawn murdered, and lifts from the dead man a set of incriminating letters showing that Elihu Willsson was infatuated with Dinah Brand.

The Op connects Dawn's murder with one of Starkey's lackeys. Dawn was killed for trying to blackmail Starkey, at the same time as Dawn was trying to blackmail the Op. That makes Reno Starkey the murderer for three of the five murders, all committed for different reasons and in different ways.

Perhaps more important than his death is his life. The "fair play" detective story ends with the revelation of guilt. As Auden suggests, this signifies the return to the innocence that existed before the crime. The common conception of Personville is that its corruption is complete. Wolfe claims that "nobody lives clean, works at an honest job, or plays fair ..." (77) while Heise comes to the conclusion that "[t]his city of forty thousand is - with the exception of a couple of crowds and an anonymous waiter, bartender, and restaurant customer or two empty of people who are not underworld criminals" (500). Charles Proctor Dawn is the exemplary figure here, a multiple blackmailer who eventually falls foul of someone who would rather kill him than pay. 


\section{Five Murders in a Fictional City}

Helen Albury, his client, is the chief counter example. She is naïve about the city and so is unable to accept her brother's guilt. Dawn inveigles himself into her confidences, and takes advantage of her. Dawn, then, like the other victims, does not exist in quaint isolation, but is intimately affected by the city and the events of the unfolding narrative. When the Op reports Mickey Lineham's summary of the new Personville as "sweet-smelling and thornless bed of roses", Charles Proctor Dawn provides a template for the problems that will linger on beyond the arrival of the Federal Authorities (187).

The main other contra example of non-criminality is the group of striking miners. Bill Quint advises them to use sabotage to retain the concessions made in the past. Instead they choose the relatively legitimate tactic of striking, and are punished for it. Neither Helen Albury nor the relatively honest miners receive extensive treatment by the text because both are outside of the Op's rubric of "crooks and grafters" (38).

Hammett worked significantly outside most of the specific strictures of The Detective Club and its acolytes. They devised their rules to remove irrelevant matters from pure detection. This is a movement toward clarity of purpose. The omissions from Red Harvest reflect a similar focus. We do not have ordinary citizens precisely because they are not involved in crime. Hammett shows us only the corrupt and the story of the Op's machinations against them. The question of a greater good, or the society being saved, are merely distractions from the Red Harvest of lives.

\section{The Red Harvest Formula}

Red Harvest makes use of the classic detective formulae in order to tell a story that was not itself a formulation. The examination of the formulaic aspects of the work helps to explain why something happens. As Hammett becomes more skilful in the use of formula, he is better able to close the gap between a naturalistic close text analysis and the demands of the structure.

Red Harvest's action is structured around a series of three mysteries, and two more are used to advance some parts of the story or themes of the novel. It represents an early version of a hybrid approach to formula fiction in which formulae are interpolated and concatenated to create works that do more than simply execute a purely formulaic vision, especially if we have unconsciously used the wrong formula. The murders in Red Harvest do not stand alone, they are woven together to form a complex picture of corruption and intrigue. This is an innovation which has largely gone unremarked, as non-formula interpretations of this text dominate the critical discourse on this novel. Its mix of action and investigation have become essentially a staple approach for Hollywood films in the general area of crime underworld dramas, as exemplified by Yojimbo and Miller's Crossing. 


\section{Conclusion}

The detective formula is just one of many different kinds of story formula. Aristotle's Poetics is arguably the most famous study of formula in the Western literary tradition. The Poetics sets out constraints for the content and structure of tragedies, constraints that have been regarded at times in subsequent millennia as fixed and unbreakable laws. In some ways, Aristotle's prescription outlived the genre itself. A Glossary of Literary Terms uses Hamlet to illustrate an application of the tragic plot, drawing on Aristotle and Freytag's Pyramid (236). Yet, this simplistic structure does not at all explain the features of the text and can even be misleading in places; for example, discussing Hamlet's failure to kill Claudius as the "crisis, the reversal or 'turning point' of the fortunes of the protagonist" more than implies that up until that point things were going well for Hamlet, which is not really the case (Abrams 236 emphasis in original). A reader-response reading, which ignores formulaic interpretations, was carried out by Robin Laws in Hamlet's Hit Points and shows instead a steady and remorseless emotional movement toward fear for the protagonist's wellbeing, slowly removing our hope that it will all work out for the best (27). In this mode, Hamlet's failure to kill Claudius is not the central pivot of the story, it is just another incremental failure. Hamlet uses many of the formulaic elements and structures that Aristotle would recognise, but it does not do this in a straightforward way.

Simplistic formulaic notions under-read Hamlet, but there is an equally serious problem with pure reader-response criticism, which is that it cannot show how the different parts of the story relate structurally. It can only record what the effect of the narrative is, not how that effect is created and structured. Laws offers minimal interpretation of the carefully formed structure and its sublimation of a story formula into a work that asks philosophical questions as well as delivering Aristotle's pity and fear.

In order to interpret formula fictions correctly, we must be aware of the formula, as well as aware of the contents of that formula. We can use formula concepts to help understand works like Chaucer's The Knight's Tale. A non-formula reading will interpret Palamon and Arcite as opposites, since one prays to Venus and one to Mars. A simplistic formula reading would regard these characters as the same since the actions they take are structurally identical. A reading that combines both of these approaches will interpret them in a synoptic way as different conceptions of virtue that co-exist within the chivalric paradigm.

This is the challenge faced by critics of the detective genre. Critics like Haycraft and Symons, who try and draw distinctions between "detective" and "crime" literature, are to this extent missing the benefit of formulaic readings. Novels like The Postman Always Rings Twice (1934) or Double Indemnity (1935) are clearly not "detective fictions", yet detective 


\section{Five Murders in a Fictional City}

formulae are integral to their function. To read them without making use of formula concepts is potentially to misunderstand the design of their plots. This is, more specifically, the challenge facing criticism of Hammett.

Hammett is best and most often remembered as the founder of the "hard-boiled" school of detective fiction. Built into this one-line biography are a number of equivocations and difficulties, beginning with the very existence of the "hard-boiled" school of writing. In his survey of the relationship between "Crime Fiction and the Literary Canon" (2010), Joel Black argues for the essential sameness of the "hard-boiled" and "fair play" genres, because "either as the brutal acts of violence portrayed in "hard-boiled" crime fiction, or the contrived schemes depicted in the golden age of detective stories, crime becomes a metaphor for the corruption of society" (87). This is an unconscious linkage of those two genres via the detective formulation, which is integral to both.

Even if we accept that there is a meaningful distinction to be made between the "fair play" school and the "hard-boiled" school, Hammett's work can only equivocally be categorized as "hard-boiled". The "hard-boiled" school is characterized by an almost dystopian view of society riven with corruption, policed by the incompetent, motivated by cruelty, where one lone figure stands for justice in a wild, almost nonsensical, tale of tough talk and fast action. There is some truth in each component of this definition in Hammett's writing, but only subject to exceptions and qualifications.

Hammett's reputation began with his short stories in Black Mask, because they were detective stories unlike the others in the crime fiction marketplace. His transition from pulp crime author to novelist elevated his exposure and his reputation, but it was The Maltese Falcon - "an undisputed work of crime fiction that critics have been nearly unanimous in crediting with transcending the genre and gaining acceptance as a literary masterpiece" (Black 85) - that secured his lasting reputation. This reputation has been bolstered by the 1941 film, which remains the method of introduction to Hammett for even such distinguished scholars as Steven Marcus (12) and by the link forged with Raymond Chandler by his essay "The Simple Art of Murder".

Almost as famous as his career is Hammett's long silence after some hastily produced short stories and script treatments for sequels to The Thin Man film in the late 1930s. He became very active in communist causes, eventually spending six months in gaol after refusing to testify about a bail bond organization he was involved in.

The problem has become that Hammett's work is now parsed through these interrelated ciphers. The unwary can put too much weight on any of them, distorting the text as written and understood. This is a problem complicated by the distance in time and culture that is ever-expanding between the 1920s and the present. It seems at times that the core functionality of Hammett's novels as detective novels has been forgotten. Black exemplifies 
this view in his summary of the literary value of The Maltese Falcon that uses "the pretext of an exciting story about murder and betrayal to make profound observations about society and life" (87, my emphasis). For Beekman, Hammett is a precursor to Chandler. For Wolfe, and Freedman and Kendrick, Red Harvest is a preview of Hammett's communism. For the general reading public, Bogart's performances as Sam Spade and Philip Marlowe are the definitive essence of the "hard-boiled" private detective.

Black locates the literary virtues of The Maltese Falcon in its presumed philosophical inquest in the central passage that all treatments of the book seem to need to address - the Flitcraft parable - arguing that "a passage like this dealing with the contingency of life is not what we expect to find" (86) and that it "showed how works of crime fiction can achieve literary greatness by providing a format for addressing such heady philosophical issues as contingency and identity" (88). The fundamental problem with this assessment is that the Flitcraft parable, for all its illuminative powers, is an interpolation not integral to the story. In emphasizing it, as so many other scholars have done, Black overlooks the real sources of literary value that translated so well into the film: the characterization and the use of the detective formula not to create a closed system of meaning as intended by Freeman and Wright, but the antithesis, ambiguity.

Hammett complicates the detective formula by introducing unreliable narration, nesting and concatenating mysteries, and by extending the narrative beyond the point where the clue-puzzle complex is resolved down simply to the name of the guilty person. He does this in different ways in each of his novels, after trialling different approaches in his short stories.

Crucially, Hammett relocated his mysteries out of the broadly middle- and upper-class settings that were the generic norm and into a more crime-saturated environment. While some critics tend to conflate these criminal spaces with working class spaces, the criminal activity extends through all levels of society, which has caused other critics to see Hammett's world as totally corrupt and corrupting. In either analytic stance, Hammett does not offer the kind of reconciliation at the conclusion of his stories that W.H. Auden discerns in the general course of detective fiction. In addition to these alterations to formula application, Hammett had a distinctive prose style.

Together, these innovations are seen as the foundations for a new kind of detective writing, variously described as "American" and "hard-boiled", with the implicit distinction from the mainstream of detective fiction which is diversely described as "English", "classical", "whodunit" or "fair play". In bifurcating the genre in this way, critics have de-emphasized the structural similarities that underpin the way the stories work in favour of how they are presented. Beginning with Hammett himself in The Thin Man and sequels many of the socalled "hard-boiled" school in fact revert to both the form and content of the main genre. In later "hard-boiled" authors, such as Sara Paretsky and Bill Pronzini, traces remain of 
Five Murders in a Fictional City

Hammett's early innovations in the pervasion of corruption, but their novels often feature a closed circle of suspects and their mysteries broadly follow the conventions of the genre as understood by Hammett's contemporaries.

In examining the work of Dashiell Hammett, we need to bring back an awareness of formula structures to complement prose analyses and accounts of historical influence. 


\section{Bibliography}

Abbott, H. Porter. The Cambridge Introduction to Narrative. 2nd ed. Cambridge ; New York: Cambridge University Press, 2008. Print. Cambridge Introductions to Literature.

Abrahams, Paul P. “On Re-Reading The Maltese Falcon”. The Journal of American Culture 18.1 (1995): 97. Print.

Abrams, M. H. A Glossary of Literary Terms. 8th ed. Boston: Thomson, Wadsworth, 2005. Print.

Alvarez, A. "The Thin Man”. The Critical Response to Dashiell Hammett. Ed. Christopher Metress. Westport, Conn.: Greenwood Press, 1994. Print.

Aristotle, 384 BCE-322 BCE. The Poetics of Aristotle. Trans. S. H. (Samuel Henry) Butcher. 1999. Project Gutenberg. Web. 5 June 2013.

Auden, W.H. "The Guilty Vicarage". Detective Fiction: Crime and Compromise. Ed. Dick Allen \& David Chacko. Harcourt Brace Jovanovich, 1974. Print.

Austen, Jane. Pride and Prejudice. New York: Modern Library, 1995. Print.

Baudrillard, Jean. Simulacra and Simulation. Ann Arbor: University of Michigan Press, 1994. Print.

Bazelon, David T. "Dashiell Hammett's Private Eye: No Loyalty Beyond the Job". The Critical Response to Dashiell Hammett. Ed. Christopher Metress. Westport, Conn.: Greenwood Press, 1994. Print.

Beekman, E. M. "Raymond Chandler \& an American Genre". The Massachusetts Review 14.1 (1973): 149-173. Print.

Black, Joel. "Crime Fiction and the Literary Canon". A Companion to Crime Fiction. Ed. Charles J. Rzepka \& Lee Horsley. Chichester, U.K. ; Malden, MA: Wiley-Blackwell, 2010. Print. Blackwell Companions to Literature and Culture 66. 


\section{Five Murders in a Fictional City}

Black, Shane. Kiss Kiss Bang Bang. Warner Bros., 2005. Film.

Bloom, Harold. The Anxiety of Influence; a Theory of Poetry. New York: Oxford University Press, 1973. Print.

Bordwell, David. “ApProppriations and ImPropprieties: Problems in the Morphology of Film Narrative". Cinema Journal 27.3 (1988): 5-20. JSTOR. Web. 5 Oct. 2012.

Brazil, John R. "Murder Trials, Murder, and Twenties America”. American Quarterly 33.2 (1981): 163-184. JSTOR. Web. 5 June 2012.

Breu, Christopher. Hard-Boiled Masculinities. Minneapolis: University of Minnesota Press, 2005. Print.

Bruccoli, Matthew J, and Richard Layman, eds. Hardboiled Mystery Writers: Raymond Chandler, Dashiell Hammett, Ross Macdonald. Detroit, Mich: Gale Research, 1989. Print. Dictionary of Literary Biography v. 6.

Cain, James M. Double Indemnity. New York: Vintage Books, 1992. Print.

---. The Postman Always Rings Twice. New York: Vintage Books, 1992. Print.

Cawelti, John G. Adventure, Mystery, and Romance : Formula Stories as Art and Popular Culture. Chicago: University of Chicago Press, 1976. Print.

Chandler, Raymond. Farewell, My Lovely. New York, NY: Vintage Books, 1992. Print.

---. Raymond Chandler Speaking. Ed. Dorothy Gardiner \& Kathrine Sorley Walker. London: Penguin, 1988. Print.

---. Raymond Chandler: Collected Stories. New York: Knopf : Distributed by Random House, 2002. Print.

---. The Big Sleep. New York: Vintage Books, 1992. Print.

---. The Long Goodbye. New York: Vintage Books, 1992. Print.

---. “The Simple Art of Murder". The Simple Art of Murder. New York: Vintage Books, 1988. Print. 
---. “The Simple Art of Murder”. The Simple Art of Murder. New York: Vintage Books, 1988. Print.

Chesterton, G. K. “A Defence Of Detective Stories”. The Art of the Mystery Story: a Collection of Critical Essays. Ed. Howard Haycraft. New York: Biblio and Tannen, 1976. Print.

Christie, Agatha. And Then There Were None. Toronto; New York: Bantam Books, 1983. Print.

---. One, Two, Buckle My Shoe. London: Collins, 1940. Print.

---. The ABC Murders. London: Published for the Crime Club by Collins, 1936. Print.

---. The Murder of Roger Ackroyd. Toronto; New York: Bantam Books, 1983. Print.

---. Third Girl. New York: Dodd, Mead, 1967. Print.

Copjec, Joan. Shades of Noir: a Reader. London; New York: Verso, 1993. Print.

DeFino, Dean. "Lead Birds and Falling Beams". Journal of Modern Literature 27.4 (2004): 73-81. Print.

Dooley, Dennis. Dashiell Hammett. New York: F. Ungar Pub. Co., 1984. Print.

Durham, Philip. Down These Mean Streets a Man Must Go; Raymond Chandler's Knight. Chapel Hill: University of North Carolina Press, 1963. Print.

---. “The Black Mask School”. Tough Guy Writers of the Thirties. Ed. David Madden. Carbondale: Southern Illinois University Press, 1968. Print. Crosscurrents: Modern Critiques.

Dyke, W. S. Van. After the Thin Man. Metro-Goldwyn-Mayer, 1936. Film.

---. Another Thin Man. Metro-Goldwyn-Mayer, 1939. Film.

---. The Thin Man. Metro-Goldwyn-Mayer, 1934. Film.

Eco, Umberto. On Literature. Random House, 2006. Print. 
Five Murders in a Fictional City

---. The Role of the Reader: Explorations in the Semiotics of Texts. Bloomington: Indiana University Press, 1979. Print. Advances in Semiotics.

Edenbaum, Robert I. "The Poetics of the Private Eye: The Novels of Dashiell Hammett". The Critical Response to Dashiell Hammett. Ed. Christopher Metress. Westport, Conn.: Greenwood Press, 1994. Print.

Ellroy, James. White Jazz : a Novel. New York: Knopf : Distributed by Random House, 1992. Print.

Freedman, Carl, and Christopher Kendrick. "Forms of Labor in Dashiell Hammett's Red Harvest”. PMLA 106.2 (1991): 209-221. JSTOR. Web. 5 June 2012.

Freeman, R Austin. “The Art of the Detective Story”. The Art of the Mystery Story : a Collection of Critical Essays. Ed. Howard Haycraft. New York: Biblio and Tannen, 1924. Print.

Frye, Northrop. The Secular Scripture: a Study of the Structure of Romance. Cambridge, Mass: Harvard University Press, 1976. Print. The Charles Eliot Norton Lectures 19741975.

Gardner, Erle Stanley. "Honest Money”. The Black Lizard Big Book of Pulps. Ed. Otto Penzler. New York: Vintage Crime/Black Lizard, 2007. Print.

Gatenby, Bruce. “'A Long and Laughable Story': Hammett's The Dain Curse and the Postmodern Condition". The Critical Response to Dashiell Hammett. Ed. Christopher Metress. Westport, Conn.: Greenwood Press, 1994. Print.

Glover, David. “The Frontier of Genre: Further to John S. Whitley's 'Stirring Things Up: Dashiell Hammett's Continental Op"”. Journal of American Studies 15.2 (1981): 249252. Print. 
Graves, Robert, and Laura Riding. A Survey of Modernist Poetry and A Pamphlet Against Anthologies. Ed. Charles Mundye \& Patrick McGuinness. Manchester: Carcanet, 2002. Print.

Gray, W. Russel. "Jimmying the Back Door of Literature: Dashiell Hammett's Blue-Collar Modernism". The Journal of Popular Culture 41.5 (2008): 762-783. Wiley Online Library. Web. 8 May 2013.

Gregory, Sinda. Private Investigations: The Novels of Dashiell Hammett. Carbondale: Southern Illinois University Press, 1985. Print.

Grella, George. "Murder and the Mean Streets: The Hardboiled Detective Novel". Detective Fiction: Crime and Compromise. Ed. Dick Allen \& David Chacko. Harcourt Brace Jovanovich, 1974. Print.

---. “The Gangster Novel”. Tough Guy Writers of the Thirties. Ed. David Madden. Carbondale: Southern Illinois University Press, 1968. Print. Crosscurrents: Modern Critiques.

Gutkowski, Emanuela. “An 'Investigation in Pragmatics': Agatha Christie’s The Murder of Roger Ackroyd". Clues 29.1 (2011): 51-60. Print.

Hagemann, E. R. A Comprehensive Index to Black Mask, 1920-1951. Bowling Green, Ohio: Bowling Green State University Popular Press, 1982. Print.

Hall, Jasmine Yong. "Dashiell Hammett (1894-1961)". A Companion to Crime Fiction. Ed.

Charles J. Rzepka \& Lee Horsley. Chichester, U.K.; Malden, MA: Wiley-Blackwell, 2010. Print. Blackwell Companions to Literature and Culture 66.

---. "Jameson, Genre, and Gumshoes: The Maltese Falcon as Inverted Romance”. The Critical Response to Dashiell Hammett. Ed. Christopher Metress. Westport, Conn.: Greenwood Press, 1994. Print.

Hammett, Dashiell. \$106,000 Blood Money. [New York ]: L.E. Spivak, 1927. Print. 
Five Murders in a Fictional City

---. Complete Novels. Ed. Steven Marcus. New York: Literary Classics of the United States : Distributed by Penguin Books, 1999. Print.

---. Crime Stories and Other Writings. New York: Literary Classics of the United States :

Distributed by Penguin Books, 2001. Print.

---. Lost Stories : 21 Long-lost Stories from the Best-selling Creator of Sam Spade, the Maltese Falcon, and the Thin Man. San Francisco; Chicago: Vince Emery

Productions ; Distributed by Independent Publishers Group, 2005. Print.

---. Nightmare Town: Stories. Ed. Kirby McCauley, Martin Harry Greenberg, \& Edward

Gorman. New York: Knopf, 1999. Print.

---. Return of the Thin Man: The Original Screen Stories. Ed. Richard Layman \& Julie M

Rivett. New York: Mysterious Press, 2012. Print.

---. Selected Letters of Dashiell Hammett. Ed. Richard Layman \& Julie M Rivett.

Washington, D.C.: Counterpoint, 2000. Print.

---. "The Advertisement IS Literature". Hardboiled Mystery Writers : Raymond Chandler,

Dashiell Hammett, Ross Macdonald : a Literary Reference. Ed. Matthew J Bruccoli \&

Richard Layman. New York: Carroll \& Graf Publishers, 2002. Print.

---. The Big Knockover and Other Stories. Harmondsworth: Penguin, 1969. Print.

---. The Continental Op. Ed. Steven Marcus. New York: Random House, 1974. Print.

---. Woman in the Dark : a Novel of Dangerous Romance. New York: A.A. Knopf, 1988.

Print.

Hammett, Jo. Dashiell Hammett: a Daughter Remembers. New York: Carroll \& Graf Publishers, 2001. Print.

Haycraft, Howard. Murder for Pleasure: The Life and Times of the Detective Story. London: Peter Davies, 1942. Print. 
---, ed. The Art of the Mystery Story: a Collection of Critical Essays. New York: Biblio and Tannen, 1976. Print.

Heise, Thomas. “'Going Blood-Simple Like the Natives': Contagious Urban Spaces and Modern Power in Dashiell Hammett's Red Harvest". MFS Modern Fiction Studies 51.3 (2005): 485-512. Print.

Hickman, Miranda B. "Introduction: The Complex History of a 'Simple Art'”. Studies in the Novel 35.3 (2003): 285. Print.

Hill, Walter. Last Man Standing. New Line Cinema, 1996. Film.

Hitchcock, Alfred. Rope. Universal, 1948. Film.

Homer. The Iliad of Homer. Trans. Richmond Alexander Lattimore. Chicago: University of Chicago Press, 1962. Print.

---. The Odyssey of Homer. Trans. Richmond Alexander Lattimore. New York: HarperPerennial, 1991. Print.

Horsley, Lee. Twentieth-Century Crime Fiction. Oxford, England; New York: Oxford University Press, 2005. Print.

Humann, Heather Duerre. "Gender and Genre in Mickey Spillane’s Vengeance Is Mine! (1950)”. Clues 29.2 (2011): 66-72. Print.

Huston, John. The Maltese Falcon. Warner Bros., 1941. Film.

Irwin, John T. "Unless the Threat of Death Is Behind Them ”: Hard-Boiled Fiction and Film Noir. Baltimore: Johns Hopkins University Press, 2006. Print.

Jameson, Fredric. “The Synoptic Chandler”. Shades of Noir: a Reader. Ed. Joan Copjec. London; New York: Verso, 1993. Print.

Johnson, Diane. The Life of Dashiell Hammett. London: Chatto \& Windus, 1984. Print.

Kerr, Lucille. 'Novels and 'Noir' in New York”. World Literature Today 69.4 (1995): 733 739. JSTOR. Web. 5 June 2012. 
Five Murders in a Fictional City

Knight, Stephen Thomas. Crime Fiction Since 1800: Detection, Death, Diversity. Basingstoke [England]; New York: Palgrave Macmillan, 2010. Print.

---. Form and Ideology in Crime Fiction. Bloomington: Indiana University Press, 1980. Print. Kurosawa, Akira. Yojimbo. 1961. Film.

Laws, Robin D. Hamlet's Hit Points: What Three Classisc Narratives Tell Us About Roleplaying Games. Roseville, Minn.: Gameplaywright Press, 2010. Print. ---, ed. The New Hero. Vol. 1. London: Stone Skin Press, 2012. Print.

Layman, Richard, ed. Discovering the Maltese Falcon and Sam Spade: The Evolution of Dashiell Hammett's Masterpiece, Including John Huston's Movie with Humphrey Bogart. San Francisco, Calif.: Vince Emery, 2005. Print.

---. Shadow Man : the Life of Dashiell Hammett. New York: Harcourt Brace Jovanovich, 1981. Print.

---. "Theme Issue: Dashiell Hammett: The Maltese Falcon at Seventy-Five". Clues 23.2 (2005): 4-10. Print.

Leone, Sergio. A Fistful of Dollars. United Artists, 1967. Film.

Madden, David, ed. Tough Guy Writers of the Thirties. Carbondale: Southern Illinois University Press, 1968. Print. Crosscurrents: Modern Critiques.

Malin, Irving. "Focus on the Maltese Falcon: The Metaphysical Falcon”. The Critical Response to Dashiell Hammett. Ed. Christopher Metress. Westport, Conn.: Greenwood Press, 1994. Print.

Malmgren, Carl D. “The Crime of the Sign: Dashiell Hammett's Detective Fiction”. Twentieth Century Literature 45.3 (1999): 371-384. JSTOR. Web. 19 June 2012. Marcus, Steven. “Introduction”. The Continental Op. New York: Random House, 1974. Print. Marling, William. Dashiell Hammett. Boston: Twayne Publishers, 1983. Print. 
---. The American Roman Noir: Hammett, Cain, and Chandler. Athens, Ga: University of Georgia Press, 1995. Print.

Mathis, Andrew E. The King Arthur Myth in Modern American Literature. Jefferson, N.C: McFarland, 2002. Print.

McCann, Sean. "Constructing Race Williams: The Klan and the Making of Hard-Boiled Crime Fiction". American Quarterly 49.4 (1997): 677-716. Print.

---. Gumshoe America: Hard-boiled Crime Fiction and the Rise and Fall of New Deal Liberalism. Durham, N.C: Duke University Press, 2000. Print. New Americanists. McGurl, Mark. "Making 'Literature' of It: Hammett and High Culture”. American Literary History 9.4 (1997): 702-717. Print.

Mellen, Joan. Hellman and Hammett: The Legendary Passion of Lillian Hellman and Dashiell Hammett. New York, NY: HarperCollins, 1996. Print.

Merrill, Robert. "Raymond Chandler's Plots and the Concept of Plot". Narrative 7.1 (1999): 3-21. Print.

Metress, Christopher. "Dashiell Hammett and the Challenge of New Individualism: Rereading Red Harvest and The Maltese Falcon”. The Critical Response to Dashiell Hammett. Ed. Christopher Metress. Westport, Conn.: Greenwood Press, 1994. Print.

---. "Introduction". The Critical Response to Dashiell Hammett. Ed. Christopher Metress. Westport, Conn.: Greenwood Press, 1994. Print.

---. "Reading the Rara Avis: Seventy-Five Years of Maltese Falcon Criticism". Clues 23.2 (2005): 65-77. Print.

---, ed. The Critical Response to Dashiell Hammett. Westport, Conn.: Greenwood Press, 1994. Print.

Milne, A. A. (Alan Alexander). The Red House Mystery. 1999. Project Gutenberg. Web. 17 Aug. 2012. 


\section{Five Murders in a Fictional City}

Mooney, William. "Sex, Booze, and the Code: Four Versions of the Maltese Falcon". Literature/Film Quarterly 39.1 (2011): 54-70. Print.

Moore, Lewis D. Cracking the Hard-Boiled Detective : a Critical History from the 1920s to the Present. Jefferson, N.C.: McFarland \& Co., 2006. Print.

Moretti, Franco. Signs Taken For Wonders: Essays in the Sociology of Literary Forms. London: NLB, 1983. Print.

---. "The Slaughterhouse of Literature”. MLQ: Modern Language Quarterly 61.1 (2000): 207-227. Print.

Nebel, Frederick. "Wise Guy”. The Black Lizard Big Book of Pulps. Ed. Otto Penzler. New York: Vintage Crime/Black Lizard, 2007. Print.

Nolan, Tom. "Hammett and Macdonald”. Clues 23.2 (2005): 51-63. Print.

Nolan, William F. Dashiell Hammett: a Casebook. Santa Barbara: McNally \& Loftin, 1969. Print.

---. Hammett : a Life at the Edge. New York: Congdon \& Weed : Distributed by St. Martin's Press, 1983. Print.

---. The Black Mask Boys: Masters in the Hard-boiled School of Detective Fiction. New York: W. Morrow, 1985. Print.

Panek, LeRoy. Reading Early Hammett: a Critical Study of the Fiction Prior to the Maltese Falcon. Jefferson, N.C.: McFarland \& Co., 2004. Print.

Peltier, Josiane. "Economic Discourse in The Maltese Falcon". Clues 23.2 (2005): 21-30. Print.

Penzler, Otto, ed. The Black Lizard Big Book of Pulps. New York: Vintage Crime/Black Lizard, 2007. Print. 
Pepper, Andrew. “The 'Hard-boiled' Genre”. A Companion to Crime Fiction. Ed. Charles J. Rzepka \& Lee Horsley. Chichester, U.K. ; Malden, MA: Wiley-Blackwell, 2010. Print. Blackwell Companions to Literature and Culture 66.

Poe, Edgar Allan. The Murders in the Rue Morgue and Other Stories. Cologne: Könemann, 1995. Print.

Porter, Joseph C. "The End of the Trail: The American West of Dashiell Hammett and Raymond Chandler”. Western Historical Quarterly 6.4 (1975): 411-424. Print.

Pronzini, Bill, and Jack Adrian, eds. Hard-Boiled: An Anthology of American Crime Stories. Oxford; New York: Oxford University Press, 1995. Print.

---. "Introduction". Hard-Boiled: An Anthology of American Crime Stories. Ed. Bill Pronzini \& Jack Adrian. Oxford; New York: Oxford University Press, 1995. Print.

Pyrhönen, Heta. “Criticism and Theory”. A Companion to Crime Fiction. Ed. Charles J. Rzepka \& Lee Horsley. Chichester, U.K. ; Malden, MA: Wiley-Blackwell, 2010. Print. Blackwell Companions to Literature and Culture 66.

Rabinowitz, Peter J. "The Turn of the Glass Key: Popular Fiction as Reading Strategy”. Critical Inquiry 11.3 (1985): 418-431. Print.

Raczkowski, Christopher T. "The Simple Art of Murder Criticism”. MFS Modern Fiction Studies 53.4 (2007): 876-886. Project MUSE. Web. 18 June 2012.

Revzin, I. I. "Notes on the Semiotic Analysis of Detective Novels: With Examples from the Novels of Agatha Christie”. Trans. Julian Graffy. New Literary History 9.2 (1978): 385-388. Print.

Rivett, Julie M. “On Samuel Spade and Samuel Dashiell Hammett: A Granddaughter’s Perspective”. Clues 23.2 (2005): 11-20. Print.

Rowland, Susan. “The Wasteland and the Grail Knight: Myth and Cultural Criticism in Detective Fiction”. Clues 28.2 (2010): 44-54. Print. 


\section{Five Murders in a Fictional City}

Rzepka, Charles J. Detective Fiction. Cambridge: Polity, 2005. Print.

Rzepka, Charles J., and Lee Horsley, eds. A Companion to Crime Fiction. Chichester, U.K. ; Malden, MA: Wiley-Blackwell, 2010. Print. Blackwell Companions to Literature and Culture 66.

Shakespeare, William. Hamlet. 1998. Project Gutenberg. Web. 5 June 2013.

Sharp, Michael D. "Plotting Chandler's Demise: Ross MacDonald and the Neo-Aristotelian Detective Novel”. Studies in the Novel 35.3 (2003): 405-426. Print.

Shaw, Milton. "Dashiell Hammett: One of the Early Masketeers". Discovering the Maltese Falcon and Sam Spade: The Evolution of Dashiell Hammett's Masterpiece, Including John Huston's Movie with Humphrey Bogart. Ed. Richard Layman. San Francisco, Calif.: Vince Emery, 2005. Print.

Smith, Erin A. Hard-Boiled: Working-Class Readers and Pulp Magazines. Philadelphia: Temple University Press, 2000. Print.

Sterne, Laurence. The Life and Opinions of Tristram Shandy, Gentleman. Oxford: Clarendon Press, 1983. Print. The World's Classics.

Stowe, William W. "Critical Investigations: Convention and Ideology in Detective Fiction". Texas Studies in Literature and Language 31.4 (1989): 570-591. Print.

Symons, Julian. Bloody Murder: From the Detective Story to the Crime Novel. New York: Viking, 1985. Print.

---. Dashiell Hammett. Orlando, Florida: Harcourt Brace Jovanovich, 1985. Print.

Thompson, George J. Hammett's Moral Vision. San Francisco: Vince Emery, 2007. Print. Thompson, Jon. “Dashiell Hammett's Hard-Boiled Modernism”. The Critical Response to Dashiell Hammett. Ed. Christopher Metress. Westport, Conn.: Greenwood Press, 1994. Print. 
Walker, John. "City Jungles and Expressionist Reifications from Brecht to Hammett”. Twentieth Century Literature 44.1 (1998): 119-133. JSTOR. Web. 5 June 2012.

Whitley, John S. “Stirring Things Up: Dashiell Hammett's Continental Op”. Journal of American Studies 14.3 (1980): 443-455. Print.

Wilson, Edmund. "Who Cares Who Killed Roger Ackroyd?" The Art of the Mystery Story: A Collection of Critical Essays. Ed. Howard Haycraft. New York: Biblio and Tannen, 1976. Print.

---. "Why Do People Read Detective Stories?” The New Yorker 14 Oct. 1944. The New Yorker. Web. 10 May 2013.

Wolfe, Peter. Beams Falling: The Art of Dashiell Hammett. Bowling Green, Ohio: Bowling Green University Popular Press, 1980. Print.

Wright, Willard Huntingdon. "Twenty Rules for Writing Detective Stories". The Art of the Mystery Story: a Collection of Critical Essays. Ed. Howard Haycraft. New York: Biblio and Tannen, 1928. Print.

Zumoff, J.A. “The Politics of Dashiell Hammett's Red Harvest”. Mosaic (Winnipeg) 40.4 (2007): 119+. Galegroup. Web.

---. "Tijuana the American Town: Images of the Corrupt City in Hammett's 'The Golden Horseshoe"”. Clues 26.4 (2008): 35-48. Print. 